University of South Florida

DIGITAL COMMONS Digital Commons @ University of @ UNIVERSITY OF SOUTH FLORIDA South Florida

$10-1-2012$

\title{
Assessing the Impact of Proposed Transit Investments and Public Policy Choices on Land Use Patterns (A Simulation Approach with UrbanSim)
}

CUTR

Follow this and additional works at: https://digitalcommons.usf.edu/cutr_nctr

\section{Recommended Citation}

"Assessing the Impact of Proposed Transit Investments and Public Policy Choices on Land Use Patterns (A Simulation Approach with UrbanSim)," National Center for Transit Research (NCTR) Report No. CUTRNCTR-RR-2011-08, Center for Urban Transportation Research, University of South Florida, 2012.

DOI: https://doi.org/10.5038/CUTR-NCTR-RR-2011-08

Available at: https://scholarcommons.usf.edu/cutr_nctr/112

This Technical Report is brought to you for free and open access by the National Center for Transit Research (NCTR) Archive (2000-2020) at Digital Commons @ University of South Florida. It has been accepted for inclusion in Research Reports by an authorized administrator of Digital Commons @ University of South Florida. For more information, please contact digitalcommons@usf.edu. 


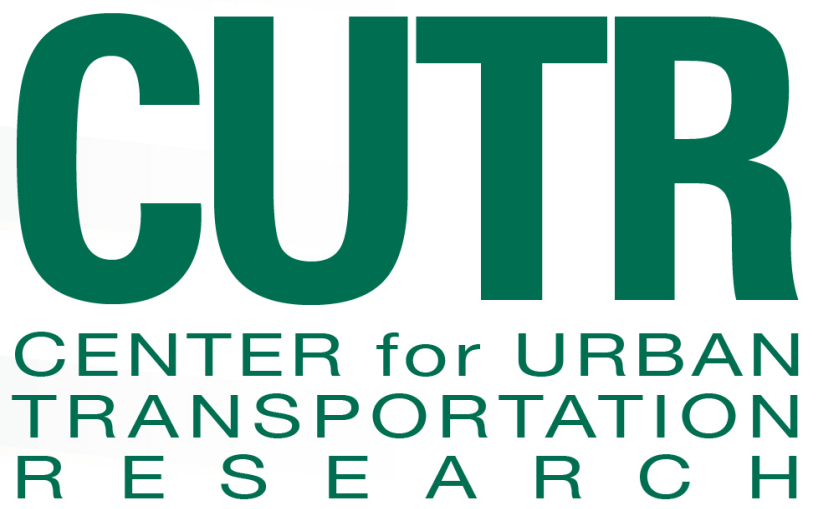

\section{Assessing the Impact of Proposed Transit Investments and Public Policy Choices on Land Use Patterns (A Simulation Approach with UrbanSim)}

Final Report

October 2012

PROJECT NO.

BDK85 977-26

PREPARED FOR Florida Department of Transportation

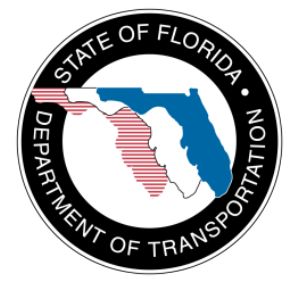




\section{Assessing the Impact of Proposed Transit Investments and Public Policy Choices on Land Use Patterns (A Simulation Approach with UrbanSim)}

BDK85 977-26

\section{Prepared for:}

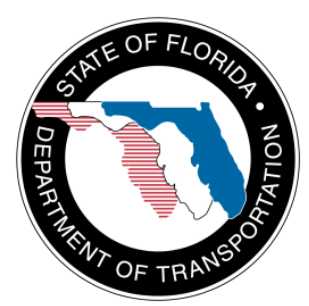

Florida Department of Transportation

Diane Quigley, Project Manager

Transit Planning Office

605 Suwannee Street, M.S. 36

Tallahassee, FL 32399-0450

Phone: (850) 576-2788

Email: diane.quigley@dot.state.fl.us

Prepared by:

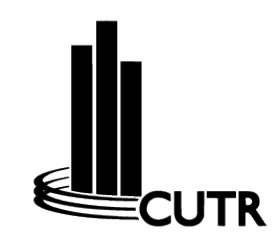

USF Center for Urban Transportation Research

Chanyoung Lee, Ph.D., Senior Research Associate

Zhenyu Wang, Ph.D., Research Specialist

Final Report

October 2012 


\section{Disclaimer}

The opinions, findings, and conclusions expressed in this publication are those of the authors and not necessarily those of the State of Florida Department of Transportation. 


\section{Metric Conversion}

\begin{tabular}{|c|c|c|c|c|}
\hline SYMBOL & WHEN YOU KNOW & MULTIPLY BY & TO FIND & SYMBOL \\
\hline \multicolumn{5}{|c|}{ LENGTH } \\
\hline in & inches & 25.4 & millimeters & $\mathrm{mm}$ \\
\hline $\mathrm{ft}$ & feet & 0.305 & meters & $\mathrm{m}$ \\
\hline yd & yards & 0.914 & meters & $\mathrm{m}$ \\
\hline mi & miles & 1.61 & kilometers & $\mathrm{km}$ \\
\hline \multicolumn{5}{|c|}{ VOLUME } \\
\hline fl oz & fluid ounces & 29.57 & milliliters & $\mathrm{mL}$ \\
\hline gal & gallons & 3.785 & liters & $\mathrm{L}$ \\
\hline $\mathrm{ft}^{3}$ & cubic feet & 0.028 & cubic meters & $\mathrm{m}^{3}$ \\
\hline$y d^{3}$ & cubic yards & 0.765 & cubic meters & $\mathrm{m}^{3}$ \\
\hline \multicolumn{5}{|c|}{ NOTE: volumes greater than $1000 \mathrm{~L}$ shall be shown in $\mathrm{m}^{3}$} \\
\hline \multicolumn{5}{|c|}{ MASS } \\
\hline $\mathbf{o z}$ & ounces & 28.35 & grams & g \\
\hline lb & pounds & 0.454 & kilograms & $\mathrm{kg}$ \\
\hline $\mathbf{T}$ & short tons (2000 lb) & 0.907 & $\begin{array}{c}\text { megagrams } \\
\text { (or "metric ton") }\end{array}$ & $\mathrm{Mg}(\mathrm{or}$ "t") \\
\hline \multicolumn{5}{|c|}{ TEMPERATURE (exact degrees) } \\
\hline${ }^{\circ} \mathbf{F}$ & Fahrenheit & $\begin{array}{c}5(F-32) / 9 \\
\text { or }(F-32) / 1.8\end{array}$ & Celsius & ${ }^{\circ} \mathrm{C}$ \\
\hline
\end{tabular}




\section{Technical Report Documentation}

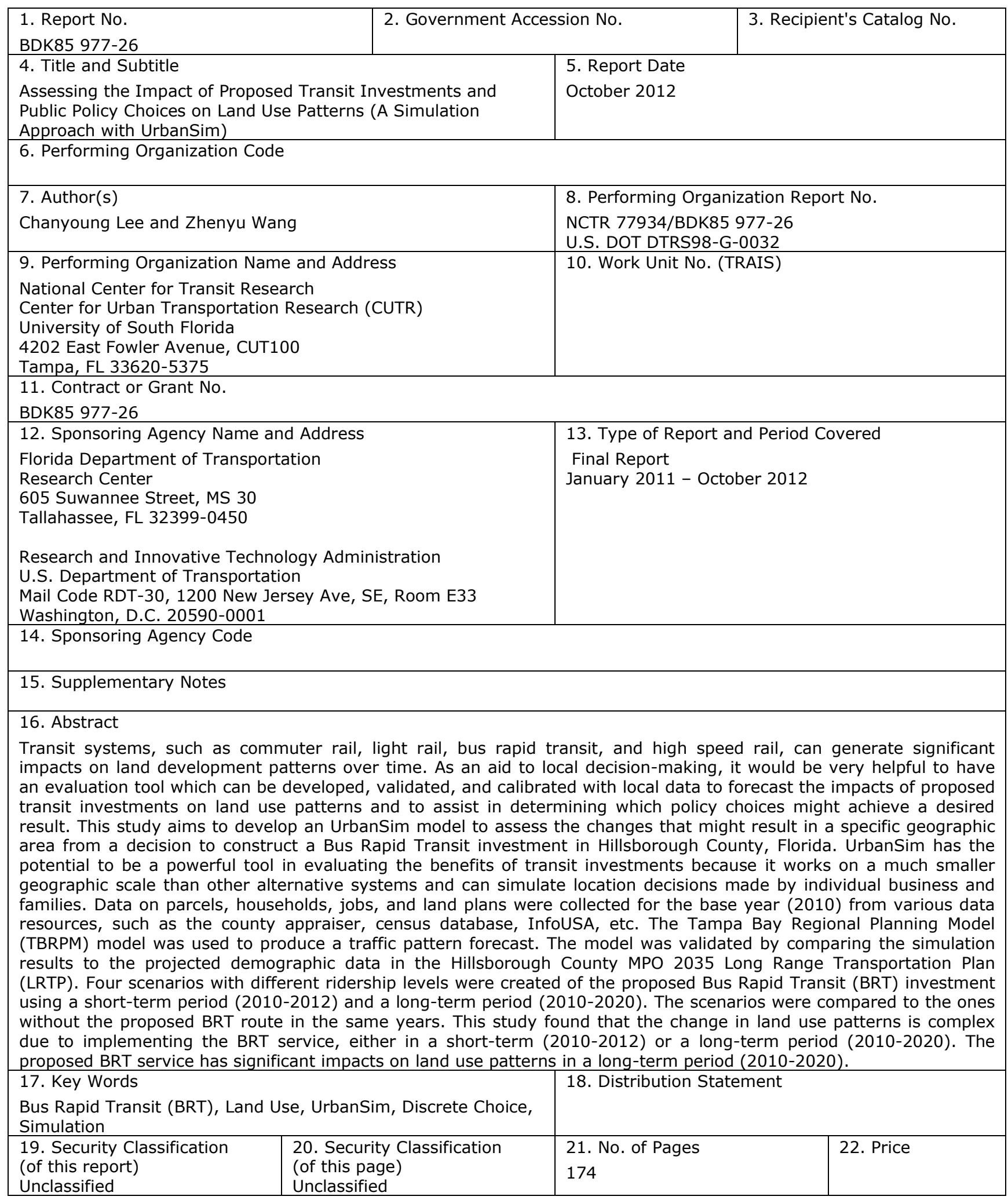




\section{Acknowledgments}

We are grateful for the critical assistance provided by the Project Manager, Diane Quigley, and her staff in the Transit Planning Office of the Florida Department of Transportation. The authors also greatly appreciate Mr. Tejsingh Rana for his contributions in the early stages of this project. 


\section{Executive Summary}

Transit systems, such as commuter rail, light rail, bus rapid transit, and high speed rail, can generate significant impacts on land development patterns over time. As an aid to local decisionmaking, it is very helpful to have an evaluation tool which can be developed, validated, and calibrated with local data to forecast the impacts of a proposed investment and to assist in determining which policy choices might achieve a desired result. UrbanSim is a software-based simulation system for supporting, planning, and analysis of urban development. Through the incorporation of interactions between land use and travel demand models, UrbanSim has the potential as a tool to evaluate the impacts of proposed transit investments on variables of interest, such as population, demographics, the local economy, the real estate market, land use, the environment, and travel patterns. While land use models provide an understanding of the causes and consequences of land use changes, travel demand models can be used to forecast the ridership of new transit systems, which change the accessibility of properties. This is significant for land use changes because they may affect individuals' choices on the location of their household and employment.

This study aims to determine the feasibility of using UrbanSim to assess changes that could result from a transit investment in an urban area, and if this use is feasible, to examine the impacts of a proposed Bus Rapid Transit (BRT) investment in Hillsborough County, Florida. To these ends, a case study of this investment is used as the basis of this project. UrbanSim has the potential to be a powerful tool in evaluating the benefits of transit investments because it works on a much smaller geographic scale, such as parcel, than other alternatives and can simulate location decisions made by individual businesses and families. The objectives for this study include the following:

1. Perform a literature review to examine previous assessments of the impacts of proposed transit investments and public policy choices on land use patterns

2. Select a proper study area and assess the data requirement for the UrbanSim model

3. Collect required data

4. Develop an UrbanSim model

5. Design and test scenarios

6. Develop supporting tools for data collection and model development 


\section{Summarize findings}

In this study, a parcel-based UrbanSim model was adopted. The parcel version requires 22 to 25 data tables which can be organized into 5 categories: Geography, Buildings, Households, Employment, and Real Estate. These data were retrieved from various sources, including county appraisers, InfoUSA, the Census Summary and Public Use Microdata Sample (PUMS) from the American Community Survey (ACS), and the Hillsborough Planning Commission Future Land Use Element. The Tampa Bay Regional Planning model was used to produce travel patterns. All of these data were linked and imported into the UrbanSim model to create a base scenario (2010). Ten sub-models were also selected to integrate into the UrbanSim model to simulate individual agent's (person) behavior in the housing and employment market. The model was validated by comparing simulation results with the zonal demographic projection of the Hillsborough MPO 2035 Long Term Regional Transportation Plan (LRTP). In total, four scenarios were developed, including two short-term (2010-2012) BRT ridership scenarios (1 percent trip shift and 5 percent trip shift) and two long-term (2010-2020) BRT ridership scenarios (1 percent trip shift and 5 percent trip shift). The scenarios were simulated and compared to the simulation results without the BRT service in the same years. Based on the build/no build scenarios, the following findings were concluded:

\section{- UrbanSim is a powerful tool for simulating land use changes.}

UrbanSim is based on theories of market economics and discrete choice behavior, and captures both the impacts of market forces as well individuals' choices on land development processes. The household and job-based simulation makes its forecasting more realistic, both spatially and temporally. The UrbanSim model developed provides a reasonable prediction based on the differences observed between the simulated land use patterns and the projections in the 2035 LRTP. It is noted that some errors between the two projections are expected since the projection method used in UrbanSim is different to that used in the 2035 LRTP.

\section{- Data preparation is the key step in implementation of the UrbanSim model.}

UrbanSim requires a great deal of effort and resources to prepare the required data. In addition, some required data are not readily available. A major component of the data preparation was to synthesize household and building data using the Iterative Proportional Updating (IPU) algorithm, a synthesis population generation algorithm. Since the resolution of the algorithm is 
Census Blockgroup, it is larger than Traffic Analysis Zone (TAZ) and parcel levels, which created a lack of marginal distributions at the zone and parcel levels. Researchers addressed this by randomly assigning the synthesized households and persons to zones, parcels, and buildings. Users of UrbanSim should be aware that this random assignment may influence the accuracy of the UrbanSim simulation. The simulation would be improved by the development of a new assignment algorithm considering relationships between household characteristics and parcel attributes; for example, households with higher incomes tend to occupy the higher value parcels/buildings.

\section{- The proposed BRT service has significant impacts on land use patterns in the long-term period (2010-2020).}

The model predicts that the population and number of households in the study area will increase by about $15 \%$ due to implementing the BRT service in a long term period (2010-2020); the unit price of housing in the study area will increase by $4 \%$ due to implementing the BRT service in a long term period (2010-2020). Compared to the impacts of the BRT investment on jobs and housing unit prices ( $4 \%$ and less than $1 \%$, respectively), the impacts on population and households in 2020 were larger (15\% and 12\%, respectively). In UrbanSim, population and households are predicted by the Household Location Choice Model, which adopted the system default structure and coefficients in this study due to a lack of survey data for Hillsborough County. A possible reason for the "large" impacts on population and households is the "nonlocalized" Household Location Choice Model. The study also adopted the system default coefficients for the sub-models. More accurate coefficients could be derived from a survey to calibrate the coefficients of the household/employment location choice models. Models localized for Hillsborough County are expected to improve the accuracy of the UrbanSim model.

\section{- Adequate support by the travel demand model is critical.}

In current travel planning models for Hillsborough County, such as the Tampa Bay Regional Planning Model (TBRPM) or Transit Boardings Estimation and Simulation Tool (TBEST), the BRT mode is not available. Thus, the research team had to assume the ridership of the proposed

BRT route to create the scenarios. The scenarios should be updated with the availability of the BRT mode in travel planning models to provide a more reasonable assessment of the impacts of the proposed BRT route. In the UrbanSim model developed in this study, the impact of BRT 
services on traffic patterns is represented by the number of trips attracted away from the auto mode, as auto mode is the only one included in the sub-models. A new model structure should be developed to contain transit variables in order to directly represent transit impacts. 


\section{Table of Contents}

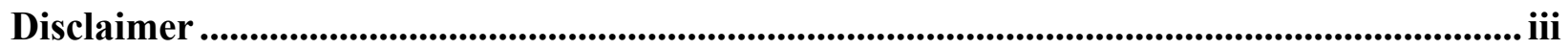

Metric Conversion ............................................................................................................................ iv

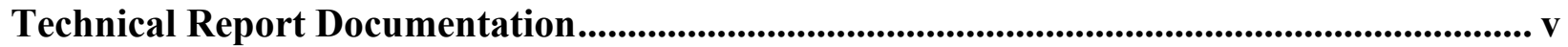

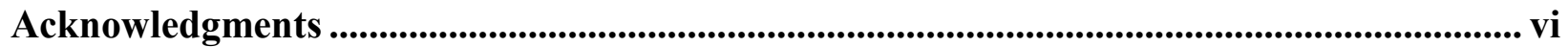

List of Figures................................................................................................................................... xiv

List of Tables ....................................................................................................................................... xvii

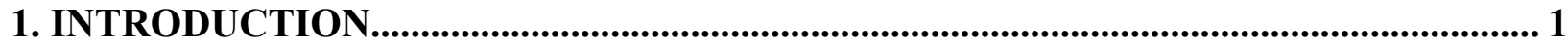

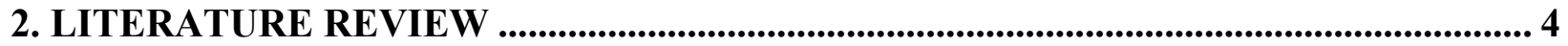

2.1 General Methods to Assess the Impact of Transit Investments .......................................... 4

- Input-Output (I-O) Models ..................................................................................... 4

- Regression Models ............................................................................................................... 4

- Statistical Comparisons ................................................................................................... 6

- Economic Forecasting and Simulation Models ..................................................... 6

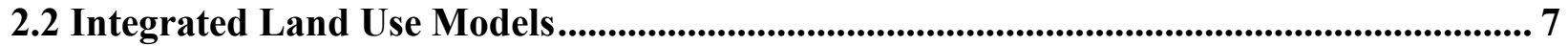

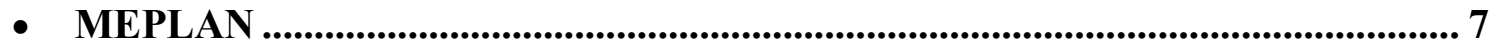

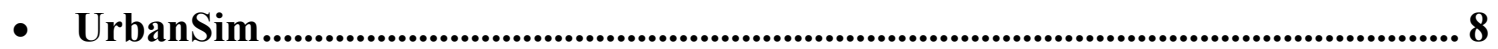

2.3 Other Methods to Assess the Impact of Transit Investments ......................................... 8

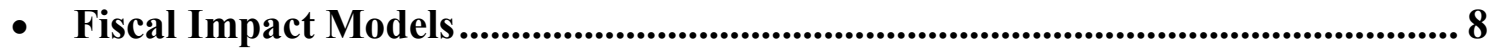

- Case Comparisons....................................................................................................9

- Interviews / Focus groups / Surveys ...................................................................9 9

- Physical Condition Analysis............................................................................... 9

- Real Estate Market Analysis..................................................................................... 9

2.4 Impact of BRT Investments on Land Use................................................................... 12

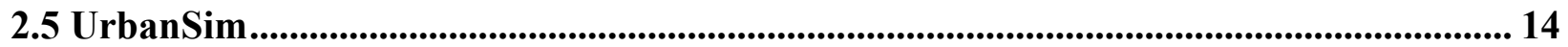

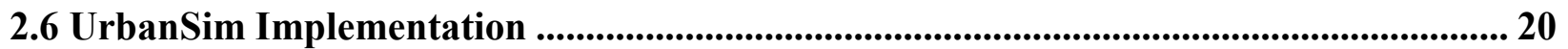

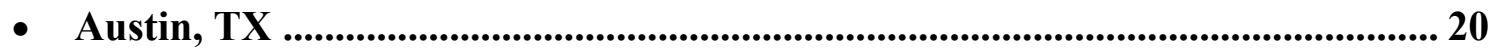

- Puget Sound Regional Council (PSRC), WA ...................................................... 21

- SustainCity, Europe ...................................................................................... 22

- Volusia County, FL ...................................................................................................... 24

3. Data Preparation .......................................................................................................................... 26

3.1 Data Requirement ............................................................................................................................. 26

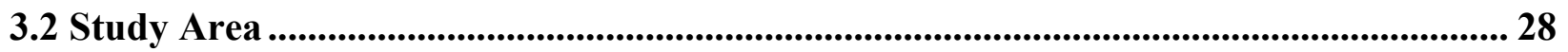

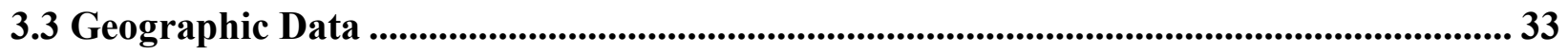




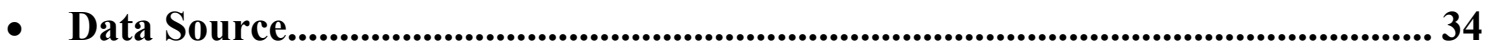

- Identify Data Connection ................................................................................................. 35

- Spatial Match ........................................................................................................................ 37

- Parcel Clearance .................................................................................................................... 37

- Generate Tables .................................................................................................................... 37

3.4 Building Data................................................................................................................................ 37

- Building Table ...................................................................................................................... 37

- Building Type Table .................................................................................................... 39

- Demolition cost data ........................................................................................................... 39

3.5 Household and Person Data ............................................................................................................. 40

- Synthesis and Census Data................................................................................................. 40

- Import Census Data and Run Synthesizer .................................................................... 42

- Spatial Match ..................................................................................................................... 44

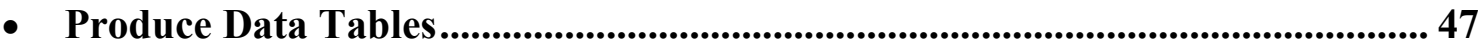

3.6 Employment Data ........................................................................................................................ 48

3.7 Land Use Development Data...................................................................................................... 52

3.8 Socioeconomic Control Data ....................................................................................................... 54

- Annual Household Control Total .................................................................................... 54

- Annual Household Relocation Rate ..................................................................55

- Annual Employment Control Total .................................................................................. 55

- Annual Employment Relocation Rate......................................................................5 56

3.9 Traffic Pattern.............................................................................................................................. 56

- Prepare Zonal Socioeconomic Data ............................................................................ 58

- Retrieve Congested Skim .................................................................................................. 58

- Aggregate Zonal Traffic Pattern .................................................................................... 60

- Output Data Tables................................................................................................................ 62

3.10 Data Compilation ....................................................................................................................... 63

4. Model Development ....................................................................................................................... 65

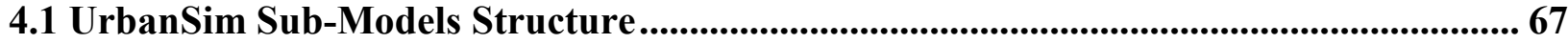

- Real Estate Price Model (REPM) ............................................................................... 68

- Expected Sales Price Model (ESPM)........................................................................ 69

- Development Proposal Choice Model (DPCM)........................................................ 70

- Building Construction Model (BCM)............................................................................ 70

- Household Transition Model (HTM) ............................................................................... 71 
- Employment Transition Model (ETM) ...................................................................... 71

- Household Relocation Model (HRM) ................................................................ 72

- Household Location Choice Model (HLCM) ................................................... 73

- Employment Relocation Model (ERM) .................................................................... 73

- Employment Location Choice Model (ELCM) ...................................................... 74

4.2 Model Specifications ................................................................................................................. 74

4.3 UrbanSim Model Assembly and Debug ............................................................... 75

- Install UrbanSim....................................................................................................... 75

- Test with Sample Dataset ................................................................................. 76

- Import the base year data and model specifications........................................... 76

- Create Base Year Scenario.................................................................................. 78

- Debug UrbanSim Model..................................................................................................... 78

5. MODEL VALIDATION ................................................................................................. 79

6. SCENARIO TESTING (BRT) ............................................................................................ 85

6.1 Scenario 1 (The BRT route with a one percent trip attraction in a short-period projectio, 2010-2012) 86

6.2 Scenario 2 (The BRT route with a five percent trip attraction in a short-period projection, 2012-2012) ............................................................................................................................ 94

6.3 Scenario 3 (The BRT route with a one percent trip attraction in a long-period projection, 2010-2020) ........................................................................................................ 101

6.4 Scenario 4 (The BRT route with a five percent trip attraction in a long-period projection, 2010-2020) ........................................................................................................................... 108

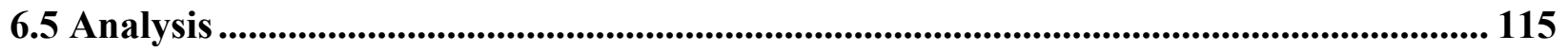

7. Scenario Testing II (HART Route 2) ........................................................................................ 117

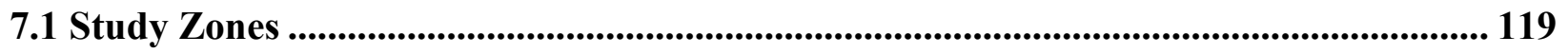

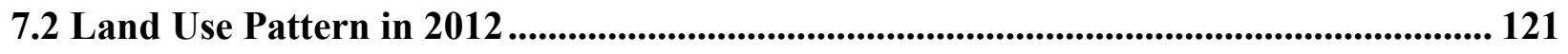

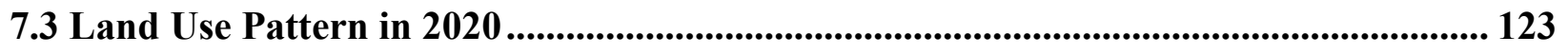

8. CONCLUSIONS AND RECOMMENDATIONS.................................................... 126

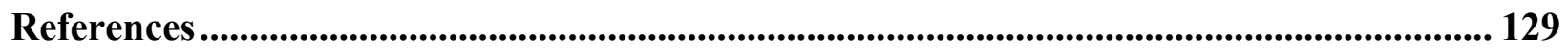

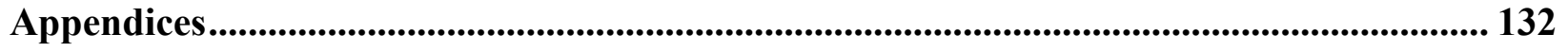

Appendix I Input Files for Parcel-Based UrbanSim ............................................................ 133

Appendix II Source Codes for Household/Person Assignment ............................................. 151 


\section{List of Figures}

Figure 1-1 Feedback Mechanism between Land Use Models and Travel Demand Models .......... 2

Figure 2-1 UrbanSim Model Components and Data Flow ………………………....................... 15

Figure 2-2 Primary UrbanSim Input and Output Data .......................................................... 16

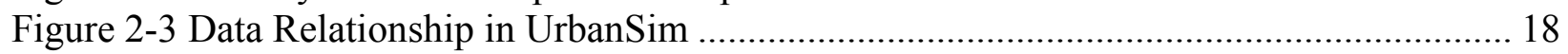

Figure 2-4 Interactions between UrbanSim and Travel demand models system......................... 19

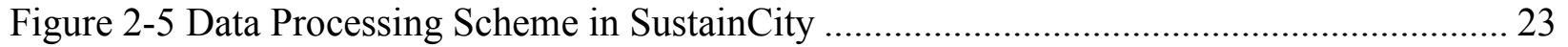

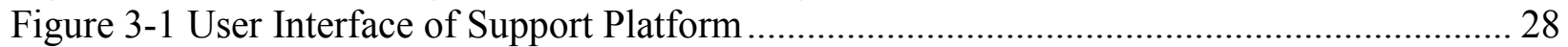

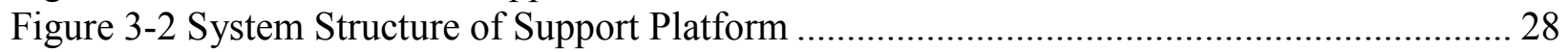

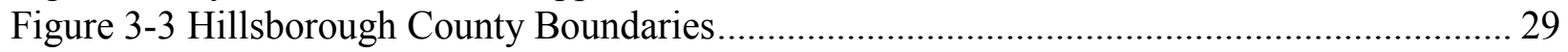

Figure 3-4 North-South Corridor BRT in Hillsborough County ……………………………....... 31

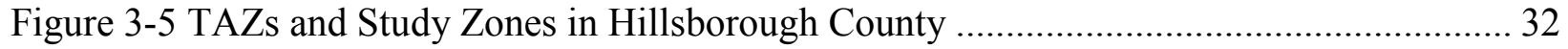

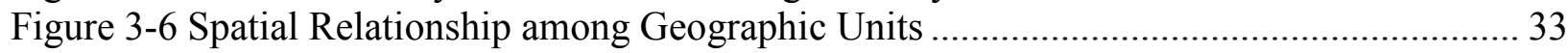

Figure 3-7 Procedure of Geographic Data Preparation............................................................ 34

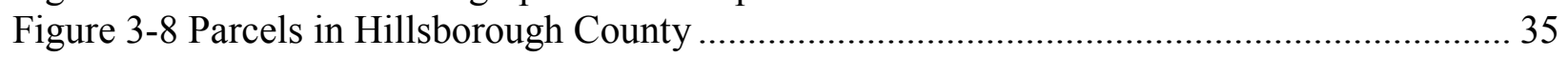

Figure 3-9 Procedure for Household and Person Data Preparation................................................ 40

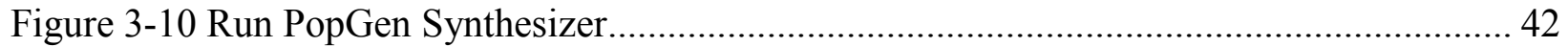

Figure 3-11 Census Block Groups in Hillsborough County ....................................................... 43

Figure 3-12 Spatial Relationship between Census Block Groups and Parcels ............................. 44

Figure 3-13 "Many-to-Many" Relationship between Synthesized Households and

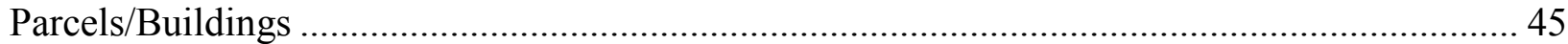

Figure 3-14 Assignment of Parcels/Buildings to Households ........................................................ 46

Figure 3-15 Procedure of Job Data Preparation......................................................................... 51

Figure 3-16 Sample of Community Development Pattern in FLUE ........................................... 54

Figure 3-17 Data Preparation for Traffic Data ........................................................................ 57

Figure 3-18 Zone-to-Zone Travel Time in Hillsborough County................................................. 59

Figure 3-19 Zone-to-Zone Trips by Purpose in Hillsborough County ......................................... 59

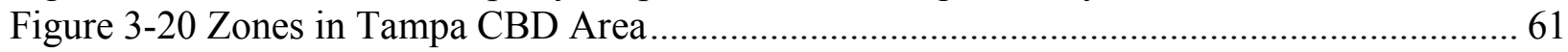

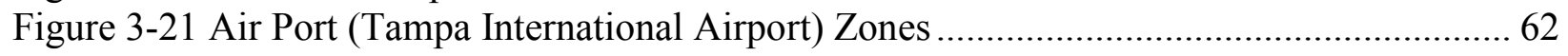

Figure 4-1 UrbanSim Model Agents Interacting in Urban Markets .............................................. 66

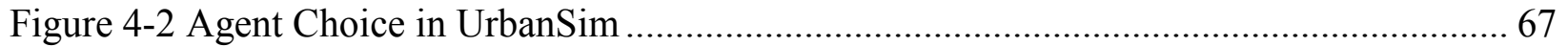

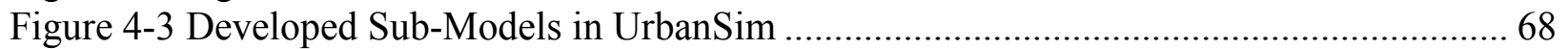

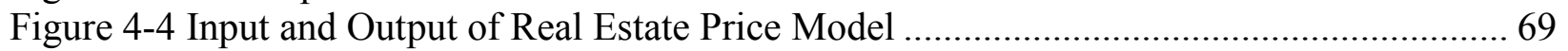

Figure 4-5 Input and Output of Expected Sales Price Model ..................................................... 69

Figure 4-6 Input and Output of Development Proposal Choice Model........................................... 70

Figure 4-7 Input and Output of Building Construction Model .................................................. 71

Figure 4-8 Input and Output Household Transition Model ....................................................... 71

Figure 4-9 Input and Output of Employment Transition Model................................................ 72

Figure 4-10 Input and Output of Household Relocation Model ................................................... 72

Figure 4-11 Input and Output of Household Location Choice Model............................................. 73

Figure 4-12 Input and Output of Employment Relocation Model................................................ 74

Figure 4-13 Input and Output of Employment Location Choice Model ....................................... 74

Figure 4-14 Create Parcel-Based UrbanSim Project ……………………………........................... 76

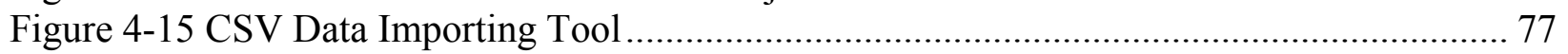

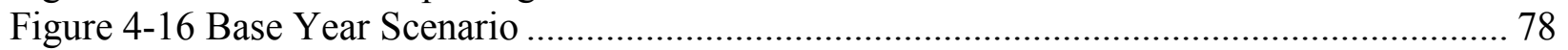




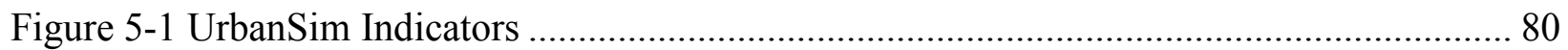

Figure 5-2 Cumulative Percentage of Household Difference..................................................... 81

Figure 5-3 Zonal Household Difference between UrbanSim and 2035 LRTP in 2010................ 82

Figure 5-4 Zonal Household Difference between UrbanSim and 2035 LRTP in 2016................. 83

Figure 5-5 Zonal Household Difference between UrbanSim and 2035 LRTP in 2020................ 84

Figure 6-1 Land Use Patterns With and Without Implementation of BRT (1\% Trip Attraction) in

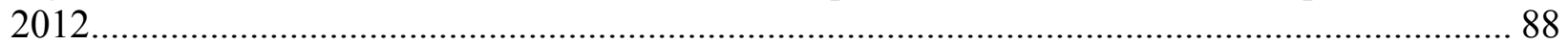

Figure 6-2 Zonal Change in Population due to Implementation of BRT (1\% Trip Attraction) in

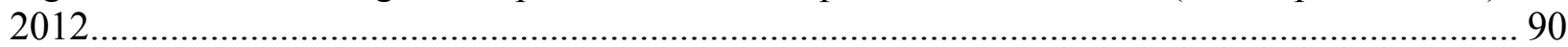

Figure 6-3 Zonal Change in Households Due to Implementation of BRT (1\% Trip Attraction) in

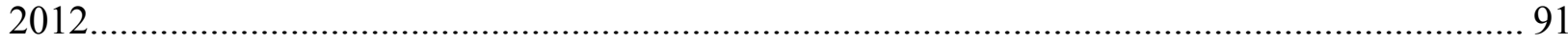

Figure 6-4 Zonal Change in Jobs due to Implementation of BRT (1\% Trip Attraction) in 201292 Figure 6-5 Zonal Change in Unit Price due to Implementation of BRT (1\% Trip Attraction) in

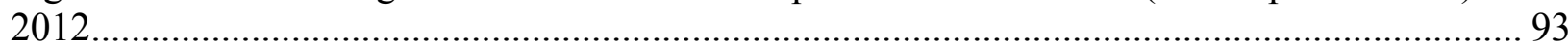

Figure 6-6 Land Use Patterns With and Without Implementation of BRT (5\% Trip Attraction) in

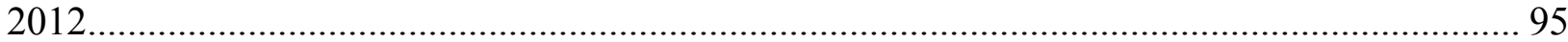

Figure 6-7 Zonal Change in Population due to Implementation of BRT (5\% Trip Attraction) in

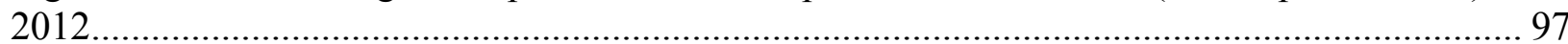

Figure 6-8 Zonal Change in Households due to Implementation of BRT (5\% Trip Attraction) in

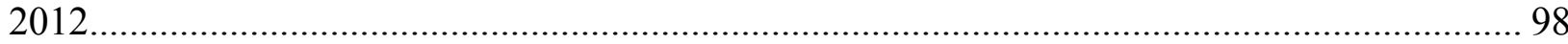

Figure 6-9 Zonal Change in Jobs due to Implementation of BRT (5\% Trip Attraction) in 201299 Figure 6-10 Zonal Change in Unit Price due to Implementation of BRT (5\% Trip Attraction) in

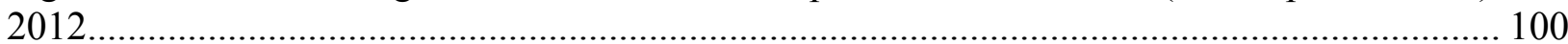

Figure 6-11 Land Use Patterns With and Without Implementation of BRT (1\% Trip attraction) in

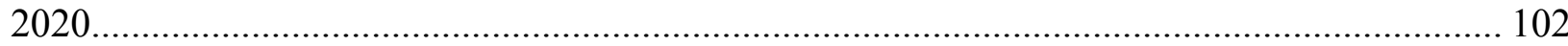

Figure 6-12 Zonal Change in Population due to Implementation of BRT (1\% Trip Attraction) in 2020. 104

Figure 6-13 Zonal Change in Households due to Implementation of BRT (1\% Trip Attraction) in 2020. 105

Figure 6-14 Zonal Change in Jobs due to Implementation of BRT (1\% Trip Attraction) in 2020 106

Figure 6-15 Zonal Change in Unit Price due to Implementation of BRT (1\% Trip Attraction) in 2020. 107

Figure 6-16 Land Use Patterns With and Without Implementation of BRT (5\% Trip Attraction) in 2020 109

Figure 6-17 Zonal Change in Population due to Implementation of BRT (5\% Trip Attraction) in 2020. 111

Figure 6-18 Zonal Change in Households due to Implementation of BRT (5\% Trip Attraction) in 2020 112

Figure 6-19 Zonal Change in in Jobs due to Implementation of BRT (5\% Trip Attraction) in 2020.

Figure 6-20 Zonal Change in Unit Price due to Implementation of BRT (5\% Trip Attraction) in

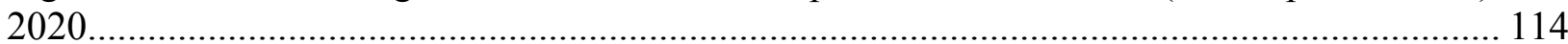

Figure 6-21 Changes in Land Use Patterns due to Implementation of BRT Service ................. 116

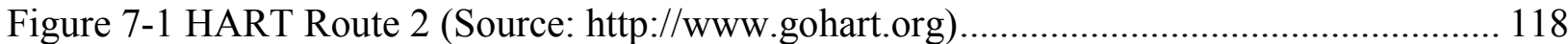

Figure 7-2 Influence Zones of HART Route 2 (2-mile buffer) ................................................... 120 
Figure 7-3 Land Use Patterns With and Without Upgrading HART Route 2 in 2012 ............. 122

Figure 7-4 Land Use Patterns With and Without Upgrading HART Route 2 in 2020 ............. 124 


\section{List of Tables}

Table 2-1 Methods Used to Capture Impacts of Transportation Investments ............................. 10

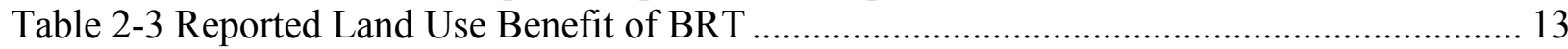

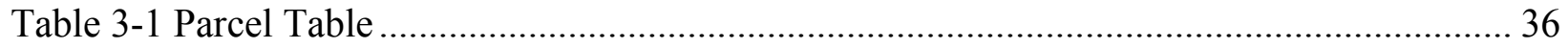

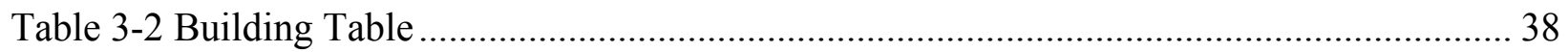

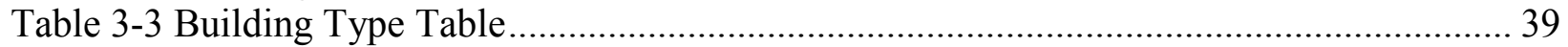

Table 3-4 Marginal Variables in Household and Person Synthesis............................................... 41

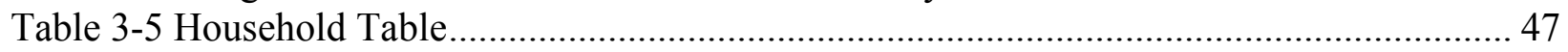

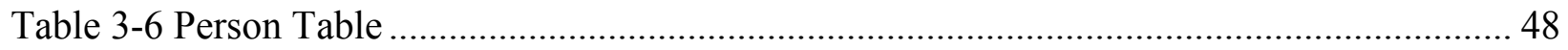

Table 3-7 Employment Sectors Classification - NAICS Codes................................................... 49

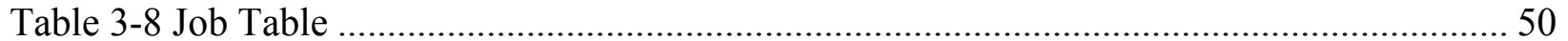

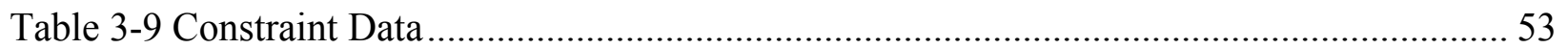

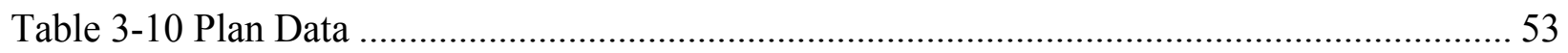

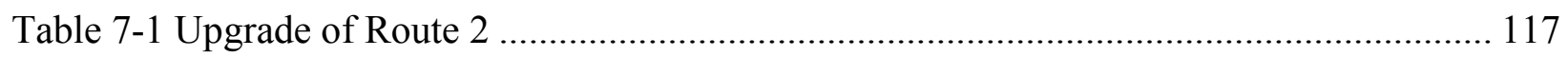

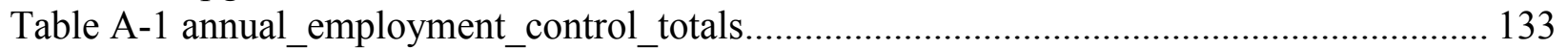

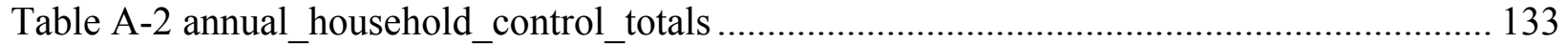

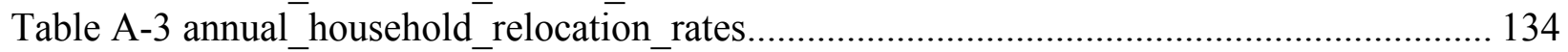

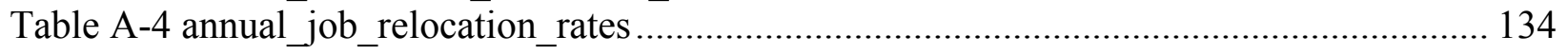

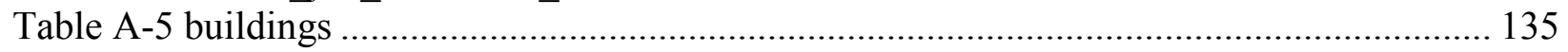

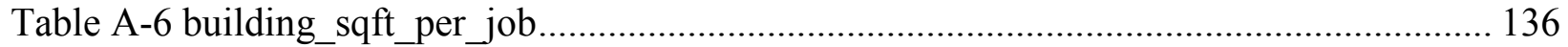

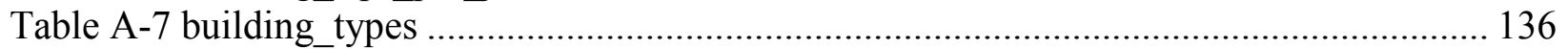

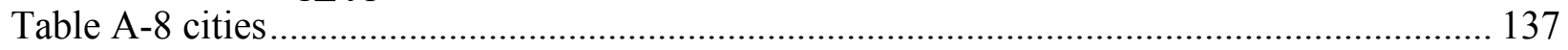

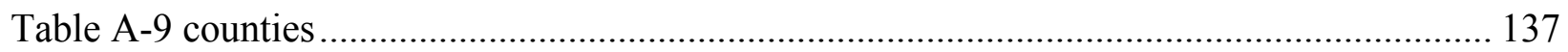

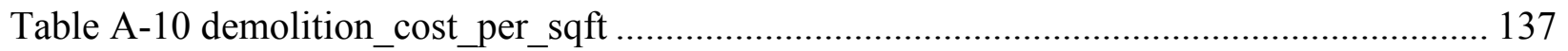

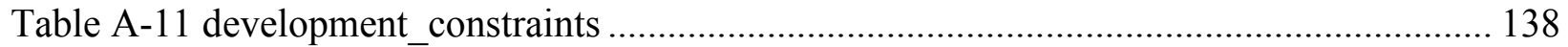

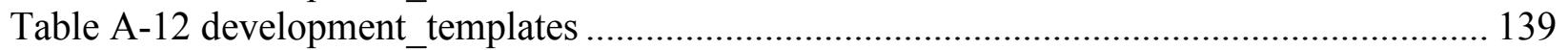

Table A-13 development_template_components ………….................................................. 140

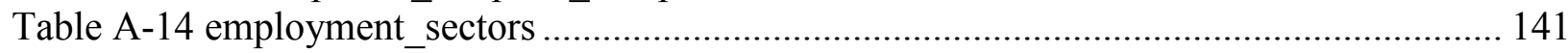

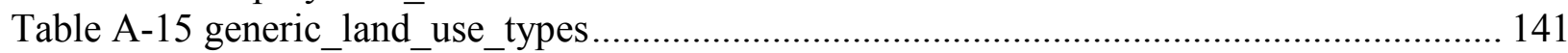

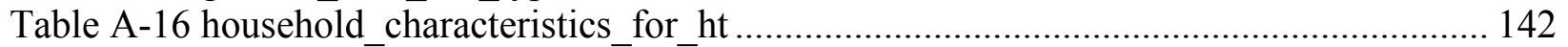

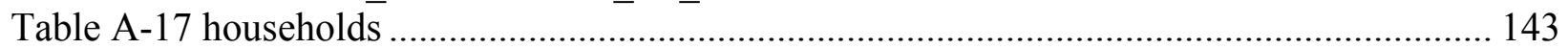

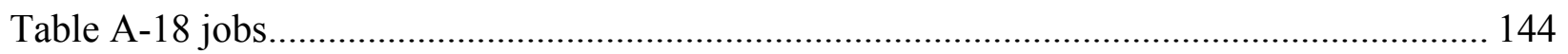

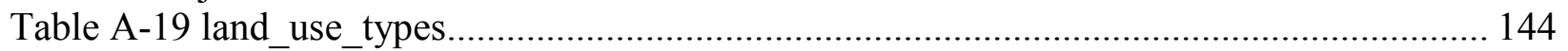

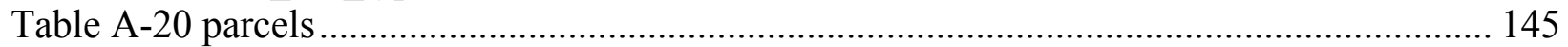

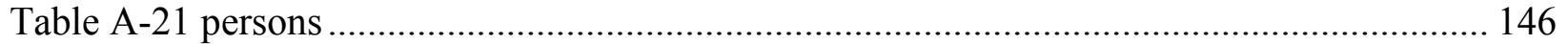

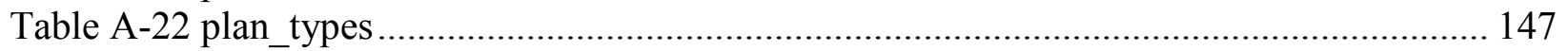

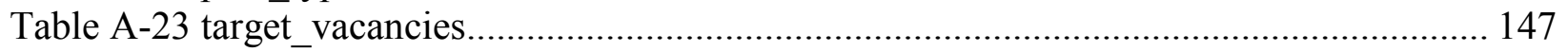

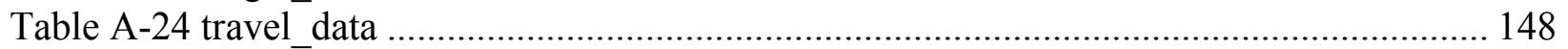

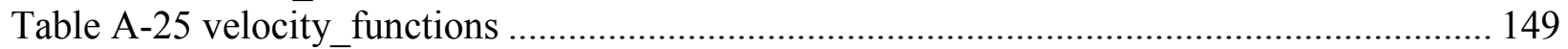

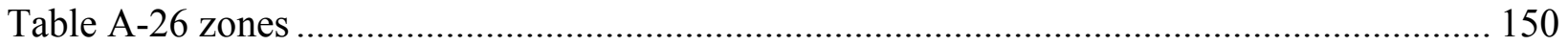




\section{INTRODUCTION}

Transit systems, such as commuter rail, light rail, bus rapid transit, and high speed rail, can generate significant impacts on land development patterns over time. According to the Transit Cooperative Research Program (TCRP) Report 35 - "Economic Impact Analysis of Transit Investments," land development and changes in property values are listed as a redistributive impact on transit investments (1). Most efforts to assess the potential impacts of a proposed transit investment on a neighborhood are made by comparing the proposed transit investment plan to other communities that have already made similar investments. Although this type of analysis is informative, it is also of somewhat limited value because a particular transit investment's impacts on a specific neighborhood or area are the result of complex interactions between existing conditions; local market forces; choices made by individual businesses and families; and land use decisions made by the local government that vary significantly from region to region.

As an aid to local decision-making, it would be very helpful to have an evaluation tool which can be developed, validated, and calibrated with local data to forecast the impacts of a proposed investment and to assist in determining which policy choices might achieve a desired result. It is believed that such a tool may also assist in minimizing potential conflicts over proposed transit investments because more is known about the future with some level of confidence.

The integration of land use and travel demand models creates a tool that can recognize the interaction between land development and travel patterns, and evaluate the impacts of proposed transit investments on the population, demographics, the local economy, the real estate market, land use, growth policies, and the environment. Land use models provide an understanding of the causes and consequences of land use changes. Accessibility of properties plays a key role in land use changes because it can significantly affect individuals' choices on the location of their household and employment. Travel demand models can be used to forecast the ridership of new transit systems which will change accessibility of properties. Travel demand models require socioeconomic data in the horizon years for future forecasts to predict future travel patterns based on future land use forecasts, sometimes with the aid of a land use model. The accuracy of a 
land use forecast greatly affects that of a demand forecast model. Figure 1-1 shows the feedback mechanism between land use models and travel demand models.

Analysis of Project Effects on Air Quality

Considering Land Use Feedback

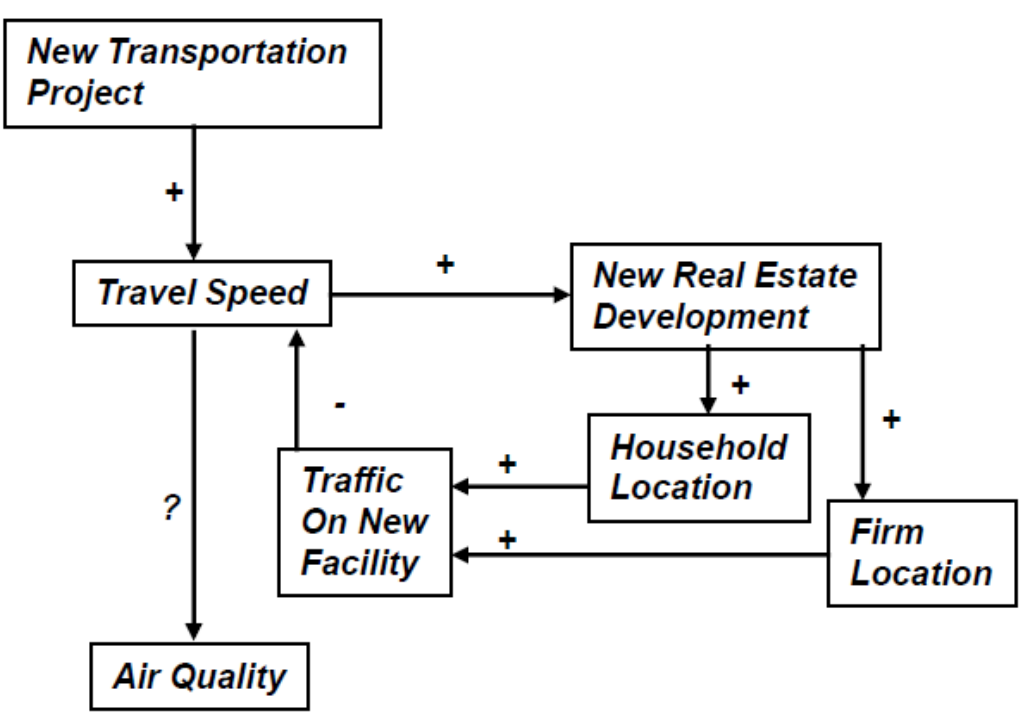

\section{Figure 1-1 Feedback Mechanism between Land Use Models and Travel Demand Models}

(Source: www.urbansim.org)

Existing land use models range from rule-based programs that provide information and guidance on the process of allocating growth to different subareas, to sophisticated models that incorporate economic theories and market mechanisms.

UrbanSim was originally developed by Paul Waddell of the University of Washington. UrbanSim simulates land use changes by considering factors such as changes in population, demographics, structure of the local economy, the real estate market, land use and growth policies, environmental constraints, etc. It is based on disaggregate activity-based models that consider individuals' choices on residential and employment locations, as well as the real estate market. Additionally, it is a freeware while most of the other operational land use models are either proprietary or unavailable.

This study aims to develop a model using UrbanSim to assess whether the changes that might take place in a specific geographic area are from a transit investment. UrbanSim has the potential to be a powerful tool in evaluating the benefits of transit investments because it works on a much smaller geographic scale than other alternative systems and can simulate location decisions made by individual businesses and families. 


\subsection{Objectives}

The objectives for this study include the following:

1. Perform a literature review to examine previous assessments of the impacts of proposed transit investments and public policy choices on land use patterns

2. Select a proper study area and assess the data requirement to develop an UrbanSim model

3. Collect required data

4. Develop an UrbanSim model

5. Develop and test scenarios with the model

6. Summarize findings

In the remainder of this report, literature on proposed and operational land use models is reviewed and summarized in Chapter 2. The emphases of the literature review are underlying theories, methodologies, and applications of the models. Chapter 3 describes the study area, Hillsborough County, Florida. The study area must be an area with recent household survey data and up-to-date GIS data, including parcel-level property data, and it also must be relatively selfcontained. Data collection and processing are also described in Chapter 3. Data collected include property parcels, business establishments, census, urban area boundaries, environmental and political planning boundaries, and Traffic Analysis Zones (TAZs).

Chapter 4 discusses the specifications of the sub-models. The process of the UrbanSim model assembly and debugging is also described in Chapter 4. Chapter 5 describes the UrbanSim simulation process for Hillsborough County. The simulation results based on the base year (2010) are compared to the projected socioeconomic data from the Bureau of Economic and Business Research (BEBR), University of Florida to validate the UrbanSim model.

Chapters 6 and 7 present two case studies based on alternatives of the Hillsborough County transit improvement plan and assumptions of future demographic and economic growth. Comparisons between scenarios with and without a Bus Rapid Transit (BRT) service in the target years (2012 and 2020) are described in the chapters to evaluate the impacts of the proposed transit system. Finally, conclusions and recommendations regarding the future adoption of UrbanSim in Florida for transit investment evaluation are provided in Chapter 8. 


\section{LITERATURE REVIEW}

While transit investments aim to improve mobility of the public, it is recognized that the investment can also generate significant economic benefits. Continuous efforts have been made to improve methods used to measure the economic impact of the transit investment; therefore, there is a growing interest in assessing the impacts of those investments on land use in an effective and efficient manner. Four-step travel demand models are used to measure the impact of transportation/transit investments on the transportation system and travel behavior. These models include four sequential steps to calculate the travel demand: the number of trips generated, how they are allocated, what modes are used, and what transportation links are used for the trip. They measure the change in travel time, operating cost, mode choice, route choice, and traffic volumes of the transportation network. These results are then used in various economic impact and land use models to estimate the economic benefits of the investment (attractiveness of the area, cost of living, access of business to labor markets, etc.) and also the impact on land use patterns. The approaches used to capture the impact of transit investments on economic activities, development density, mix of uses and land use patterns (urban form and design) are as follows:

\subsection{General Methods to Assess the Impact of Transit Investments}

\section{- Input-Output (I-O) Models}

Input-output models use regression equations to measure the impact on business activities in the broader economy due to expansion/contraction of a given industry (e.g, transit). An I-O model is a matrix, which uses inter-industry purchasing and import information from the U.S. Bureau of Economic Analysis (BEA) national input-output table (nearly 500 industries) as an input. The outputs obtained from these models are expressed in terms of three measures of economic activity: earnings (wages and salaries), Gross National Product (GNP), and jobs. These models also provide inter-industry outputs by industry sector. The most commonly used I-O models are the Regional Input-Output Modeling System (RIMS II) and IMpact analysis for PLANning (IMPLAN).

\section{- Regression Models}

Regression models are widely used to evaluate the impact of transit investments on economic conditions. These models measure impacts, such as changes in employment, land value, and/or 
building square footage, due to explanatory variables, like transit service levels or transit investments.

The most commonly used regression analysis tools are hedonic price models and logistic regression, which both reveal people's preference. As a change in property value due to transit investment represents a change in accessibility of that particular property, the hedonic price model is used to measure the change in property value due to transit investment. It uses property values or change in property values $(2,3,4$, and 5) as the dependent variable and home characteristics (area, age of the property, number of bedrooms, bathrooms, etc.), neighborhood characteristics (income, race, ownership, etc.), and location characteristics (proximity to transit station) as the explanatory variables. Linear, semi-logarithmic, and log linear specifications are employed to model the economic impact of transit investment on discrete dependent variables, such as mode choice and land use category. These models capture the transit impact using property cross sections, whereas some studies $(3,5,6,7)$ suggest use of repeat sales value of a property. This helps analyze the actual object of the analysis, property price appreciation, rather than analyzing the causes of property price appreciation. These regression models serve as the basis for capturing the predictive impacts, using techniques such as input-output, economic forecasting, and simulation models.

Since the most commonly used ordinary least square (OLS) hedonic models do not take into account spatial dependencies and heterogeneity, studies $(8,9,10,11,12)$ suggest using spatial autoregressive (SAR) and geographically weighted regression (GWR) approaches to develop spatial hedonic models.

The SAR hedonic approach incorporates spatial effects in the regression model based on the assumption that response variables at each location are a function not only of the explanatory variable at that location, but of the response at neighboring locations as well. SAR models are classified into three types (SAR lag model, SAR error model, and SAR mixed model) based on where the spatial autoregressive process is believed to occur.

The GWR approach also incorporates geographic information into the regression model by estimating separate models for each data point and developing a series of distance-related weights. The GWR approach gives a heightened understanding of relationships between variables across space, as the output of this model is a set of parameters that can be mapped in 
geographic space. GWR is an alternative to SAR models as it performs best with regards to model fit, but the issue of correlated coefficients gives favor to SAR.

\section{- Statistical Comparisons}

If data needed for regression analysis are not available, simple statistical comparisons can be made before and after the transit investment based on data of development, employment, wages, and other variables. In this method, comparable neighborhoods' and subareas' transit corridors are used as a control and a comparative analysis is performed between the control and study area before and after the transit investment. The following equation represents the method:

$$
\text { Effect of Transit }=\left(I_{T A}-I_{T B}\right)-\left(I_{C A}-I_{C B}\right)
$$

where:

$$
\begin{aligned}
& \mathrm{I}=\text { Economic impact of transit } \\
& \mathrm{T}=\text { Transit corridor being studied } \\
& \mathrm{C}=\text { Transit corridor used as a control } \\
& \mathrm{B}=\text { Before transit investment } \\
& \mathrm{A}=\text { After transit investment }
\end{aligned}
$$

\section{- Economic Forecasting and Simulation Models}

Economic forecasting and simulation models link the input-output model to an econometric model by adding the ability to forecast future changes in prices and costs of labor, housing, transportation, or business on a yearly basis. They use travel time savings information from regional transportation models, and employment, wage, and salary data as inputs. They are primarily used to predict the short term and long term impacts of the transit investment on sales, business output, personal income, employment, population, and productivity.

These models consist of systems of simultaneous regression equations and stepwise regression with a relatively straightforward structure. Studies $(1,13,14)$ have used models such as Regional Economic Models, Inc. (REMI), Regional Dynamics Model (REDYN), and Transportation Economic Development Impact System (TREDIS) to capture economic impacts of public transportation investments. Models like REMI also incorporate the spatial dimension of the economy by capturing benefits due to the concentration or agglomeration of economic activities. 


\subsection{Integrated Land Use Models}

Integrated land use models are used to capture the impact of transportation investments on land use patterns, which can be defined in terms of population, employment, and density of developments. Based on the methodology adopted and classification proposed by Waddell (2004), land use models are classified into spatial interaction, spatial input-output, linear programming, micro-simulation, discrete choice modeling, cellular automata, and rule-based. There have been several studies $(15,16,17,18)$ that have summarized most of the land use models.

Land use models are quite similar to economic forecasting models, as both provide forecasts of employment by zone; however, land use models do not provide fine level details on categories of business. These models give fine level details on building space and geographic zones. MEPLAN, UrbanSim, Production Exchange and Consumption Allocation System (PECAS), and Transportation Economic and Land Use Model (TELUM) are some of the widely used integrated land use models.

\section{- MEPLAN}

MEPLAN is a proprietary software package developed by Marcial Echenique and Partners Ltd. in the United Kingdom. Hunt (19) describes its framework as the interaction between two parallel markets: a land market and a transportation market. Behavior in each system is modeled as a response to price or price-like signals (including travel disutility). It provides the following outputs:

- $\quad$ Employment by sector

- Population by income group

- Households by car ownership group

- $\quad$ Land area by activity

- $\quad$ Floor space by activity

- $\quad$ Price by floor space/land type 


\section{- UrbanSim}

UrbanSim is a disaggregate simulation model used to simulate the commercial and residential development of a region both spatially and temporally. It is linked to traditional four-step travel demand models that provide a static equilibrium traffic assignment. UrbanSim is further explained in Section 2.5.

UrbanSim uses land or real estate price data, which gives the real market valuation of each property as compared to rent data used by hedonic models. However, finding data sources for real estate transaction prices is a challenge. The UrbanSim simulation system provides the following outputs:

- $\quad$ Households by income, age, size, and presence of children

- $\quad$ Employment by industry and land use type

- $\quad$ Acreage by land use

- Dwelling units by type

- $\quad$ Square feet of nonresidential space by type

- $\quad$ Real estate prices

\subsection{Other Methods to Assess the Impact of Transit Investments}

\section{- Fiscal Impact Models}

Fiscal impact models are specialized financial models which measure the impact of economic changes due to proposed land use decisions on government (local, county and state) revenues and expenses (tax revenues). They estimate tax revenues from future development, employment, and income due to proposed transportation investment. They use information from the local government budget, census, property appraiser, and employment data to predict cost and revenues associated with the comprehensive plan or individual projects.

Fiscals, STAMP, and Fiscal Impact Analysis Model (FIAM) are the most commonly used fiscal impact models. While I-O and economic forecasting models like IMPLAN and REMI give estimates of tax revenues due to economic changes, they do not provide as detailed information as provided by fiscal impact models. 


\section{- Case Comparisons}

Case comparisons examine how transit investments have affected economic growth and development in other communities and then compare how similar investments might affect another community. This is achieved by studying literature and conducting interviews with planners, etc. Inputs measured include the following: changes in square feet of development within a corridor by land use, employment, property value, personal income, and retail sales revenue. Case comparisons are used for predictive studies.

\section{- Interviews / Focus groups / Surveys}

Local experts, corporate leaders, business owners, developers, and community members are interviewed or surveyed to predict and evaluate the economic impact of transit investments.

\section{- Physical Condition Analysis}

This analysis is focused on identifying opportunities for development within a proposed transit corridor. Field surveying is a method of assessing development conditions. This analysis measures transit impacts in terms of square feet of development by land use type and potential property tax revenue. Physical condition analysis is most effective when used in combination with case comparisons, interviews/focus groups/surveys, and real estate market analysis.

\section{- Real Estate Market Analysis}

This analysis is used to measure the impact of an investment on transit corridors' development potential. It is measured in terms of rent and land value premiums, vacancy rates, and net absorption (sqft of development). Data sources used include government sources, building permits, tax assessment records, local newspapers, and data from private data vendor market profiles.

Table 2-1 summarizes the various methods that can be applied to measure the impacts of transit investments. 
Table 2-1 Methods Used to Capture Impacts of Transportation Investments

\begin{tabular}{|c|c|c|c|c|}
\hline Category & Description & Typical Model & Advantage & Disadvantage \\
\hline Input-Output (I-O) & $\begin{array}{l}\text { Uses regression equations to measure } \\
\text { impacts on business activities in the broader } \\
\text { economy due to expansion/contraction of a } \\
\text { given transit system. }\end{array}$ & $\begin{array}{l}\text { RIMS II, } \\
\text { IMPLAN }\end{array}$ & $\begin{array}{l}\text { Prevents the need to } \\
\text { conduct expensive } \\
\text { surveys, widely used } \\
\text { for impact studies }\end{array}$ & $\begin{array}{l}\text { Expertise required to use, } \\
\text { not able to forecast impact } \\
\text { on local economy }\end{array}$ \\
\hline Regression Models & $\begin{array}{l}\text { Measures impacts such as changes in } \\
\text { employment, land value or building square } \\
\text { footage due to explanatory variables like } \\
\text { transit service levels or transit investments. }\end{array}$ & $\begin{array}{l}\text { Hedonic Model, } \\
\text { Logit Mode, } \\
\text { SAR, } \\
\text { GWR }\end{array}$ & $\begin{array}{l}\text { Widely recognized and } \\
\text { accepted approach }\end{array}$ & $\begin{array}{l}\text { Data intensive, expertise } \\
\text { required to use, not able to } \\
\text { capture the impact on } \\
\text { economic activities } \\
\text { effectively }\end{array}$ \\
\hline $\begin{array}{l}\text { Economic Forecasting } \\
\text { and Simulation }\end{array}$ & $\begin{array}{l}\text { Links the input-output model to an } \\
\text { econometric model by adding the ability to } \\
\text { forecast future changes in prices and costs of } \\
\text { labor, housing, transportation or business on } \\
\text { a yearly basis. }\end{array}$ & $\begin{array}{l}\text { REMI, } \\
\text { REDYN, } \\
\text { INFORUM, } \\
\text { TREDIS }\end{array}$ & $\begin{array}{l}\text { Powerful tool to } \\
\text { understand economic } \\
\text { impacts over time } \\
\text { (dynamic), less } \\
\text { computer time to run }\end{array}$ & $\begin{array}{l}\text { Expertise required to } \\
\text { use, acquisition of data can } \\
\text { be time consuming }\end{array}$ \\
\hline $\begin{array}{l}\text { Integrated Urban Land } \\
\text { Use Models }\end{array}$ & $\begin{array}{l}\text { Captures the impact of transportation } \\
\text { investments on land use patterns, which can } \\
\text { be defined in terms of population, } \\
\text { employment, and density of developments. }\end{array}$ & $\begin{array}{l}\text { MEPLAN, } \\
\text { UrbanSim, } \\
\text { PECAS, } \\
\text { TELUM }\end{array}$ & Unknown & Unknown \\
\hline $\begin{array}{l}\text { Statistical } \\
\text { Comparisons }\end{array}$ & $\begin{array}{l}\text { Simple statistical comparisons can be done } \\
\text { based on data of development, employment, } \\
\text { wages, and other variables from both before } \\
\text { and after data on transit investments. }\end{array}$ & & $\begin{array}{l}\text { Less data-intensive, } \\
\text { expertise is not } \\
\text { required }\end{array}$ & $\begin{array}{l}\text { Control areas are difficult } \\
\text { to find }\end{array}$ \\
\hline Fiscal Impact Models & $\begin{array}{l}\text { Measures impact of economic changes due to } \\
\text { proposed land use decisions on government } \\
\text { (local, county and state) revenues and } \\
\text { expenses (tax revenues). }\end{array}$ & $\begin{array}{l}\text { Fiscals, } \\
\text { STAMP, } \\
\text { FIAM }\end{array}$ & $\begin{array}{l}\text { Detailed estimates of } \\
\text { financial benefits of a } \\
\text { transportation project, } \\
\text { basis for future budget } \\
\text { projections }\end{array}$ & $\begin{array}{l}\text { Careful methodology } \\
\text { examination is required as } \\
\text { the resource allocation } \\
\text { may be based on this } \\
\text { analysis }\end{array}$ \\
\hline Case Comparisons & $\begin{array}{l}\text { Compares how transit investment has } \\
\text { affected economic growth and development } \\
\text { in other communities with how similar } \\
\text { investment might affect another community. }\end{array}$ & & $\begin{array}{l}\text { Easy to administer, low } \\
\text { cost, helps in } \\
\text { identifying additional } \\
\text { steps required to } \\
\text { capture the impact of } \\
\text { transit investment }\end{array}$ & $\begin{array}{l}\text { Mislead decision makers, } \\
\text { impacts of such investment } \\
\text { is unique for each area }\end{array}$ \\
\hline
\end{tabular}


Table 2-2 (continued)

\begin{tabular}{|l|l|l|l|l|}
\hline \multicolumn{1}{|c|}{ Category } & \multicolumn{1}{|c|}{ Description } & Typical Model & \multicolumn{1}{c|}{ Advantage } & \multicolumn{1}{c|}{ Disadvantage } \\
\hline $\begin{array}{l}\text { Interviews / Focus } \\
\text { groups / Surveys }\end{array}$ & $\begin{array}{l}\text { Local experts, corporate leaders, business } \\
\text { owners, developers, and community } \\
\text { members are interviewed or surveyed to } \\
\text { predict and evaluate economic impacts of } \\
\text { transit investment. }\end{array}$ & $\begin{array}{l}\text { New perspective which } \\
\text { may not be apparent to } \\
\text { researcher, easy and } \\
\text { inexpensive to use }\end{array}$ & $\begin{array}{l}\text { It is based on opinions and } \\
\text { perceptions which may } \\
\text { lead to bias }\end{array}$ \\
\hline $\begin{array}{l}\text { Physical Condition } \\
\text { Analysis }\end{array}$ & $\begin{array}{l}\text { Identifies opportunities for development } \\
\text { within a proposed transit corridor. Field } \\
\text { survey is the method of assessing the } \\
\text { development conditions.The SBD Zones }\end{array}$ & $\begin{array}{l}\text { Cost effective, not data } \\
\text { intensive }\end{array}$ & $\begin{array}{l}\text { Not practical on a larger } \\
\text { (regional) scale }\end{array}$ \\
\hline $\begin{array}{l}\text { Real Estate Market } \\
\text { Analysis }\end{array}$ & $\begin{array}{l}\text { Measured in terms of rent and land value } \\
\text { premium, vacancy rates land assembly, and } \\
\text { net absorption (sq. ft. of development). Data } \\
\text { sources used include government sources; } \\
\text { building permits and tax assessment records, } \\
\text { local newspapers, and data from private data } \\
\text { vendor market profiles. }\end{array}$ & $\begin{array}{l}\text { Less time consuming, } \\
\text { relatively low cost, } \\
\text { easy to understand }\end{array}$ & $\begin{array}{l}\text { Can be data demanding, } \\
\text { inconsistencies in required } \\
\text { data, can be easily biased }\end{array}$ \\
\end{tabular}




\subsection{Impact of BRT Investments on Land Use}

Munoz-Raskin (20) studied the relation of BRT and residential property values within walking distance to the system in Bogota's TransMilenio (Colombia). This study uses data on 130,692 new multifamily properties provided by the Bogotá Department of Housing and Control from 2001 to 2004 to find out the impact of BRT on multifamily properties. It concludes that properties within the immediate proximity of feeder lines $(0-5$ minute walk, $\leq 1 / 4$ mile $)$ were valued more than those requiring a 5-10 minute walk.

Breakthrough Technologies Institute (21) performed a detailed review of developments around BRT corridors in four cities: Brisbane (Australia), Cleveland (Ohio), Boston (Massachusetts), and Ottawa (Ontario). It also conducted written surveys and personal interviews with local developers and public agencies to assess their attitudes on BRT and development. The results indicated that BRT services can lead to commercial growth and a rise in land values.

Rodríguez and Mojica (22) developed a before-and-after hedonic model to evaluate the network effects of an extension to Bogotá's BRT system. This study attempted to capture the impact of the extension of Bogota's BRT on property values using a hedonic model. The study found increases in the price of the properties within 500 meters of the BRT.

Diaz et al. (23) evaluated the major elements, system performance, and system benefits of the BRT system and provided transportation planners and decision makers with basic information and data to support the development and evaluation of bus rapid transit concepts.

Rodriguez and Targa (24) examined the impact of the proximity to Bogota's BRT on asking prices for apartment rentals. The authors found increases of 6.8 to 9.3 percent for every 5 minutes of walking time closer to a TransMilenio BRT station. They also found that properties on the bus route, but not necessarily close to a TransMilenio station, had a lower increase, presumably due to the negative noise and pollution effects of bus traffic.

Kittelson \& Associates Inc. (25) reviewed existing documentation of land development impacts associated with recent BRT projects, as well as public agency and developer perceptions of how BRT service and BRT components impact land development location, design, and decisionmaking. The perceptions were obtained from a BRT land development survey conducted for two existing BRT systems: the Transitway in Ottawa and the Silver Line in Boston. 
Transit-oriented development (TOD) policies were obtained from Ottawa and Pittsburgh. Guidelines are provided for assessing the likely land development impacts of new BRT systems (or system improvements) and determining what land development policy and design standards might be applied to encourage TOD around BRT facilities.

Parsons Brinckerhoff Quade \& Douglas, Inc (26) conducted a detailed review of the land use and transportation policies that supported development activities around busway stations at six international locations from 1974 to 1995 . Their report concluded that the busway investments had been used to guide employment and commercial growth in the region.

Perdomo et al. (27) assessed property values from cadastral data for 1,547 properties within $1 \mathrm{~km}$ of TransMilenio BRT stations. The study found that property prices increased between 0.12 and 0.38 percent (depending on the distance to the BRT), for every 5 minutes of walking time closer to a BRT station. Kaplowitz (28) analyzed if BRT provides similar incentives to developers as light rail. The author concluded that BRT does attract development as rail transit but if BRT features attractive stations and offers good quality service, they can attract new developments equivalent to those attracted by rail transit. However, this study seems to draw conclusions based on limited evidence and does not include interviews with developers.

The reported land use benefit of BRT interments is summarized in Table 2-2.

Table 2-3 Reported Land Use Benefit of BRT

\begin{tabular}{|l|l|}
\hline \multicolumn{1}{|c|}{ BRT System } & \multicolumn{1}{c|}{ Land Development Benefits } \\
\hline Adelaide Guided Busway & The Tea Tree Gully area is becoming an urban village \\
\hline Bogotá TransMilenio & $\begin{array}{l}\text { For every 5 minutes of additional walking time to a BRT station, } \\
\text { the rental price of a property decreases between } 6.8 \% \text { and 9.3\% } \\
\text { after } \\
\text { controlling for structural characteristics and neighborhood attributes }\end{array}$ \\
\hline $\begin{array}{l}\text { Boston Silver Line (rebuilt } \\
\text { Washington Street) }\end{array}$ & $\begin{array}{l}\text { \$700+ million in new investments within two to three blocks of } \\
\text { BRT line }\end{array}$ \\
\hline $\begin{array}{l}\text { Brisbane South East } \\
\text { Busway }\end{array}$ & $\begin{array}{l}\text { Up to 20\% gain in property values near busway. Property values in } \\
\text { areas within 6 miles of station grew two to three times faster than } \\
\text { those at greater distances. Higher increase in median home values } \\
\text { around busway than other suburban areas }\end{array}$ \\
\hline Ottawa Transitway System & $\$ 1$ billion (Canadian) in new construction at Transitway Stations \\
\hline Pittsburgh East Busway & $\begin{array}{l}\text { 59 new developments within 1,500 feet of stations, \$302 million in } \\
\text { land development benefits of which \$275 million was new } \\
\text { construction, 80\% clustered at stations. }\end{array}$ \\
\hline
\end{tabular}




\subsection{UrbanSim}

UrbanSim is a software-based simulation system for supporting planning and analysis of urban development and incorporating the interactions between land use, transportation, the economy, and the environment (29). It is intended for use by Metropolitan Planning Organizations (MPOs), cities, counties, non-governmental organizations, researchers, and students interested in exploring the effects of infrastructure and policy choices on community outcomes, such as motorized and non-motorized accessibility, housing affordability, greenhouse gas emissions, and the protection of open space and environmentally sensitive habitats. The urban simulation process reflects the broad scope of interactions among households, firms, developers, and governments within markets for real estate, labor, and goods and services.

In any given simulation year, the UrbanSim model predicts how the individual actors make decisions that culminate in the annual land development and location decisions.

- Developers use land to construct housing and nonresidential floor space that are demanded by households and businesses, which are also interacting in the labor market and the markets for goods and services.

- Governments provide infrastructure and services, regulate, and in some cases alter prices for the use of land and infrastructure.

- The key agents that generate or respond to the policies outlined are households, individuals, employers, developers, and governments.

- Households make a cluster of interdependent long-term lifestyle choices, including when to move, neighborhoods to locate within, type of housing to rent or purchase, and number of vehicles to own. Individuals within households choose their labor force and educational status, job mobility and job search, daily activity schedule, and transportation mode and route.

- Employers choose to start and close establishments, site locations, size of employment, and types and quantities of real estate to rent or purchase.

- Developers choose to undertake real-estate development projects and the scale and locations of those projects.

- Governments set policies and make investments that affect the choices of other agents, and also make development choices regarding public facilities, including type, location, and scale of development. 
The UrbanSim components and data flow is given in Figure 2-1.

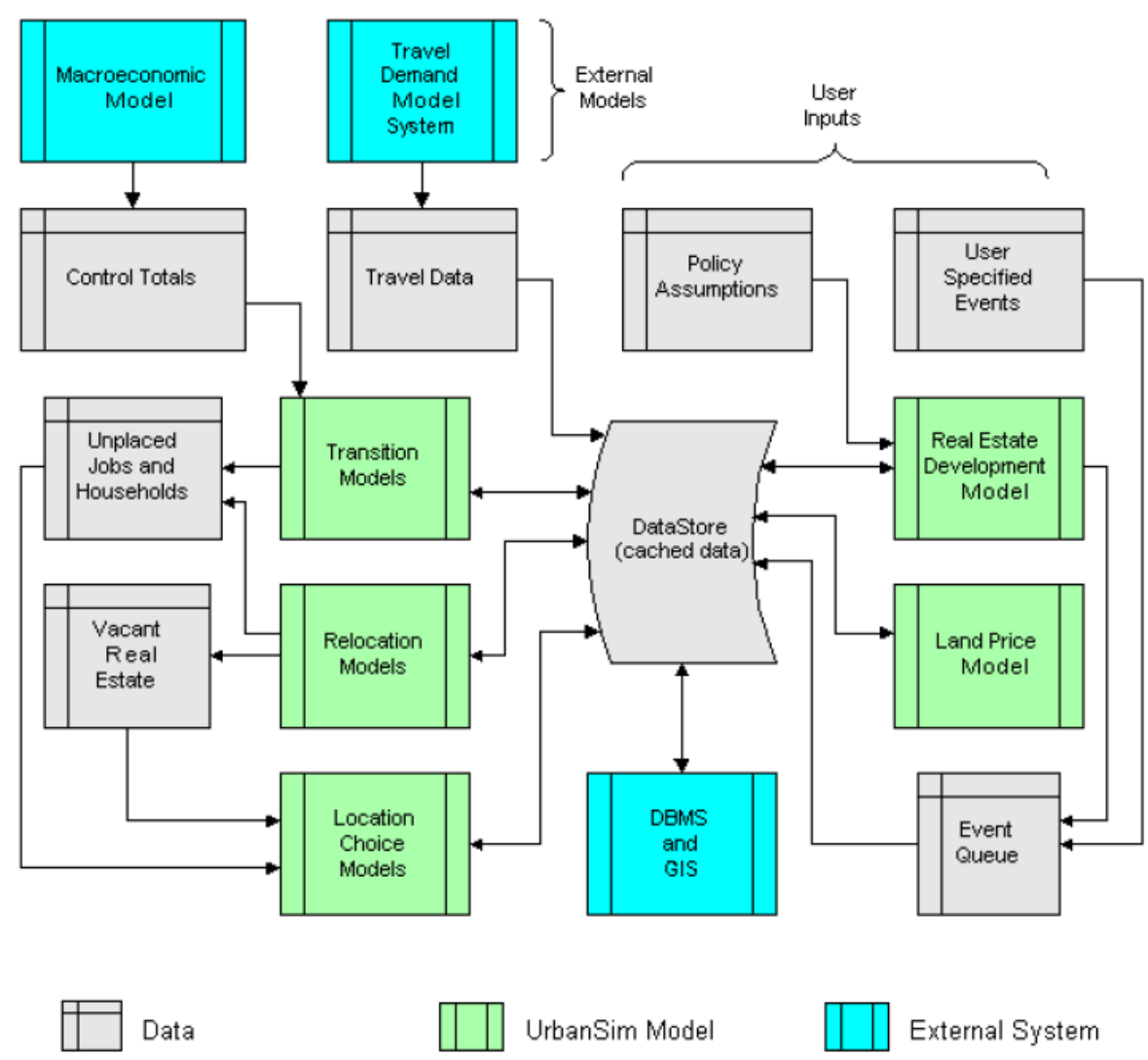

Figure 2-1 UrbanSim Model Components and Data Flow

(Source: www.urbansim.org)

UrbanSim requires high quality data input, including:

- $\quad$ Regional Control Totals

- $\quad$ Parcel Data

- Business Establishments

- $\quad$ Household Data (Census, Travel Survey)

- $\quad$ Land Use Plan

- $\quad$ Environmental Constraints

Meanwhile, UrbanSim provides the flexibility to aggregate/disaggregate households, businesses, and land use at parcel, zone, or grid cell level for output, including:

- $\quad$ Future year distributions of population 
- Households by type (e.g., income, age of head, household size, presence of children, and housing type)

- $\quad$ Businesses by type (e.g., industry and number of employees)

- $\quad$ Land use by type (user-specified)

- Units of housing by type

- $\quad$ Square footage of nonresidential space by type

- Densities of development by type of land use

- $\quad$ Prices of land and improvements by land use

The primary input and output data in UrbanSim are shown in Figure 2-2.

$\begin{array}{ccccc}\text { Parcels } & \text { Buildings } & \text { Households } & \text { Persons } \\ \begin{array}{c}\text { Zarcel id } \\ \text { Zones, } \\ \text { cities, zip } \\ \text { code, etc. }\end{array} & \text { Building id } & \text { Household id } & \begin{array}{c}\text { Person id } \\ \text { Household id / } \\ \text { Job id (if worker) }\end{array} & \text { Building id } \\ \text { Bob id } & \text { Building id } & & \end{array}$

\section{Figure 2-2 Primary UrbanSim Input and Output Data}

(Source: www.urbansim.org)

Currently, UrbanSim provides three versions in different geographic resolutions:

\section{- $\quad$ Grid-cell Version}

The grid-cell version of UrbanSim was the first version, followed by the parcel and zone versions. The grid-cell approach to developing the data for UrbanSim, as the name suggests, begins with the decision of a resolution to use for a grid to overlay the study area. There is no definitively correct grid cell resolution, and a pragmatic choice of 150 meters by 150 meters was chosen in early UrbanSim applications, mainly as a compromise between the high level of resolution desired and the increased computational demands made by higher resolution data. The data relationship in the grid-cell version is shown in Figure 2-3. 
The main disadvantage of the grid-cell data structure has already been mentioned: It requires unnaturally splitting the underlying parcel information and recombining it in ways that create artificial representations of the data. This problem also makes it difficult to apply information on development regulations from general plans, since those are also based on polygons, and in fact, apply to parcels.

\section{- $\quad$ Parcel-based Version}

To address some of the limitations of the grid-cell data structure, recent improvements to the UrbanSim software have adopted a data structure based on parcels. The parcel-based UrbanSim application uses a data model that reflects parcels, buildings, households, and jobs as the primary objects and units of analysis. Households and jobs choose locations by selecting a specific building, which is associated with a specific parcel. Real estate development is based on development projects occurring on specific parcels. The data relationship is shown in Figure 2-3.

- Zone-Based Version

Given the available flexibility in configuring models in UrbanSim, an alternative data structure can be readily substituted for parcel or grid-cell based data. Locations can be defined by zones used in the travel demand models to make them consistent with current-generation zone-based travel demand models. This approach can also be used to create a rather simple model system using less geographic detail. By using the same data structure for households, jobs, and buildings, the only change needed for a zone-based model system is to assign locations to buildings at a coarser level of detail. This retains all of the accounting systems in the UrbanSim model: households and jobs are still located in buildings, and buildings can be linked spatially to zones. The data relationship is shown in Figure 2-3. 


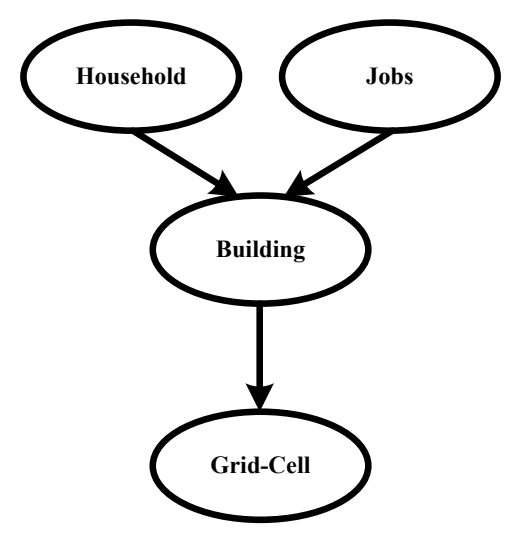

Grid-Cell Version

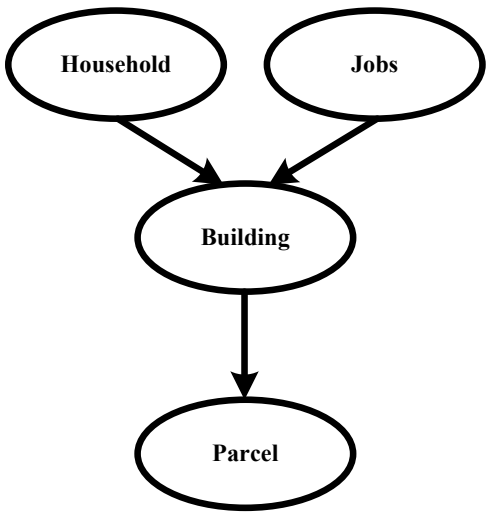

Parcel Version

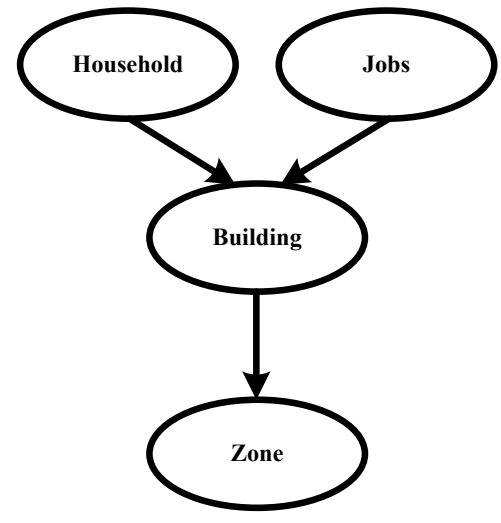

Zone Version

Figure 2-3 Data Relationship in UrbanSim

Two major exogenous input that are not predicted directly by UrbanSim are obtained from external model systems: a macroeconomic model to predict future macroeconomic conditions such as population and employment by sector, and a travel demand model system to predict travel conditions such as congested times and composite utilities of travel between each interchange. The latter is loosely coupled to UrbanSim, with land use predictions input to the external travel demand models, and travel conditions input to subsequent annual iterations of the UrbanSim land use model system (source: UrbanSim User Manual).

The travel demand models used by Metropolitan Planning Organizations are almost all traditional four-step travel demand models. The first model in the process is the trip generation model, which uses zonal population and employment characteristics. When UrbanSim is connected to a travel demand models system, it generates a summary of the household and job data to a zone level in order to create the summary input data needed by the travel demand models (source: UrbanSim User Manual).

When the travel demand models completes the fourth step of traffic assignment to a transportation network, it can produce 'skims' from zone to zone that summarize key model predictions, such as the following (source: UrbanSim User Manual):

- Travel time by mode by time of day by purpose

- $\quad$ Trips by mode by time of day by purpose

- Composite utility of travel using all modes by purpose

- $\quad$ Generalized costs (time + time equivalent of tolls) by purpose 
- $\quad$ Logsums, or composite utilities, from the mode choice model, by purpose and time of day

These skims can be combined with the spatial information in UrbanSim regarding the location of households and jobs to produce a variety of accessibility measures, which in turn can influence UrbanSim models of residential location, workplace location, employment location, real estate prices, and real estate development. Figure 2-4 summarizes the interactions between UrbanSim and the travel demand models system.

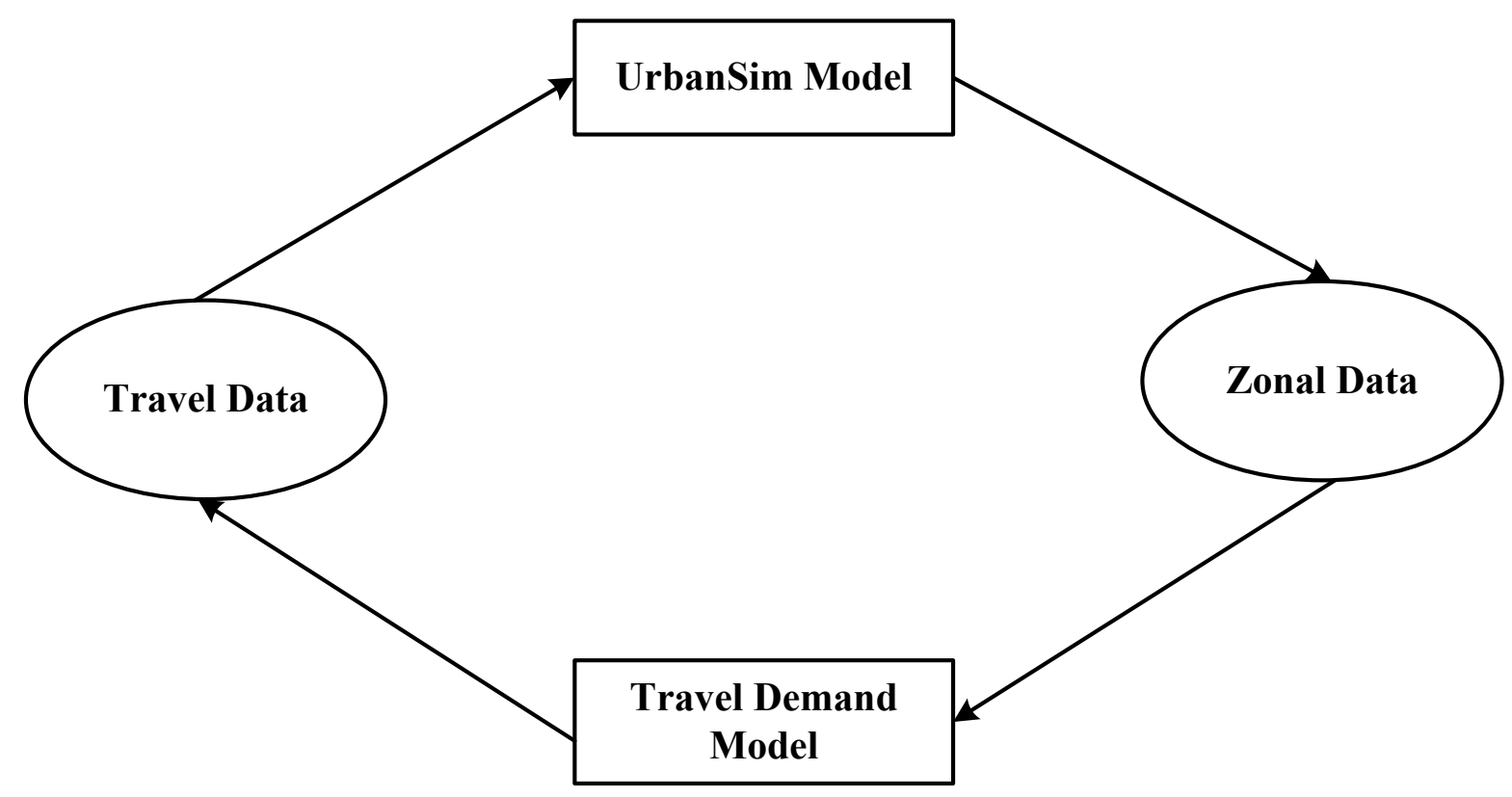

Figure 2-4 Interactions between UrbanSim and Travel demand models system 


\subsection{UrbanSim Implementation}

- Austin, TX (30)

With an annualized population increase of 3.5\% per year over the past 10 years, Austin is one of the fastest growing mid-size regions in the U.S. Such shifts, coupled with major transportation investments and variations in transport, land use, and energy policies, significantly impact the region's future land use patterns, traffic conditions, greenhouse gas emissions (GHG), housing affordability, environmental encroachment, and other key facets of community life. In 2011, UrbanSim was used to model land use patterns of the Austin, Texas, region for 2030 at fine spatial resolution (typically $150 \mathrm{~m} \times 150 \mathrm{~m}$ grid cells). Three tasks, including data preparation, model specification, and scenario testing, were conducted. The data preparation included:

- Household and Employment Data

The household data set consists of a list of all households with current locations (by gridcell), household size (number of members), age of the household head, race, and number of workers, children and autos. Household data was synthesized using iterative proportional fitting techniques at the level of year-2000 Census block groups.

The employment data consists of a list of all jobs (by sector), their cell locations, and building type occupied. This data set was generated from a file of firm point locations provided by CAMPO.

- Built Space and Transportation Data

The Travis County Appraisal District (TCAD) provided residential unit locations (and year-built information), as well as square footage (and year-built information) of all commercial and industrial establishments within the region's central county. These data were used to estimate the proportions of each type of residential unit, square footage, and age distributions for buildings in Hays and Williamson counties.

UrbanSim requires network travel times to the region's CBD (Central Business District) and major airport from each TAZ centroid, along with Euclidean distances to the nearest arterials and freeways from TAZ and gridcell centroids. These values were computed using CAMPO’s 1997 network.

- Energy Data 
The 2005 Residential Energy Consumption Survey data (RECS) and 2003 Commercial Buildings Energy Consumption Survey data (CBECS) were obtained from the Energy Information Administration (EIA) and used to estimate energy per square foot to apply to UrbanSim's 2030 outputs.

Future land use patterns depend on household and job location choices, which in turn depend on the supply, quality, and price of built space, access to jobs and other destinations, household income, industry sector, and so forth. The following key sub-models were specified:

- Household Location Choice Model (HLCM)

- Employment Location Choice Models (ELCMs)

- Modeling Land Prices

Several scenarios were implemented to test the sensitivity of UrbanSim to various policies. These scenarios included:

- No Travel Demand Model (No TDM) scenario

UrbanSim simulated a 30-year horizon without TDM integration (so travel costs stay constant over the forecasting horizon and accessibility indices do not vary as much as they would with a TDM in place).

- Business as Usual (BAU) scenario

Austin's 1997 network held constant over the forecast period.

- Urban Growth Boundary (UGB) scenario

New development was not permitted in zones outside boundary.

- Addition of a 49.2-mile bypass freeway (SH130) to the network

As expected, several land use results (e.g., population densities), travel patterns, and energy consumption results responded to scenario contexts. Local access variables (within 600-meter Euclidean distances) also enjoy significant relevance in this implementation of UrbanSim.

\section{- Puget Sound Regional Council (PSRC), WA (31)}

Land use forecasting at the PSRC has undergone significant changes over the last few years. Since 2003, the Regional Council has been implementing UrbanSim as the framework for land use forecasting. The PSRC land use model is a parcel-based urban simulation process reflecting the broad scope of interactions among households, firms, developers, and governments within 
markets for real estate, labor, and goods and services. The PSRC land use model and the travel demand models have an interactive relationship, as outputs of one model become inputs to the other, enabling the PSRC to directly model and assess the impacts of land use on travel forecasts, and the influence of the transportation system on the land use patterns of the region over time.

The land use model (UrbanSim) and the EMME model, which is a complete travel demand modeling system for urban, regional and national transportation forecasting, have been coupled/integrated such that modeling of land use and transportation policy assumptions interact with each other. The land use policy assumptions are introduced through the characterization of future year land use designations or zoning regulations, while the transportation policies are implemented through modifications of the region's transportation network and demand model assumptions.

\section{- SustainCity, Europe (32)}

SustainCity is an EU-funded project with twelve European research institutions. The aim of SustainCity is to extend the integrated land use model UrbanSim to the so-called version UrbanSimE, being adapted to the European context of cities: new choice models will be calibrated and additional models for households, demographics and employment will be created. UrbanSim was used in three case studies: Brussels, Paris and Zurich. The data requirement and collection scheme is shown in Figure 2-5. 


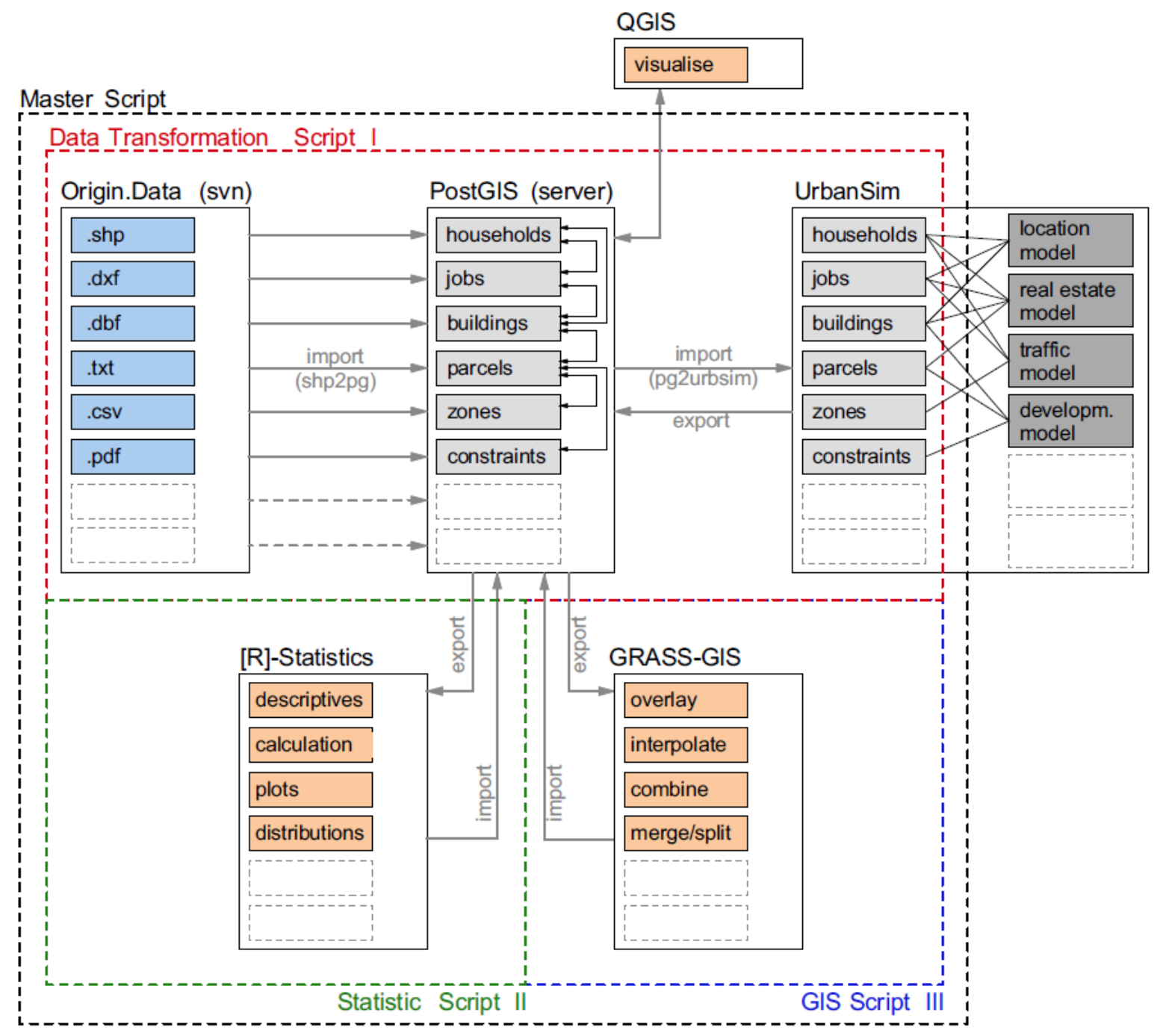

Figure 2-5 Data Processing Scheme in SustainCity

After conditioning data and implementing a base model in UrbanSim including only dummy variables, the next step concerns the implementation of the basic model structure for more technical details. The focus lies on the estimation of the following models for SustainCity:

- Household location model, transition and relocation choice,

- Employment location model, transition and relocation choice,

- Land development model: Real estate price model, development proposal choice, building construction, process pipeline events,

- Parcel transition model. 
For reasons of better data disposability, this project shifted the base year of the simulation from 1997 to 2000 . The simulation period is set to be from 2000 to 2030 and will use the latest register information (2010) for validation.

\section{- Volusia County, FL (18)}

FSUTMS (Florida Standard Urban Transportation Model Structure) requires future land use forecasts as input data to predict future travel demand and transportation needs. Given that the performance of the FSUTMS models relies heavily on the accuracy of land use forecasts, there is a strong desire by planners to improve model input, especially for future forecast years. The purpose of this study was to survey the current practices used in Florida, as well as to investigate the potential of UrbanSim as a land use model for Florida applications. In this project, UrbanSim was applied to Volusia County, Florida, based on five scenarios of growth and transportation improvements. The model was validated by comparing the simulation results to the socioeconomic and demographic data adopted in the 2020 Long Range Transportation Plan (LRTP) and the 2005 InfoUSA employment data.

The scenarios that were applied to UrbanSim, in conjunction with the FSUTMS, were developed based on the LRTP and socioeconomic projections provided by BEBR. The scenarios examined were the following:

- $\quad$ Scenario 1: The final plan in the 2020 LRTP with a mid-range projection.

- $\quad$ Scenario 2: The alternative 2 in the 2020 LRTP with a mid-range projection.

- Scenario 3: The alternative 3 in the 2020 LRTP with a mid-range projection.

- $\quad$ Scenario 4: The final plan in the 2020 LRTP with a low-range projection.

- $\quad$ Scenario 5: The final plan in the 2020 LRTP with a high-range projection.

Based on the model development and scenario testing, they concluded that UrbanSim can simulate land use changes reasonably well. Feedback from the travel demand models to UrbanSim influences the land development patterns. It will be useful to measure the sensitivity of UrbanSim to accessibility to determine the necessary frequency of the feedback. Through feedback, UrbanSim also has the potential of testing the effects of different project schedules on both land use and transportation. A detailed user manual on data processing is needed. 
In addition to the UrbanSim projects mentioned above, the UrbanSim model has also been deployed or is starting to be deployed in several areas, including:

- $\quad$ Detroit, MI

- Durham, NC

- $\quad$ Eugene-Springfield, OR

- $\quad$ Honolulu, HI

- Houston, TX

- $\quad$ Phoenix, AZ

- $\quad$ Salt Lake City, UT

- $\quad$ San Francisco, CA

- $\quad$ Tucson, AZ

- $\quad$ Amsterdam, Netherlands

- $\quad$ Rome, Italy

- Taipei, Taiwan

- Tel Aviv, Israel

- $\quad$ Turin, Italy

- $\quad$ Cape Town, South Africa

- $\quad$ Ethekwini, South Africa

- $\quad$ Gauteng, South Africa

- $\quad$ Nelson Mandela Bay, South Africa

- Accra, Ghana 


\section{Data Preparation}

UrbanSim requires vast amounts of data from various sources. The quality and integrity of data preparation determines the accuracy of the UrbanSim simulation. Data preparation is the key step in UrbanSim model development, and it is also the most time consuming task. UrbanSim currently uses three types of databases:

- baseyear database - defining the initial state of a simulation in a particular base year.

- scenario database - defining changes to a base year (or another scenario) database.

- output database - optional repository for simulation results.

UrbanSim gets its input data from either a base year database or a scenario. A base year database contains a snapshot of the base information defining the initial state before the UrbanSim simulation. Most of the data is about a particular year, e.g., geographic information, initial household data, job information, etc. A scenario database contains additional and augmenting information to alter the base year data when simulating a particular scenario such as new transportation links, an expanded urban growth boundary, etc. Any of the tables may be placed in either of the databases, although typically most are placed in the base year database. The scenario databases typically only contain tables specifying different possible futures, e.g., tables of exogenous events scheduled for future years. This chapter provides an overview of the data preparation and compilation for applying UrbanSim to Hillsborough County, Florida in the base year (2010). A detailed description of the data collection includes identifying data requirements, addressing data resources, developing the data collection environment, selecting the study area, processing data collection, and assembling data tables.

\subsection{Data Requirement}

It is important to recognize that the data needed for an UrbanSim simulation system are dependent on the UrbanSim models and their specifications. UrbanSim is an evolving set of models, some of which have been adapted to different data structures and geographic units of analysis, such as gridcells, parcels, and zones. Each of these models, depending on how the user specifies the model, creates its own data requirements. In this study, the parcel-based version of UrbanSim was adopted. The parcel-based version requires 22 to 25 data tables which can be organized into 5 categories: Geography, Buildings, Households, Employment, and Real Estate. 
Each table contains a number of attributes (data fields) and the tables are linked by key variables. The required data was obtained through the following steps:

1) Identify Data Source

The first step of data processing is to identify the data source for each data field in each data table. The data sources may include the county maintained appraisal databases, travel demand models, census information, InfoUSA data, synthesized data, etc.

2) Retrieve Data

The second step is to retrieve the required data items from the original data sources using ArcGIS, SPSS, or the codes developed by the research team. These retrieved data were imported to a project database powered by Microsoft SQL server 2005, as shown in Figure 3-2.

3) Translate Data

The data types in UrbanSim databases include identification data, categorical data, and numeric data. Identification data, a unique number labeling the data item in each table, were assigned by the research team. Collected data were converted from the original formats to UrbanSim formats.

4) Assign Data

The data items might be organized at a geographic unit which is different from the objective geographic unit. These data were aggregated or disaggregated into the objective unit based on certain algorithms.

5) Produce Data Tables

The assigned data were organized into the data tables that are required in the UrbanSim model. The data tables were stored in the project database.

6) Link Data Tables

The data tables were matched by "key" variables, which were usually the identification data.

7) Export Data Tables

UrbanSim can link to MySQL, MS SQL server, or text files (CSV format). In this study, the produced data tables were exported to CSV files for UrbanSim input because this method is simple and effective. The CSV files were imported into UrbanSim as the base year database. 
It is well-known that data preparation for the UrbanSim model is a demanding process which requires a great deal of resources and effort. In this study, a support platform was developed to automate the data preparation. This platform is a Windows standalone package based on the Microsoft .NET framework. All data operations were executed using SQL commands to assess the project server, which is powered by Microsoft SQL server 2005. Other tools used for data preparation included ArcGIS and SPSS. The user interface and system architecture are given in Figure 3-1 and 3-2, respectively.

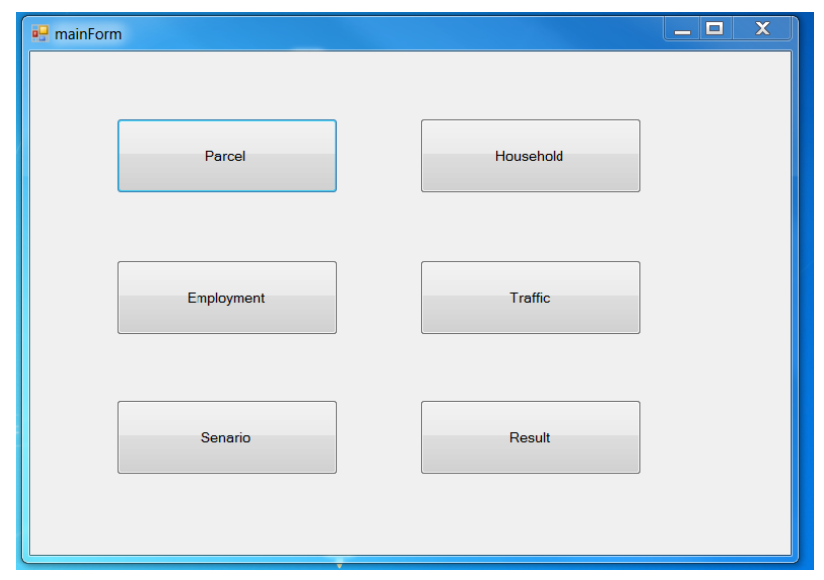

Figure 3-1 User Interface of Support Platform

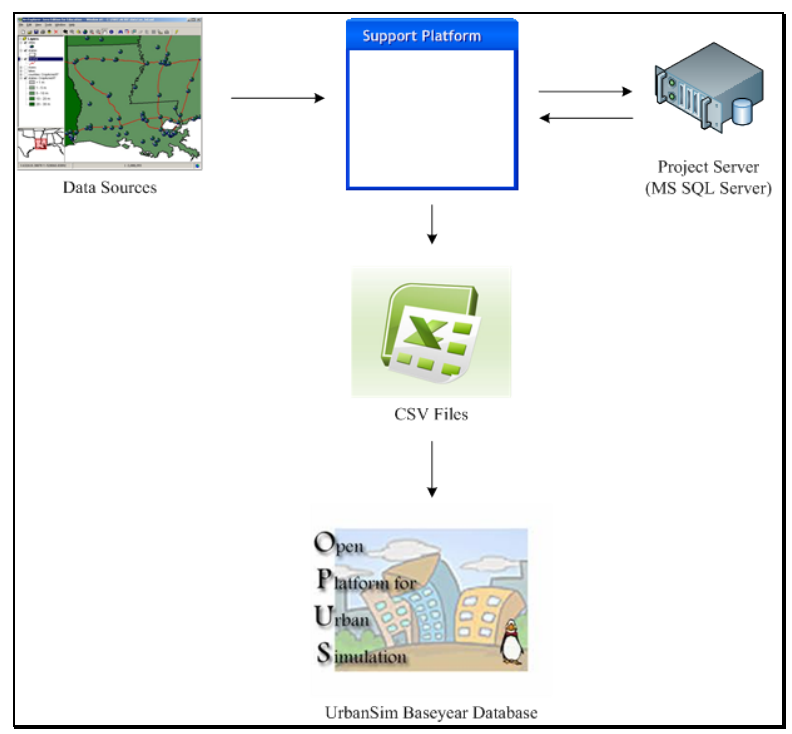

Figure 3-2 System Structure of Support Platform

\subsection{Study Area}

To evaluate the applicability of UrbanSim to Florida's urban areas and investigate model application for evaluating transit investments, the new BRT line project in Hillsborough County 
was selected as the study case. Hillsborough County met the selection criteria, as the study area has up-to-date geographic information system (GIS) data, parcel-level property data, employment data, and new transit investment plans (BRT).

Hillsborough County is located midway along the west coast of Florida and has 1,048 square miles of land and 24 square miles of inland water area, for a total of 1,072 square miles. The unincorporated area encompasses 909 square miles, or more than 84 percent of the total county area. Municipalities account for 163 square miles. Incorporated cities are Tampa, Temple Terrace, and Plant City. In 2010, the total population, households, and labor forces in Hillsborough County were 1,229,226; 474,030; and 600,967 respectively. The county has GIS data, including parcel data, which are essential to calibrating an UrbanSim model. Figure 3-3 shows the location of Hillsborough County.

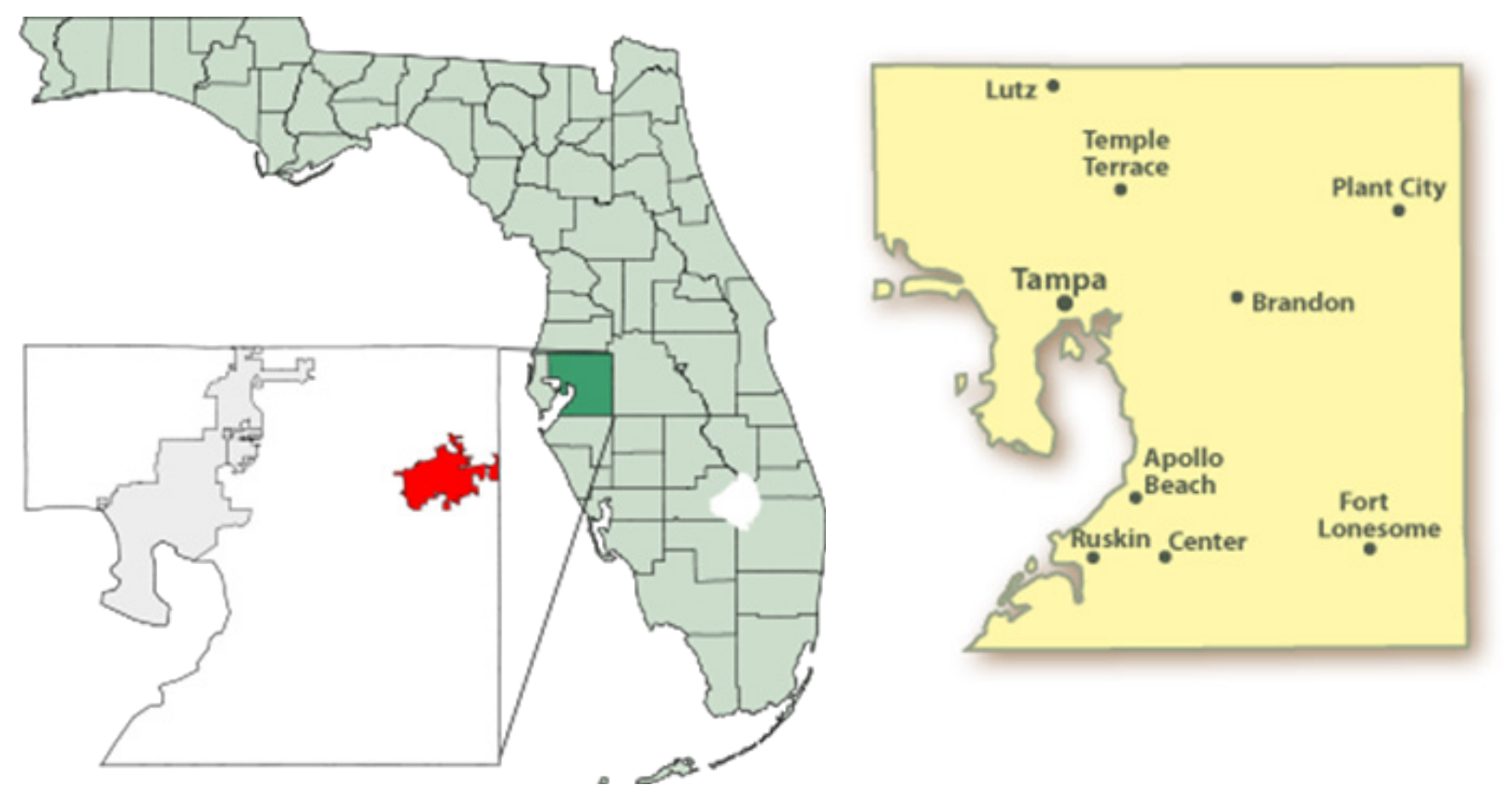

Figure 3-3 Hillsborough County Boundaries

Hillsborough Area Regional Transit (HART) Authority, a regional transportation authority and special tax district charged with planning, financing, constructing, and operating public transit facilities and service within Hillsborough County, provides fixed route local and express bus services to most of Hillsborough County. Bus rapid transit (BRT) has been included in local and regional plans in the Tampa Bay Area as an element of the regional congestion reduction 
strategy. The North-South BRT corridor was selected for implementation in this study based on ridership projections and connectivity to other existing HART routes.

The North-South BRT corridor begins at the Marion Transit Center (MTC), travels south along the Marion Street Transit Parkway (MSTP), then turns east along the one-way pair of Kennedy Avenue and Jackson Avenue, turns north on Nebraska Avenue, then turns east of Fletcher Avenue, and finally terminates near the Fletcher Avenue and Interstate 75 interchange at a Park and Ride facility, shown in Figure 3-4. The BRT route will operate in mixed traffic, with the exception of the MSTP, and several existing HART routes will either share the proposed stations or will have stops in close proximity to a proposed station to facilitate transfers.

This study evaluated the impact of the proposed North-South BRT route on its adjacent areas. These areas were delimited as the traffic analysis zones that are influenced by the North-South BRT route, as shown in Figure 3-5. In this study, a parcel-based UrbanSim simulation model was developed for the entire Hillsborough County area. A model validation and evaluation of the BRT route was conducted on the study zones. 


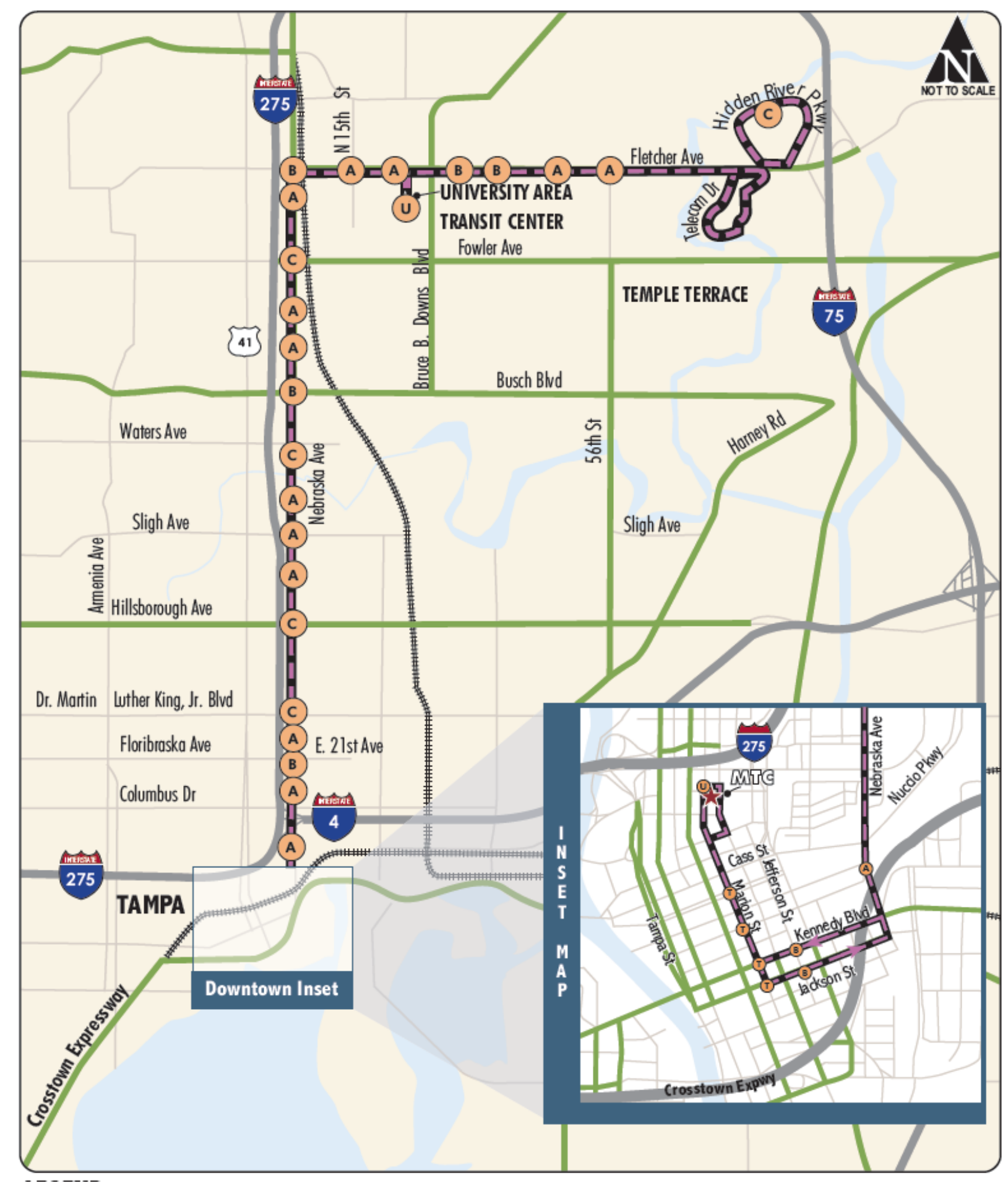

Figure 3-4 North-South Corridor BRT in Hillsborough County

(Source: HART North/South Corridor BRT Project Development and Environmental Study) 


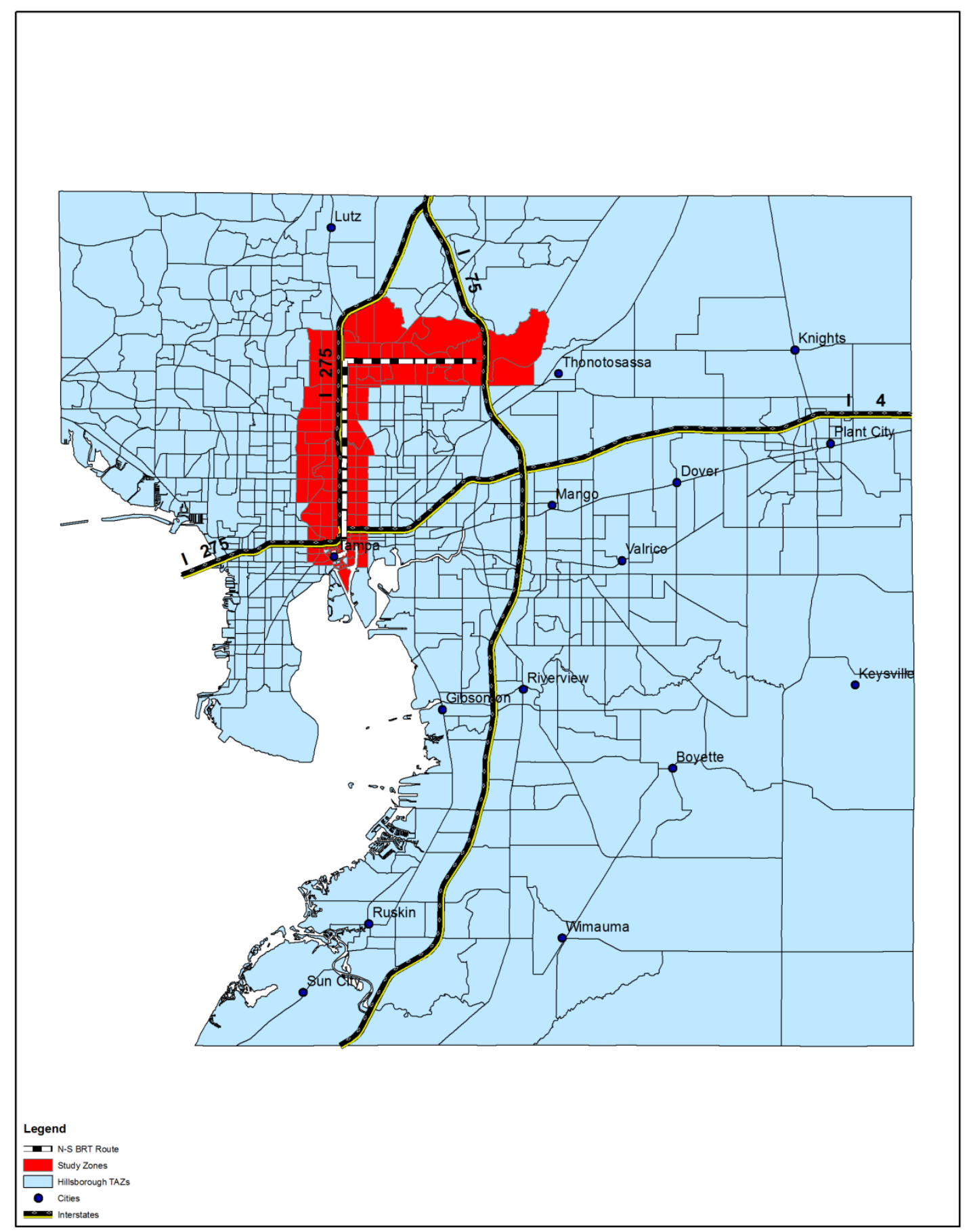

Figure 3-5 TAZs and Study Zones in Hillsborough County 


\subsection{Geographic Data}

The Geography category contains the geographic information at the parcel level, which is the basic geographic unit in the parcel-based UrbanSim version. Each parcel may contain one or more buildings which have associated households and/or jobs. Parcels can be aggregated to a higher geographic level, such as zones (TAZ), census block groups, and city. The spatial relationship among the geographic units in the UrbanSim model is shown in Figure 3-6.

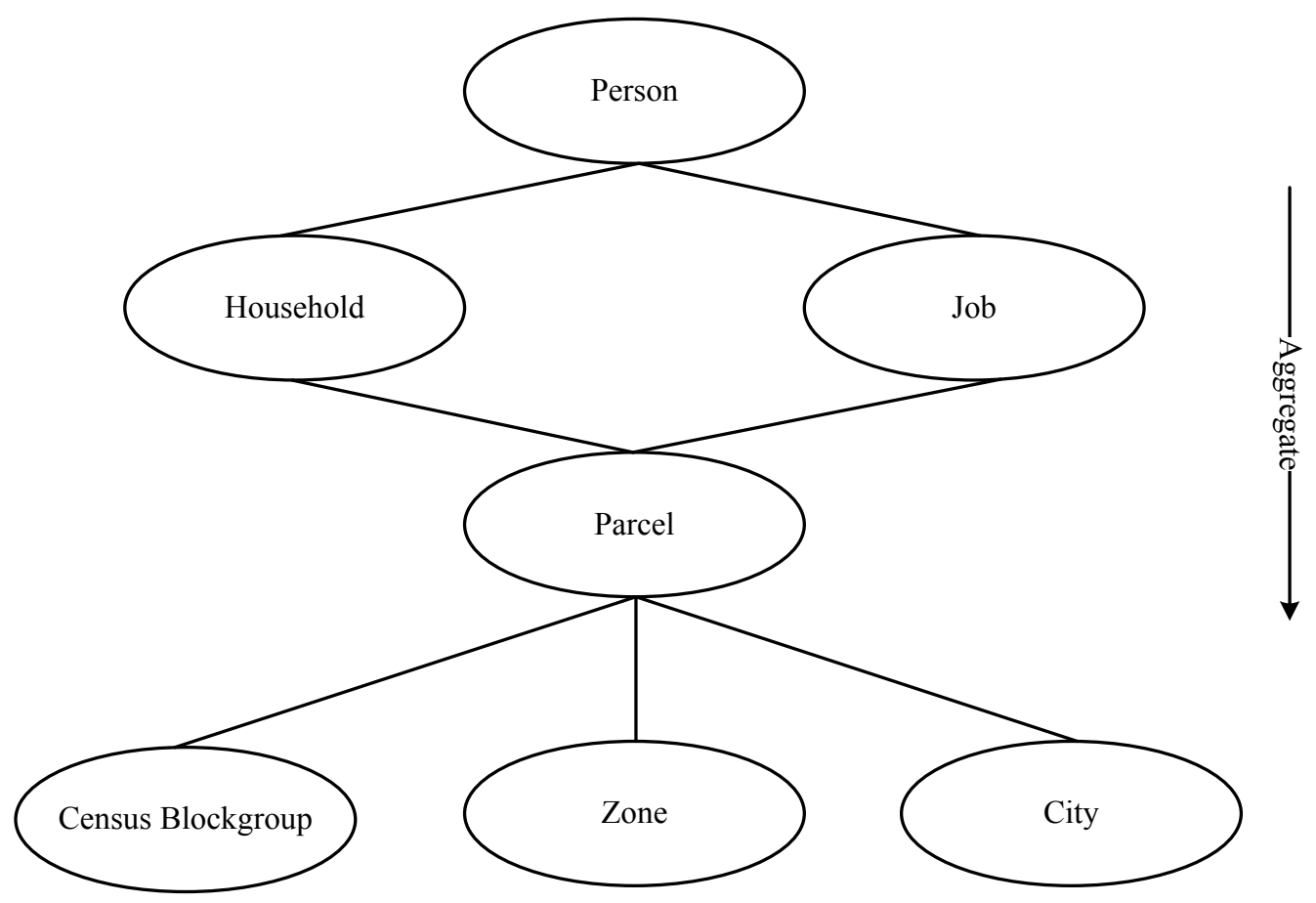

Figure 3-6 Spatial Relationship among Geographic Units

The parcels table contains attributes of individual parcels. The most commonly used parcels are based on ownership since most relevant data (like land and improvement value) is associated with ownership records. It should also be noted that additional geographic data may be added by the user to the parcel table, using the same approach as below. This section gives a detailed description of the preparation of parcel related data, as shown in Figure 3-7. 


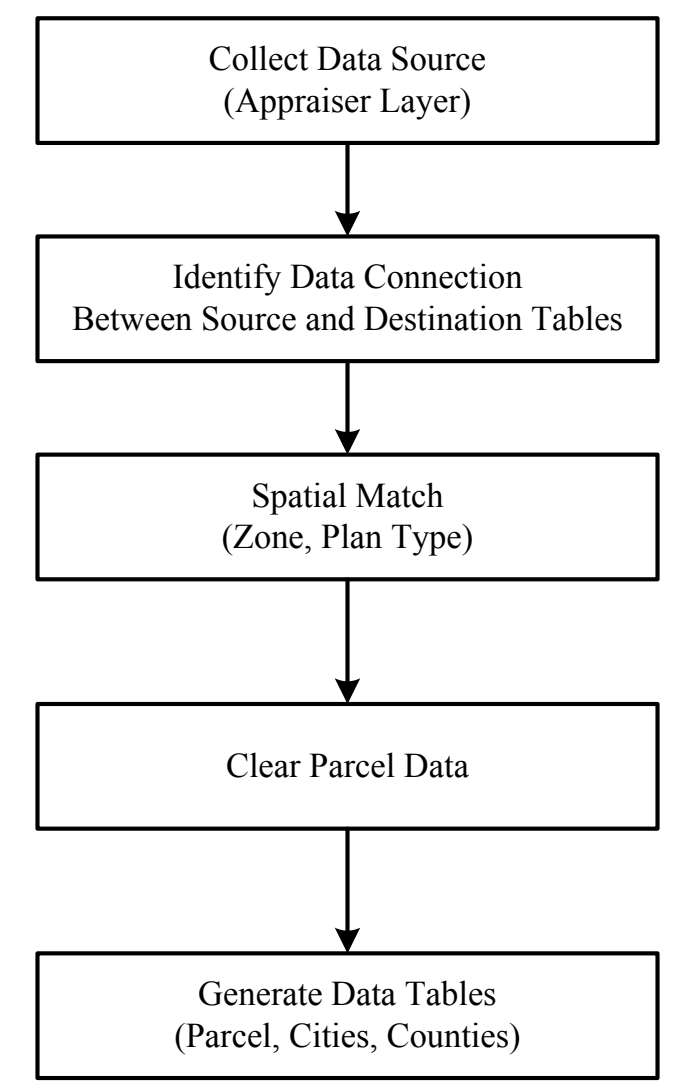

\section{Figure 3-7 Procedure of Geographic Data Preparation}

\section{- Data Source}

Hillsborough County maintains a property appraiser database, which contains all parcels with related attributes in GIS format. In this study, the property appraiser database for 2010 was used to retrieve parcel data. In total, 471,890 parcels were found in this database with owner, address, area, building number, year, value, tax, and coordinate information. A unique variable, namely "STRAP," identified each parcel item in the database. The parcel map is shown in Figure 3-8. Two initial steps were made:

- Retrieve data

The parcel data were retrieved from the original property appraiser database and stored in the project database for future use.

- Transform GIS map 
In the original GIS layer, parcel data were described as polygons. For spatial matching, the parcel data were transformed from polygons to points based on the centroid of parcel polygons using ArcGIS.

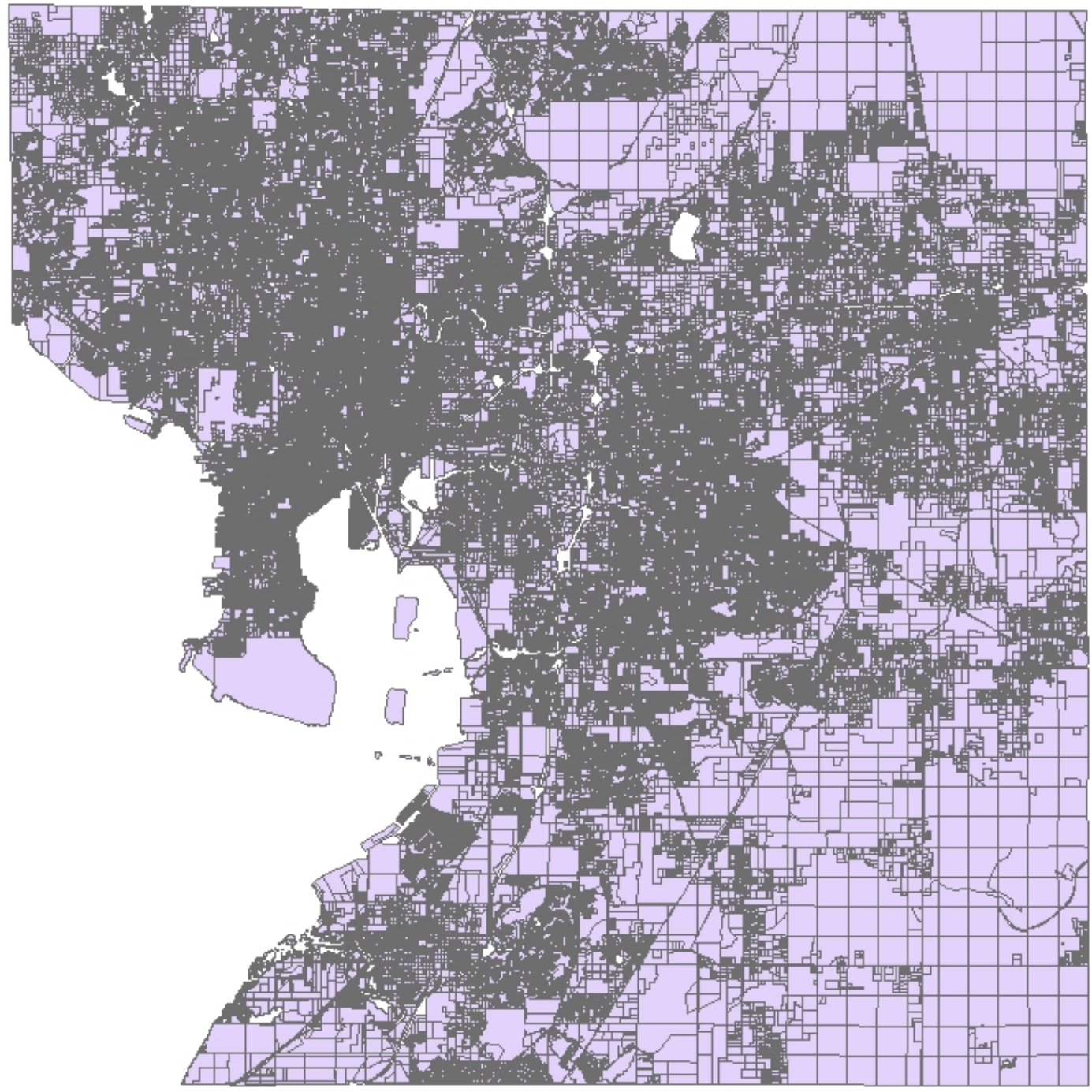

Figure 3-8 Parcels in Hillsborough County

\section{- Identify Data Connection}

The second step was to create connections between original data fields and required data fields in the UrbanSim parcel table. The data fields in the UrbanSim parcel table and associated original data fields are given in Table 3-1. 
Table 3-1 Parcel Table

\begin{tabular}{|c|c|c|c|c|}
\hline Variable Name & Data & Description & $\begin{array}{c}\text { Source } \\
\text { Database }\end{array}$ & Source Item \\
\hline parcel_id & Integer & Unique id for parcels & Assignment & \\
\hline parcel_id_local & String(20) & $\begin{array}{l}\text { Users may want to store } \\
\text { a local parcel id from the } \\
\text { assessor's office }\end{array}$ & $\begin{array}{l}\text { Property } \\
\text { Appraiser }\end{array}$ & STRAP \\
\hline land_use_type_id & Integer & $\begin{array}{l}\text { Unique id of the land use } \\
\text { type of the parcel }\end{array}$ & $\begin{array}{l}\text { Property } \\
\text { Appraiser }\end{array}$ & DOR_UC \\
\hline land_value & Integer & $\begin{array}{l}\text { Assessed value of the } \\
\text { land on the parcel }\end{array}$ & $\begin{array}{l}\text { Property } \\
\text { Appraiser }\end{array}$ & LND_VAL \\
\hline parcel_sqft & Integer & $\begin{array}{l}\text { Land area of the parcel } \\
\text { in square feet }\end{array}$ & $\begin{array}{l}\text { Property } \\
\text { Appraiser }\end{array}$ & LND_SQFOOT \\
\hline plan_type_id & Integer & $\begin{array}{l}\text { Unique id of the land use } \\
\text { plan type of the parcel } \\
\text { (regulatory designation) }\end{array}$ & $\begin{array}{l}\text { Spatial } \\
\text { Matching to } \\
\text { FLUE }\end{array}$ & \\
\hline centroid_x & Integer & $\begin{array}{l}\text { X-coordinate of the } \\
\text { parcel centroid, usually } \\
\text { in a projection measured } \\
\text { in feet }\end{array}$ & $\begin{array}{l}\text { Property } \\
\text { Appraiser }\end{array}$ & $\mathrm{X}$ \\
\hline centroid_y & Integer & $\begin{array}{l}\text { Y-coordinate of the } \\
\text { parcel centroid, usually } \\
\text { in a projection measured } \\
\text { in feet }\end{array}$ & $\begin{array}{l}\text { Property } \\
\text { Appraiser }\end{array}$ & $\mathrm{Y}$ \\
\hline tax_exempt_flag & Integer & $\begin{array}{l}\text { Optional } 1 \text { if tax exempt, } \\
0 \text { otherwise }\end{array}$ & $\begin{array}{l}\text { Property } \\
\text { Appraiser }\end{array}$ & TAX_EXEMPT_FLAG \\
\hline city_id & Integer & $\begin{array}{l}\text { Unique id of the city in } \\
\text { which the parcel is } \\
\text { located }\end{array}$ & $\begin{array}{l}\text { Property } \\
\text { Appraiser }\end{array}$ & PHY_CITY \\
\hline county_id & Integer & $\begin{array}{l}\text { Unique id of the county } \\
\text { in which the parcel is } \\
\text { located }\end{array}$ & Constant & 57 \\
\hline zone_id & Integer & $\begin{array}{l}\text { Unique id of the zone (as } \\
\text { used in the travel } \\
\text { demand models) in } \\
\text { which the parcel is } \\
\text { located }\end{array}$ & $\begin{array}{l}\text { Spatial } \\
\text { Matching to } \\
\text { TAZ }\end{array}$ & \\
\hline
\end{tabular}


The "parcel_id" is a unique integer number used to identify each parcel item in the parcel table. It is functionally equivalent to "STRAP" in the original database. However, UrbanSim cannot recognize the format of "STRAP," thus, a new data item, "parcel_id," was assigned by researchers and "STRAP" was reserved in the parcel table as "parcel_id_local". Land use of a parcel was indicated by the variable "land_use_type_id" and linked to the land use type table. Other linking variables included "plan_type_id" and "zone_id".

\section{- Spatial Match}

There are no variables in the original database to represent the zone and plan type that a parcel associates. The GIS layers of Florida traffic analysis zones and Future Land Use Element (FLUE) are available. Thus, the parcel layer was matched to the zone and FLUE layers using a spatial join. The GIS layers of zones and FLUE are polygon maps, while the parcel layer is point map. The spatial join was conducted to find the zone or FLUE in/to which a parcel falls or is closest. The addressed "zone_id" or "plan_type_id" were assigned to the parcel.

\section{- Parcel Clearance}

In the original property appraiser database, some parcels have "empty" data items or could not be matched to other UrbanSim entities. These parcel data were removed from the parcel table. The final parcel table included 459,571 parcels.

\section{- Generate Tables}

Three tables were produced: parcel, counties, and cities.

\subsection{Building Data}

The Building category contains the information of buildings, including building property, type, and demolishing cost.

\section{- Building Table}

The building table in the parcel version of the UrbanSim model represents data for an individual building located on a parcel. There can be multiple buildings on a parcel (a many to one relationship). Buildings that are mixed use, such as retail on the first floor and apartments above, can be represented as two separate buildings on the same parcel. The land area would generally be assigned by the user to each component as a prorated amount. 
Because data for built structures are limited to what is available in the Hillsborough County property appraiser database, this study synthesized buildings based on number of buildings on each parcel (NO_BULDNG) in the database. If a parcel has one or more buildings, the support application developed by the researchers produced new corresponding data rows in the building table and assigned a unique integer to each data item as "building_id". The data fields were calculated or transferred from the property appraiser database. In total, 436,390 buildings were produced. The calculation procedure and data connections are given in Table 3-2.

Table 3-2 Building Table

\begin{tabular}{|c|c|c|c|c|}
\hline Variable Name & $\begin{array}{l}\text { Data } \\
\text { Type }\end{array}$ & Description & Source Database & Source Item \\
\hline building_id & Integer & $\begin{array}{l}\text { Unique id of building } \\
\text { (one per zone and } \\
\text { building type) }\end{array}$ & Assigned & \\
\hline building_type_id & Integer & $\begin{array}{l}\text { Unique id of the building } \\
\text { type of this building }\end{array}$ & $\begin{array}{l}\text { Property } \\
\text { Appraiser }\end{array}$ & DOR_UC \\
\hline improvement_value & Integer & $\begin{array}{l}\text { Value in dollars of } \\
\text { buildings on parcel }\end{array}$ & $\begin{array}{l}\text { Property } \\
\text { Appraiser }\end{array}$ & $\frac{\text { LND_VAL }}{\text { NO_BULDNG }}$ \\
\hline land_area & Integer & $\begin{array}{l}\text { Land area in square feet } \\
\text { used by the building }\end{array}$ & $\begin{array}{l}\text { Property } \\
\text { Appraiser }\end{array}$ & LND_SQFOOT \\
\hline non_residential_sqft & Integer & $\begin{array}{l}\text { Total non-residential } \\
\text { square feet in building }\end{array}$ & $\begin{array}{l}\text { Property } \\
\text { Appraiser }\end{array}$ & $\begin{array}{c}\text { DOR_UC }>=10: \\
\text { LND_SQFOOT } \\
\text { NO_BUILDNG } \\
\text { Otherwise: } \\
0\end{array}$ \\
\hline parcel_id & Integer & $\begin{array}{l}\text { Unique id of the parcel in } \\
\text { which this building is } \\
\text { located }\end{array}$ & Parcel Table & parcel_id \\
\hline residential_units & Integer & $\begin{array}{l}\text { Total residential units in } \\
\text { building }\end{array}$ & $\begin{array}{l}\text { Property } \\
\text { Appraiser }\end{array}$ & NO_RES_UNT \\
\hline sqft_per_unit & Integer & $\begin{array}{l}\text { Average square feet per } \\
\text { residential unit in } \\
\text { building }\end{array}$ & $\begin{array}{l}\text { Property } \\
\text { Appraiser }\end{array}$ & $\begin{array}{c}\text { DOR_UC < 10: } \\
\text { LND_SQFOOT } \\
\text { NO_RES_UNT } \\
\text { Otherwise: } \\
\text { LND_SQFOOT } \\
\text { NO_BULDNG }\end{array}$ \\
\hline
\end{tabular}




\begin{tabular}{|l|c|l|l|c|}
\hline \multicolumn{1}{|c|}{ Variable Name } & $\begin{array}{c}\text { Data } \\
\text { Type }\end{array}$ & Description & Source Database & Source Item \\
\hline year_built & Integer & $\begin{array}{l}\text { Average year built of this } \\
\text { aggregated building }\end{array}$ & $\begin{array}{l}\text { Property } \\
\text { Appraiser }\end{array}$ & ACT_YR_BLT \\
\hline
\end{tabular}

- Building Type Table

The building type table provides a list of the unique building types used to classify buildings. This table was derived from the codes of "DOR_UC" in the property appraiser database. The final table is given in Table 3-3.

Table 3-3 Building Type Table

\begin{tabular}{|r|l|l|r|r|l|}
\hline \multicolumn{1}{|c|}{ ID } & \multicolumn{1}{|c|}{$\begin{array}{c}\text { Generic Type } \\
\text { Description }\end{array}$} & $\begin{array}{c}\text { Generic } \\
\text { Type ID }\end{array}$ & $\begin{array}{c}\text { Is Residential } \\
\text { (1 = Yes) }\end{array}$ & \multicolumn{1}{c|}{ Unit Name } \\
\hline 1 & single_family_residential & residential & 1 & 1 & building_sqft \\
\hline 2 & mobile_home & residential & 1 & 1 & building_sqft \\
\hline 3 & multi_family_residential & residential & 1 & 1 & building_sqft \\
\hline 4 & group_quarters & group_quarters & 2 & 1 & building_sqft \\
\hline 5 & office & commercial & 3 & 0 & building_sqft \\
\hline 6 & recreation & commercial & 3 & 0 & parcel_sqft \\
\hline 7 & commercial & commercial & 3 & 0 & building_sqft \\
\hline 8 & warehousing & industrial & 4 & 0 & building_sqft \\
\hline 9 & transport & industrial & 4 & 0 & parcel_sqft \\
\hline 10 & industrial & industrial & 4 & 0 & building_sqft \\
\hline 11 & agricultural & agricultural & 5 & 0 & building_sqft \\
\hline 12 & school & institutional & 6 & 0 & building_sqft \\
\hline 13 & military & government & 7 & 0 & building_sqft \\
\hline 14 & hospital & government & 7 & 0 & building_sqft \\
\hline 15 & civic_public & government & 7 & 0 & parcel_sqft \\
\hline 16 & government & government & 7 & 0 & building_sqft \\
\hline 17 & parking & other & 8 & 0 & building_sqft \\
\hline 18 & right_of_way & other & 8 & 0 & parcel_sqft \\
\hline 19 & vacant & other & 8 & 0 & parcel_sqft \\
\hline 20 & vacant & other & 8 & 0 & parcel_sqft \\
\hline 21 & water & other & 8 & 0 & parcel_sqft \\
\hline & & & & \\
\hline
\end{tabular}

\section{- Demolition cost data}

The demolition cost table provides information to UrbanSim models about the costs of demolition by building type. These numbers are used to calculate the cost of demolition of 
existing development so that a more accurate cost of redevelopment can be calculated. In this study, the demolition cost data was derived from http://buildingjournal.com/.

\subsection{Household and Person Data}

Household level data are required to run UrbanSim. Since this type of data is unavailable, in this study the data were synthesized using PopGen, which is an innovative software package developed by Arizona State University. This section describes the procedure of household and person data preparation, as shown in Figure 3-9.

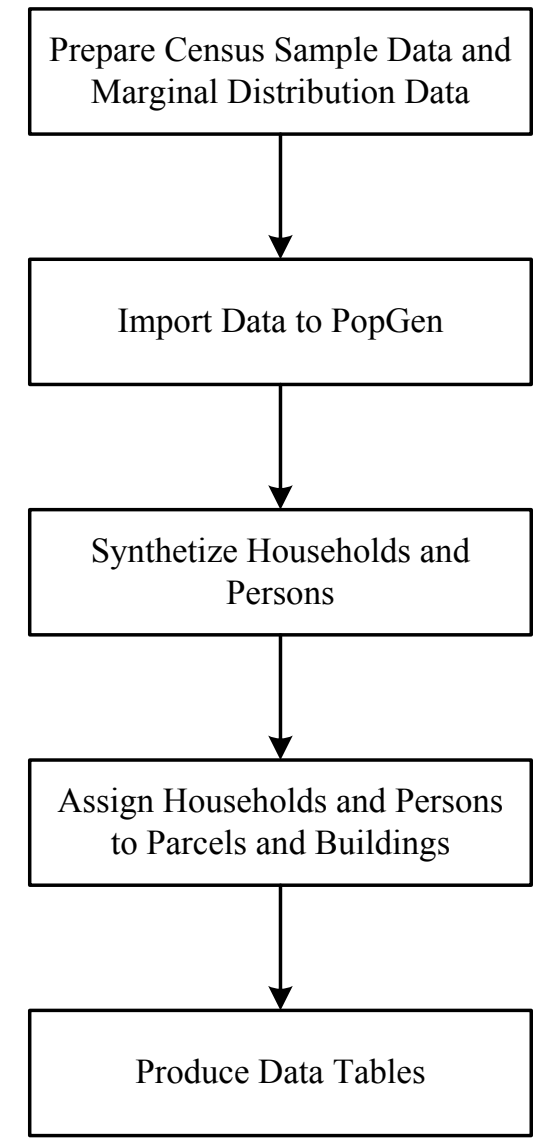

Figure 3-9 Procedure for Household and Person Data Preparation

\section{- Synthesis and Census Data}

PopGen incorporates a new Iterative Proportional Updating (IPU) algorithm to disaggregate household and person socio-demographic data for the entire population of a model region, which 
is generally not available (33). PopGen needs two known statistical distributions on the population as input for synthesizing a regional population:

- Disaggregate data for a sample of the population

Public Use Microdata Samples (PUMS) are computer-accessible files containing records for a sample of housing units, with information on the characteristics of each housing unit and the people in it. The basic unit in PUMS is an individual housing unit or person. In this study, Census 2000 PUMS were used and organized into 3 sample files: household sample file, group quarter sample file, and person sample file.

- Marginal distributions for the entire region

The American Community Survey (ACS) Summary File is a unique data product that includes all the estimations and margins of error covering demographic, social, economic, and housing subject areas. The most commonly used census data are the Census 2000 Summary File 1 (SF 1) 100-Percent Data, Census 2000 Summary File 2 (SF 2) 100-Percent Data, Census 2000 Summary File 3 (SF 3) Sample Data, and Census 2000 Summary File 4 (SF 4) Sample Data.

The sample data and marginal data were imported into PopGen and translated to PopGen's format. The variables for household samples and person samples used in PopGen are given in Table 3-4. Since the marginal distributions were given for the year 2000, they needed to be adjusted to represent the estimations in the base year (2010). The adjustment factor was derived based on the population projection in the "2035 Long Range Transportation Plan," given as follows:

$$
\text { Adjustment Factor }=\frac{\frac{\text { Target Year-2006 }}{2025-2006} \times(\text { Population in 2025-Population in 2006) }}{\text { Population in } 2000}
$$

where population is the total population of Hillsborough County in a target year. Since the household projection in the "2035 Long Range Transportation Plan" is calculated from the population with a constant household size, this adjustment factor was used to adjust the persons and households in Hillsborough County for 2010 with the assumption that the increasing rates are the same in all census geographic units.

Table 3-4 Marginal Variables in Household and Person Synthesis

\begin{tabular}{|l|l|}
\hline \multicolumn{1}{|c|}{ Household Marginal Variable } & \multicolumn{1}{c|}{ Person Marginal Variable } \\
\hline Household incoming & Age \\
\hline
\end{tabular}




\begin{tabular}{|l|l|}
\hline Household size & Gender \\
Household type & Race \\
Number of children & Employment \\
Head age & \\
House ownership & \\
Household race & \\
\hline
\end{tabular}

\section{- Import Census Data and Run Synthesizer}

The sample data and revised marginal data were imported into PopGen and the program was run, as shown in Figure 3-10. The geographic resolution was configured as census block groups, which are clusters of census blocks having the same first digit of their four-digit identifying numbers within a census tract. Block groups generally contain between 600 and 3,000 people, with an optimum size of 1,500 people. Most block groups were delineated by local participants as part of the U.S. Census Bureau's Participant Statistical Areas Program. The block groups in Hillsborough County are given in Figure 3-11. Block group units are labeled as Tract ID + Block Group ID.

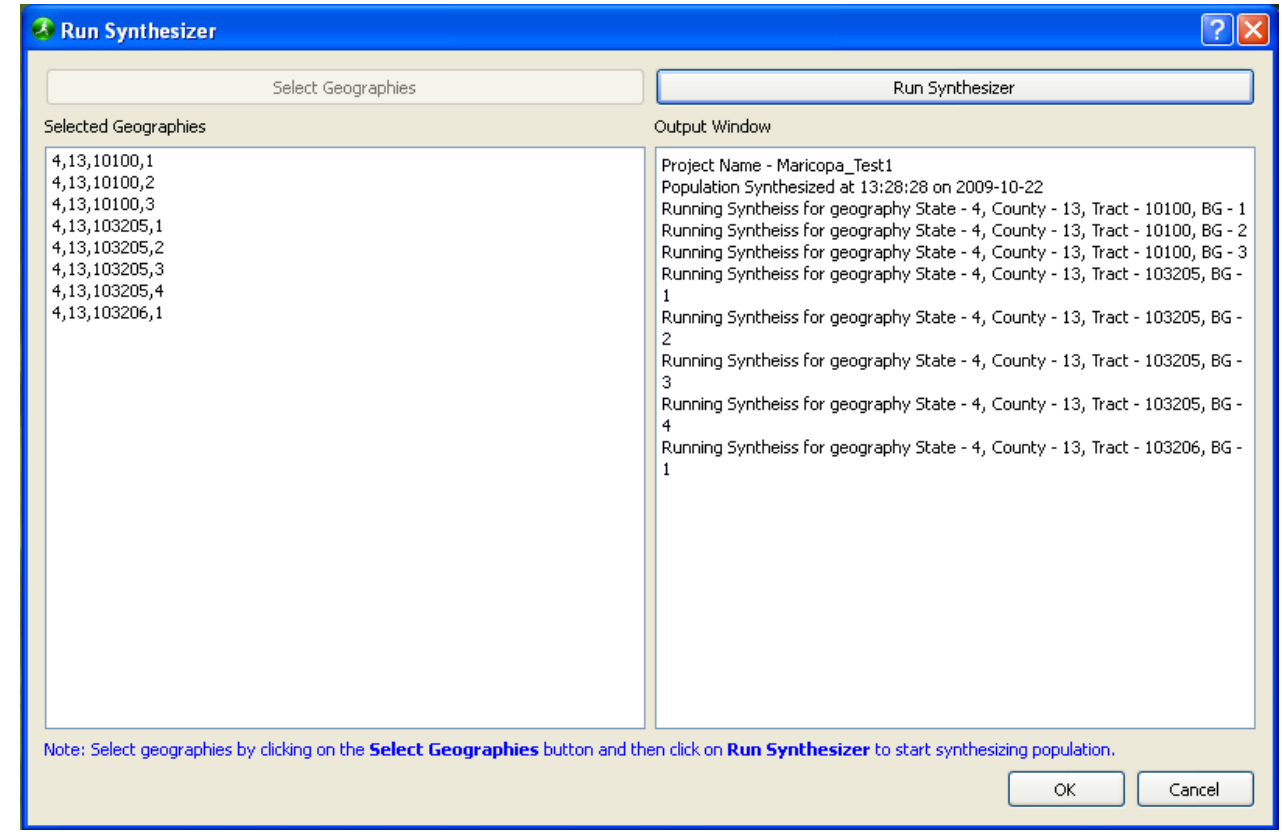

Figure 3-10 Run PopGen Synthesizer 


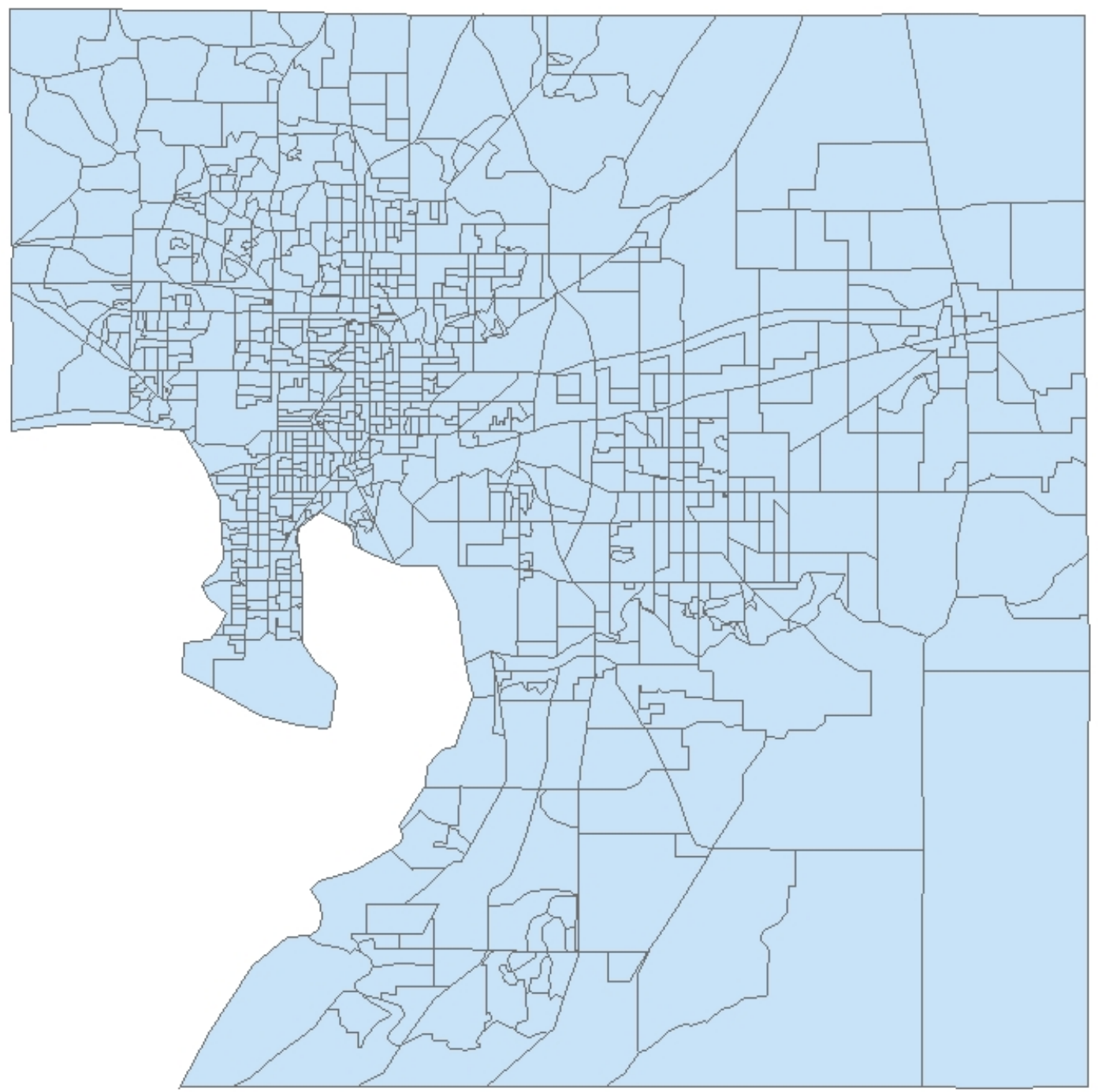

Figure 3-11 Census Block Groups in Hillsborough County

The output of the PopGen Synthesizer was two data tables: a household table and a person table. The household table contained the synthesized individual households with the household attributes listed in Table 3-4. The person table contained the synthesized individual persons with the person attributes listed in Table 3-4 and associated with each household in the household table. Both tables included geographic variables to indicate which tract + block group the individual household/person belongs to. 


\section{- Spatial Match}

The parcel-based UrbanSim model requires households and persons be connected to parcels and buildings, while the synthesized data are associated with census block groups. The inconsistence of geographic units can lead to matches between the synthesized households/persons and parcels/buildings. The procedure for data matching is given as follows:

\section{Step 1: Spatial Match between Parcels and Census Block Groups}

A census block group may contain one or more parcels. The GIS layers of census block groups and parcels were spatially joined using ArcGIS. Since the parcel layer had been transformed as a point map, the parcel points were joined to the closest block group (polygon). The matched Tract ID + Block Group ID were assigned to each parcel in the parcel table. The relationship between parcels and block groups are shown in Figure 3-12.

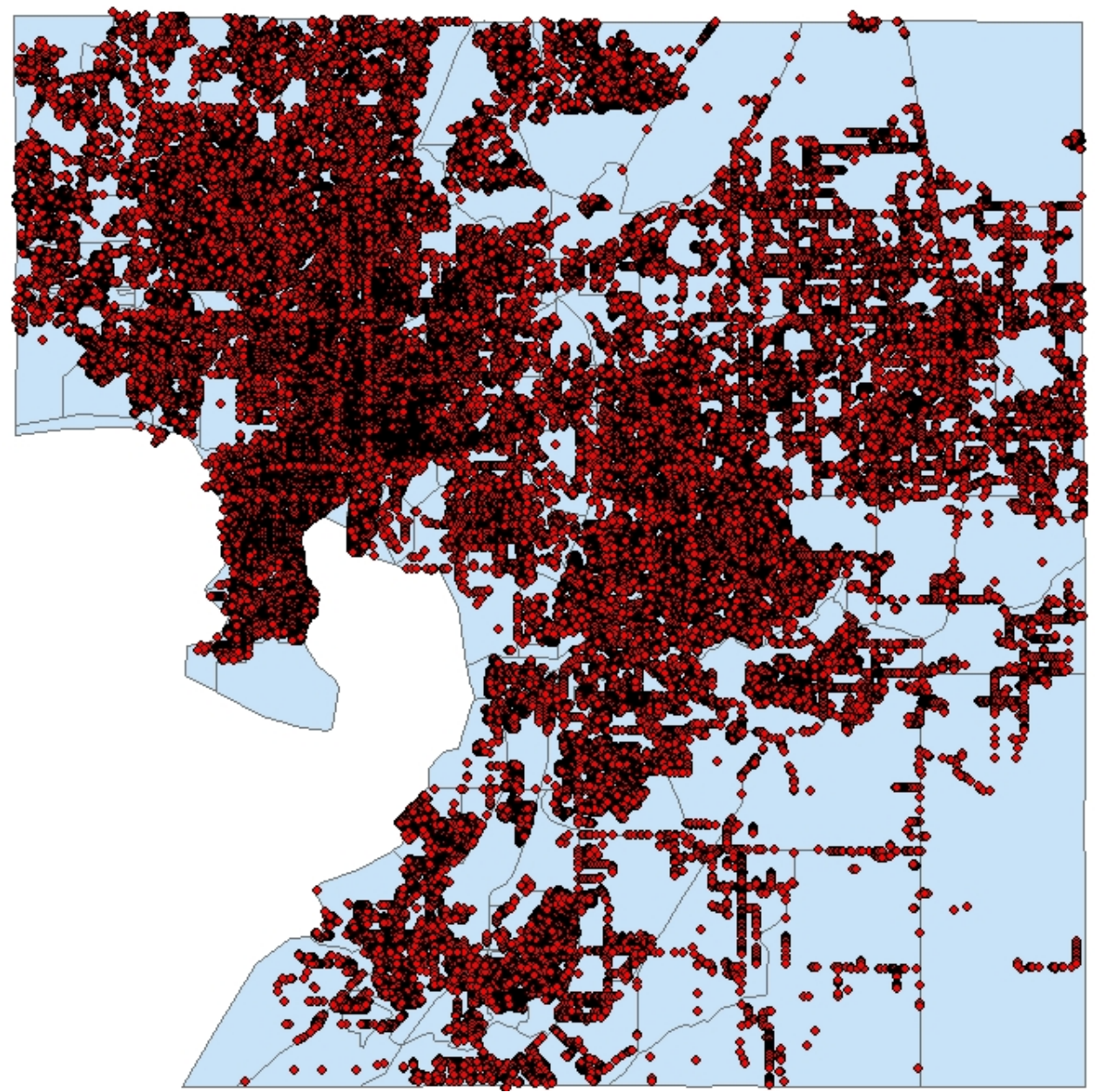

Figure 3-12 Spatial Relationship between Census Block Groups and Parcels 
Step 2 Assign Parcels and Buildings to Households

The connection between the synthesized households and parcels/buildings is a typical "many to many" relationship, shown in Figure 3-13.

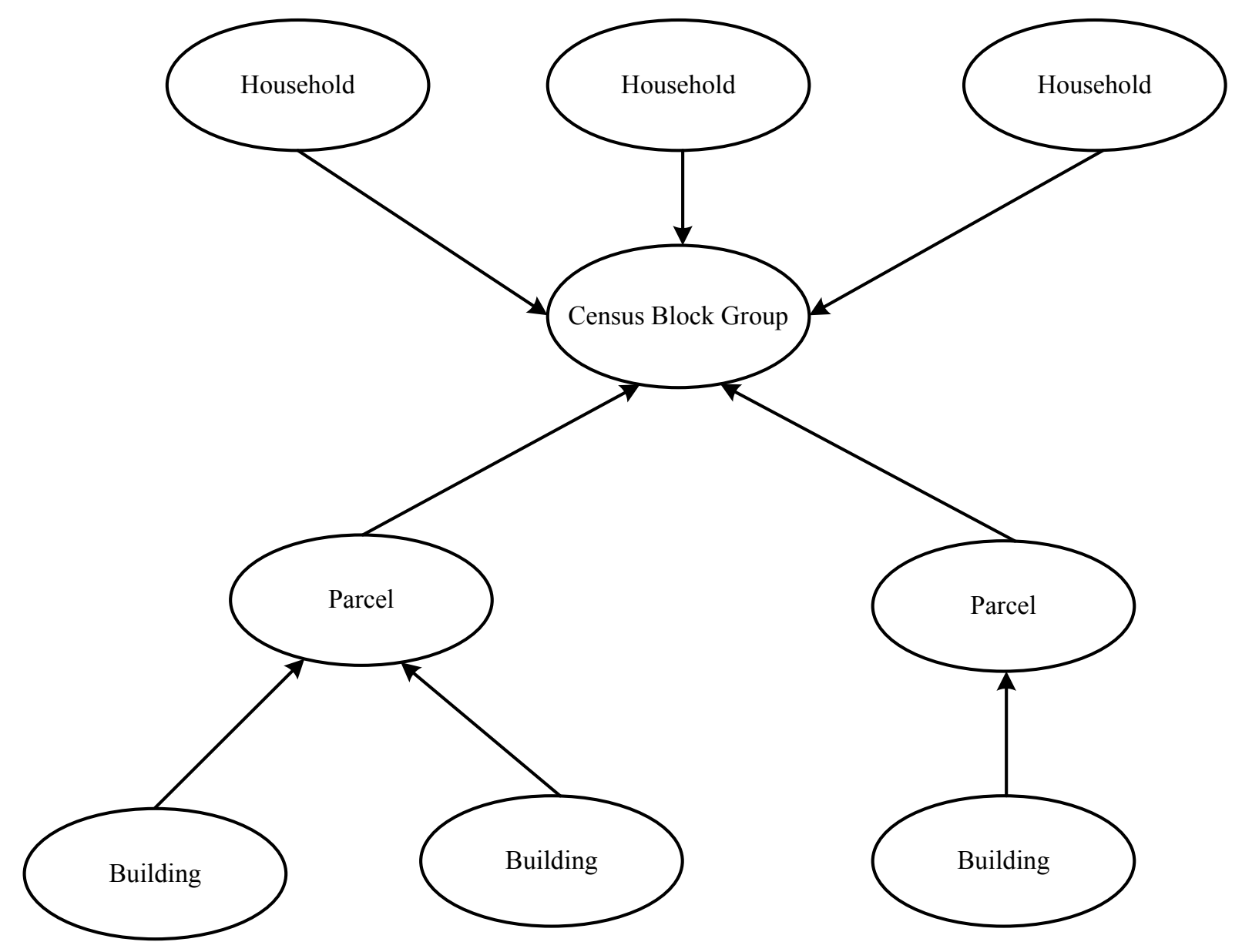

\section{Figure 3-13 "Many-to-Many" Relationship between Synthesized Households and Parcels/Buildings}

It is impossible to match households and parcels/buildings directly. Thus, a "two-stage" assignment was used in this study to connect households and parcels/buildings. In the first stage, parcels were assigned to households; in the second stage, buildings were assigned to households. Because no marginal distributions of households/persons are available at the parcel and building levels, a random assignment algorithm was adopted. The assignment flow chart is given in Figure 3-14. 


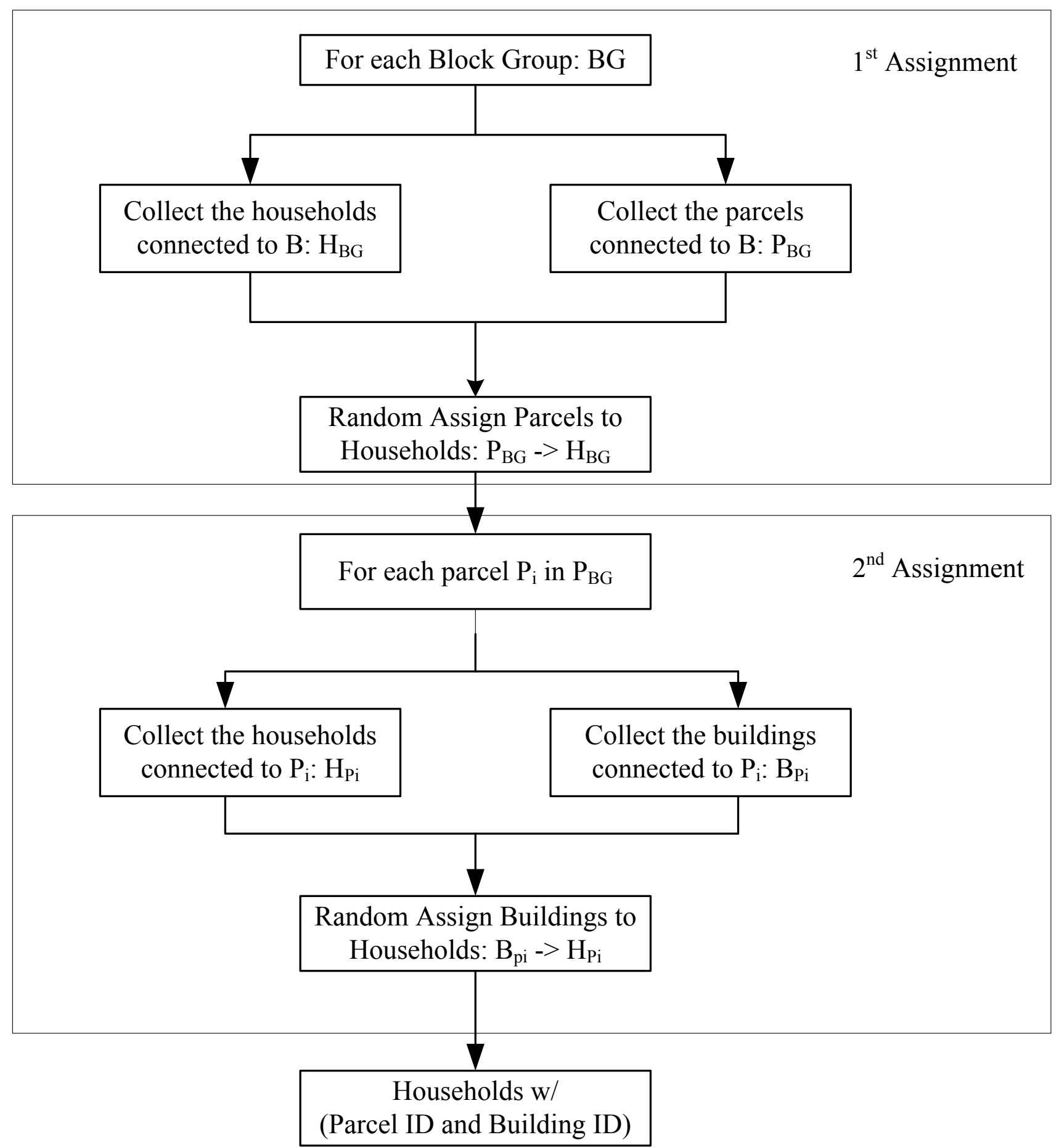

Figure 3-14 Assignment of Parcels/Buildings to Households 


\section{- Produce Data Tables}

The tables of households and persons were produced based on the synthesized data and assignment results. The description of the two tables is given in Tables 3-5 and 3-6, respectively.

Table 3-5 Household Table

\begin{tabular}{|c|c|c|c|}
\hline $\begin{array}{c}\text { Variable } \\
\text { Name }\end{array}$ & Description & $\begin{array}{c}\text { Source } \\
\text { Database }\end{array}$ & Source Item \\
\hline household_id & Unique household id & User defined & \\
\hline building_id & $\begin{array}{c}\text { Unique id of the building in which the household is } \\
\text { located }\end{array}$ & Building table & Building_id \\
\hline persons & Number of persons in the household & Census 2000 & NP \\
\hline income & Total annual income of the household & Census 2000 & HINCP \\
\hline age_of_head & Age of the head of the household (according to the & Census 2000 & AGEP \\
\hline race_id & Unique id of the race of the head of the household & Census 2000 & RAC1P \\
\hline workers & Number of workers in the household & Census 2000 & WIF \\
\hline children & 1 if children are present, 0 otherwise & Census 2000 & NOC \\
\hline cars & Number of cars owned by the household & Census 2000 & VEH \\
\hline
\end{tabular}


Table 3-6 Person Table

\begin{tabular}{|c|c|c|c|}
\hline $\begin{array}{c}\text { Variable } \\
\text { Name }\end{array}$ & Description & $\begin{array}{c}\text { Source } \\
\text { Database }\end{array}$ & $\begin{array}{c}\text { Item Name in } \\
\text { Source } \\
\text { Database }\end{array}$ \\
\hline person_id & Unique id for each person & User defined & \\
\hline household_id & Unique household id & $\begin{array}{l}\text { Household } \\
\text { table }\end{array}$ & household_id \\
\hline relate & Relationship of person to census survey respondent & Census 2000 & Relate \\
\hline age & Age of person in years & Census 2000 & Age \\
\hline $\operatorname{sex}$ & Coded as $1=$ male, $2=$ female & Census 2000 & Sex \\
\hline race_id & Unique id of the race category of the person & Census 2000 & Race \\
\hline student & 1 if person is a student, 0 otherwise & Census 2000 & Enroll \\
\hline worker & 1 if person is a worker, 0 otherwise & Census 2000 & Esr \\
\hline edu & Educational attainment of person & Census 2000 & Educ \\
\hline
\end{tabular}

\subsection{Employment Data}

Employment data for 2010 are available from a proprietary source (InfoUSA) purchased by the Florida Department of Transportation (FDOT). Founded in 1972, InfoUSA is a provider of business and consumer information products, database marketing services, data processing services, and sales and marketing solutions. InfoUSA maintains a proprietary database of 250 million consumers and 14 million businesses. The database is continuously updated from over 5,000 public sources and more than 20 million phone calls are made per year to verify and collect additional information. In developing the database, 5,200 phone books, annual reports, and other business directories are continuously reviewed to find information. Public record data from county courthouse filings, U.S. Securities and Exchange Commission (SEC) and 10-K filings, and the U.S. Secretary of State data are used; and every month the USPS National Change of Address, ZIP +4 , and Delivery Sequence files are matched to standardize and keep addresses current.

According to the InfoUSA employment data, there were a total of 46,819 public entities and private establishments in Hillsborough County in 2010. Each entity may provide one or more job positions, which are labeled as "ACTUAL_LOCATION_EMPLOYMENT_SIZE" in InfoUSA. 
In total, 590,384 jobs were found in Hillsborough County in 2010. Another important factor is employment type (employment sector) labeled by "NAICS_CODE" (North American Industrial Classification System Code) in InfoUSA. Table 3-7 gives the description of "NAICS_CODE" and employment sector codes used in the UrbanSim model. InfoUSA provides spatial information of employment data as points in a GIS layer. UrbanSim requires employment data to be connected to each building. This study conducted a spatial match between jobs and parcels in ArcGIS and assigned the buildings to jobs within each parcel. The procedure for employment data preparation is given in Figure 3-15. As a result, the job table is described in Table 3-8.

Table 3-7 Employment Sectors Classification - NAICS Codes

\begin{tabular}{|c|c|c|}
\hline NAICS_CODE & Description (name) & UrbanSim Code (sector_id) \\
\hline 11 & Agriculture, Forestry, Fishing and Hunting & 2 \\
\hline 21 & Mining, Quarrying, and Oil and Gas Extraction & 3 \\
\hline 22 & Utilities & 4 \\
\hline 23 & Construction & 6 \\
\hline $31-33$ & Manufacturing & 7 \\
\hline 42 & Wholesale Trade & 8 \\
\hline $44-45$ & Retail Trade & 9 \\
\hline $48-49$ & Fransportation and Warehousing & 10 \\
\hline 51 & Information & 11 \\
\hline 52 & Real Estate and Rental and Leasing & 12 \\
\hline 53 & Professional, Scientific, and Technical Services & 13 \\
\hline 54 & Management of Companies and Enterprises & 14 \\
\hline 55 & Administrative and Support and Waste Management & 15 \\
\hline 56 & and Remediation Services & 16 \\
\hline 61 & Educational Services & 17 \\
\hline 62 & Health Care and Social Assistance & 18 \\
\hline 71 & Arts, Entertainment, and Recreation & 19 \\
\hline 72 & Accommodation and Food Services & 21 \\
\hline 81 & Other Services (except Public Administration) & \\
\hline 92 & Public Administration & \\
\hline $99 \&$ missing & & \\
\hline & Non-classified Establishments & \\
\hline & & \\
\hline & & \\
\hline
\end{tabular}


Table 3-8 Job Table

\begin{tabular}{|l|l|l|l|}
\hline \multicolumn{1}{|c|}{ Column Name } & \multicolumn{1}{|c|}{ Description } & Source Database & Source Item \\
\hline job_id & Unique id for each job & User defined & \\
\hline building_id & $\begin{array}{l}\text { Unique id for the building in which the } \\
\text { job is located }\end{array}$ & Building Table & building_id \\
\hline home_based_status & 1 if the job is home-based, 0 otherwise & InfoUSA & WORK_AT_HOME \\
\hline sector_id & $\begin{array}{l}\text { Unique id of the employment sector of } \\
\text { the job }\end{array}$ & InfoUSA & NAICS_CODE \\
\hline
\end{tabular}




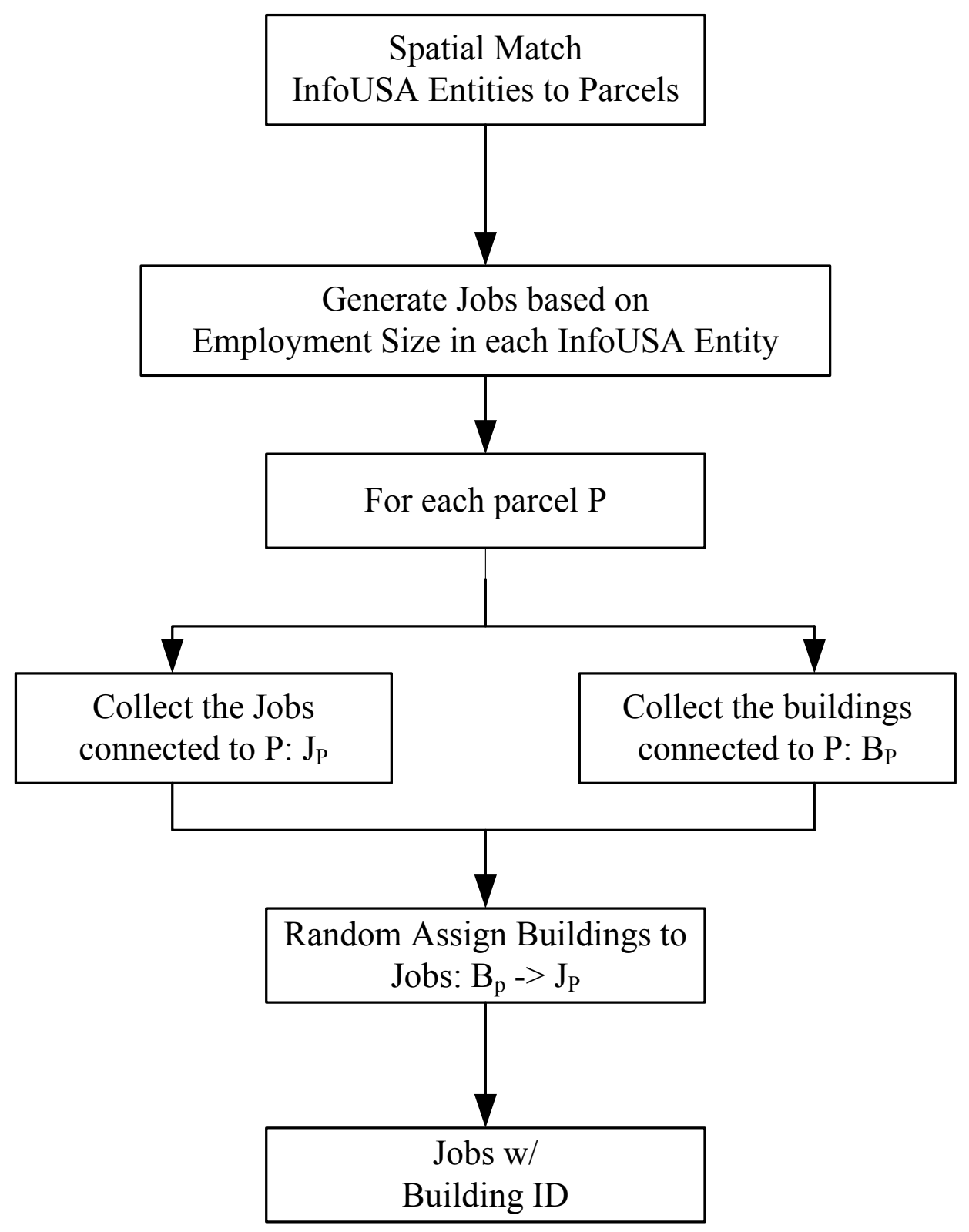

Figure 3-15 Procedure of Job Data Preparation 


\subsection{Land Use Development Data}

This section describes land use development data which cover future land use plans. There are two choices in the parcel-based UrbanSim model to prepare the land use development data:

- To provide a comprehensive data set, including individual land use development plans;

- To provide land use plan templates and constraints, but not individual land use development plans. The UrbanSim model will randomly generate development plans based on the templates and constraints.

The first choice can provide "real" future land use patterns, but requires very detailed data at the parcel level. A major data source of land use development is the Developments of Regional Impact (DRI) from the Tampa Bay Regional Planning Council, which provides a large-scale development list affecting many jurisdictions. DRI categories include: airports, attractions, hotels, industrial plants/parks, commercial developments, residential developments, and multi- or mixed-use projects. After reviewing the DRI database and reports, researchers found that the geographic units that are used in DRI projects are too big to locate land development on parcels. Thus, in this study, development templates and constraints were collected to allow the UrbanSim to produce development plans

The development constraint defines constraints to restrict development on parcels. Each row in the table defines a unique constraint. The Development Project Proposal Sampling Model (DPPSM) generates proposals for a parcel by using the constraint(s) and by selecting appropriate records from the development templates that will fit on the available land of the parcel. The DPPSM determines the applicable constraint(s) for a parcel by selecting a record in the development constraints based on the parcel's plan type. A parcel may have a constraint for Floor Area Ratio (FAR) and/or Units_per_Acre.

The development constraints were summarized by reviewing the Comprehensive Plan Future Land Use Elements (FLUE) for the cities of Tampa, Temple Terrace, Plant City, and the unincorporated areas of Hillsborough County. In these reports, the land use type and the policies to ensure the character and location of land uses optimizes the combined potentials for economic benefit and environment protection are described. Meanwhile, community development patterns are also provided, including area type (urban, suburban, or rural), land use type (residential, industry, or mixed), housing, transportation, and public service. Figure 3-16 gives a sample of a 
community development pattern. The patterns were summarized and translated to development constraints in the UrbanSim model. The preparation of constraint data and plan type data is given in Tables 3-9 and 3-10.

Table 3-9 Constraint Data

\begin{tabular}{|c|c|c|c|}
\hline Variable Name & Description & Source Database & Source Item \\
\hline constraint_id & $\begin{array}{l}\text { A unique id for the } \\
\text { constraint }\end{array}$ & User Defined & \\
\hline constraint_type & $\begin{array}{l}\text { The density measure for the } \\
\text { constraint. The value must } \\
\text { be either 'units_per_acre' for } \\
\text { residential land or 'far' for } \\
\text { nonresidential land. }\end{array}$ & FLUE & FAR/Units_per_acre \\
\hline plan_type_id & The id of the plan_type & FLUE & Match to Plan data \\
\hline minimum & $\begin{array}{l}\text { The minimum density } \\
\text { allowed by the constraint }\end{array}$ & FLUE & 0 if not defined \\
\hline maximum & $\begin{array}{l}\text { The maximum density } \\
\text { allowed by the constraint }\end{array}$ & FLUE & Review report \\
\hline
\end{tabular}

Table 3-10 Plan Data

\begin{tabular}{|l|l|c|c|}
\hline \multicolumn{1}{|c|}{ Variable Name } & \multicolumn{1}{c|}{ Description } & Source Database & Source Item \\
\hline plan_type_id & The id of the plan_type & User defined & \\
\hline plan_type_name & $\begin{array}{l}\text { The minimum density } \\
\text { allowed by the constraint }\end{array}$ & FLUE & $\begin{array}{c}\text { Development Pattern } \\
\text { Code }\end{array}$ \\
\hline
\end{tabular}




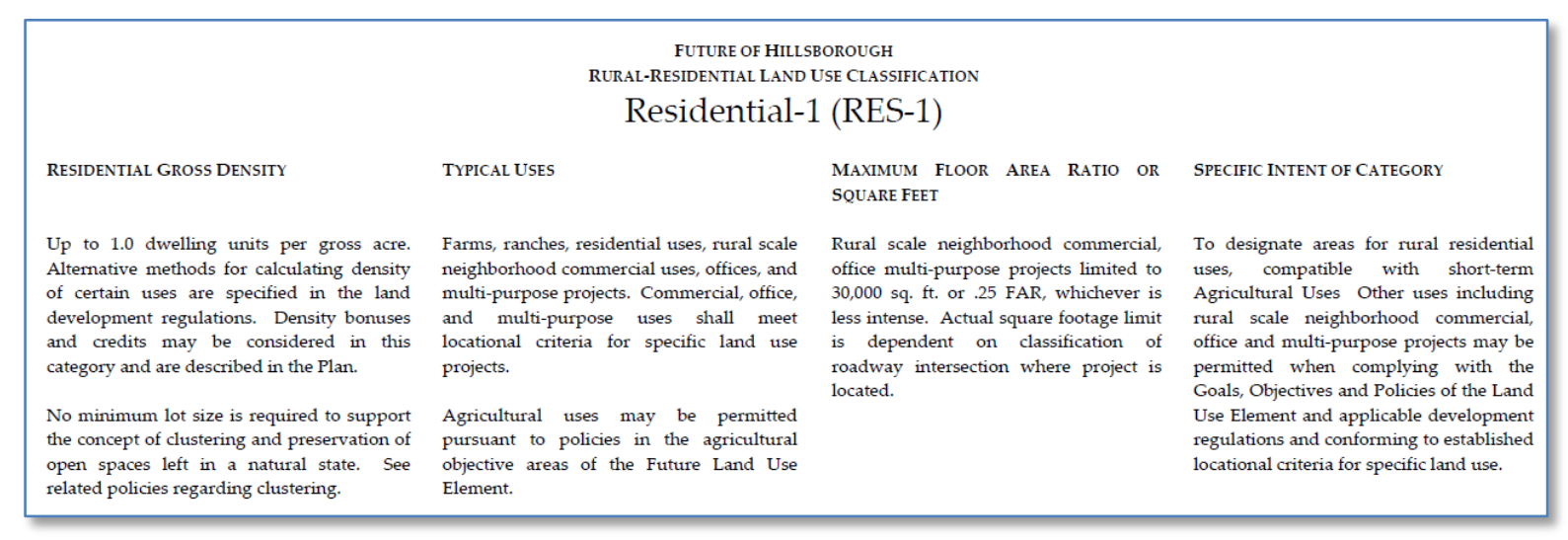

\section{Figure 3-16 Sample of Community Development Pattern in FLUE}

\subsection{Socioeconomic Control Data}

In order to forecast the future land use pattern, UrbanSim requires the socioeconomic projections for future years for the whole region. The socioeconomic control data include the annual number of households, annual household relocation rate, annual employment number, and annual employment relocation rate.

\section{- Annual Household Control Total}

The annual household number contains the control totals, or aggregate targets, for the number of households by family size for each future year. In this study, the annual household number by family size in the base year (2010) was retrieved from the Census Summary Files. The annual household control number for the future year (2011 to 2020) was calculated taking the following steps:

Step 1 Calculate Population in future years

In the "2035 Long Range Transportation Plan," the population projection for Hillsborough County is given for 2006, 2025, 2035, and 2050. The total population for 2011 - 2020 was calculated by the linear function:

$$
\begin{aligned}
& \text { Population for Target Year }=\frac{\text { Target Year-2006 }}{2025-2006} \times(\text { Population for } 2025- \\
& \text { Population for 2006) + Population for } 2006
\end{aligned}
$$




\section{Step 2 Calculate Households in future years}

Assuming the average family size in Hillsborough County is 2.55 persons per household in 2010 (Source: http://edr.state.fl.us/Content/area-profiles/county/hillsborough.pdf), the total household number in Hillsborough County is calculated by:

$$
\text { Total Households for Target Year }=\frac{\text { Population for Target Year }}{2.55}
$$

Step 3 Calculate Households by Family Size in future years

Assuming the percentage of family size is constant in future years, the households by family size for future years is calculated by:

$$
\begin{aligned}
& \text { Households for Family Size I in Target Year }= \\
& \qquad \begin{array}{r}
\frac{\text { Households for Family Size I in Base Year }}{\text { Total Households in Base Year }} \times \\
\text { Total Households in Target Year }
\end{array}
\end{aligned}
$$

\section{- Annual Household Relocation Rate}

The annual household relocation rates contain estimates of the probabilities of moving within the region for a one-year time frame. UrbanSim users can use any range or categorical variable (primary or computed) defined for households. By default, the model includes households of different incomes and ages of head of household categories. Since researchers did not find this information in the available databases, the system default relocation rates were used.

\section{- Annual Employment Control Total}

The annual employment control totals contain the control totals or aggregate quantities of employment that will be used to set the total employment in the model system for each year. Totals by employment sector are split into home-based and non-home based components, on separate records.

The annual employment control totals were calculated based on the employment projection in the "2035 Long Range Transportation Plan" using a method similar to calculating annual household control totals. 
Employment Total for Target Year $=$

$\frac{\text { Target Year }-2006}{2025-2006} \times$

(Employment Total for 2025 - Employment Total for 2006) +

Employment for 2006

The employment total was split by home-based and non-home-based based on the ratio of the two categories in the base year (2010).

\section{- Annual Employment Relocation Rate}

The annual employment relocation rates represent the probabilities that a job in a sector will relocate within the region within a one-year time frame. This study compared the employment number by sectors in InfoUSA 2007 and InfoUSA 2010, and calculated the annual rate of change for employment by sector in Hillsborough County.

Relocation Rate for Sector $\mathrm{i}=$ $\frac{\text { Jobs for Sector } i \text { in InfoUSA 2010-Jobs for Sector in InfoUSA } 2007}{\text { Jobs for Sector i in InfoUSA } 2007}$

$/(2010-2007)$

\subsection{Traffic Pattern}

Accessibility, which is defined as how easy it is for individuals to access activities they need or want to engage in from a geographic unit (parcel, zone, etc.), has long been known to influence the location of firms and households' activities. Firms reduce transport costs to labor, suppliers, and consumers; while households trade off transport costs for work and shopping against housing costs and other amenities. In addition, accessibility strongly influences land prices and density:

- Auto use supports a low-density, dispersed urban form, which reinforces auto use;

- Transit ridership increases with high density, mixed use development, nodal urban form, and high walking access; and

- Walking access to shopping increases pedestrian activity, which increases pedestrian oriented retail.

Accessibility of zone i can be calculated by: 


$$
\text { Accessibility }_{i}=\sum_{j=1}^{J}\left(\operatorname{Jobs}_{j} e^{\text {Logsum }_{i j}}\right)
$$

where $J o b s_{j}$ is employment activities in zone $\mathrm{j}$; $\operatorname{Logsum}_{i j}$ is the logsum for households from TAZ i to TAZ $\mathrm{j}$; and $\mathrm{J}$ is the number of TAZs (TAZ is Traffic Analysis Zone).

UrbanSim requires the retrieval of logsum values (traffic patterns) from a transportation planning model. In Hillsborough County, the travel demand model is the Tampa Bay Regional Planning Model (TBRPM) powered by Cube Voyager. The preparation procedure for traffic data is shown in Figure 3-17.

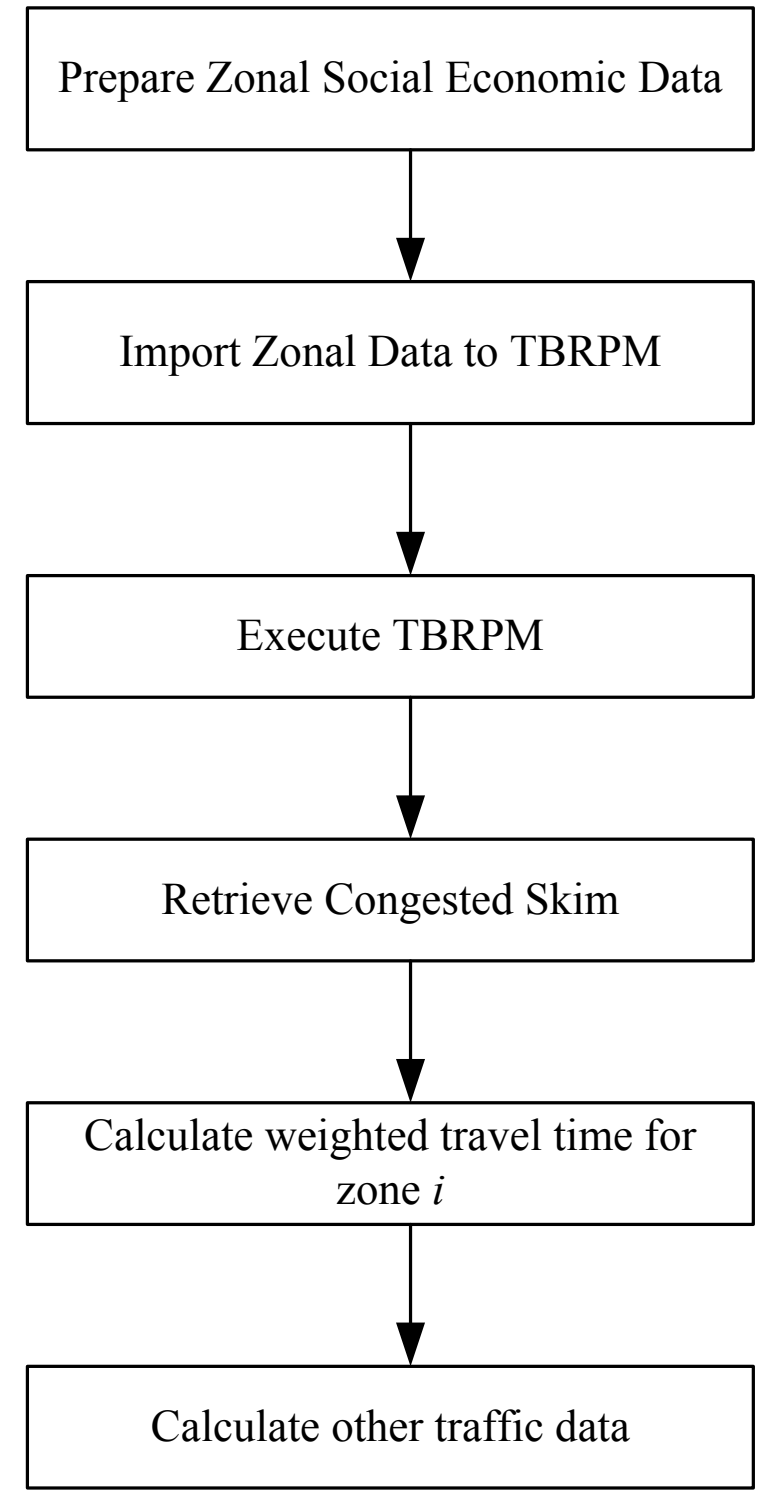

Figure 3-17 Data Preparation for Traffic Data 


\section{- Prepare Zonal Socioeconomic Data}

Two zonal socioeconomic datasets are included in the TBRPM model: ZDATA1, consisting of population, dwelling units, and hotel/motels information; and ZDATA2, consisting of employment and school enrollment information. In TBRPM ver 7.1, three scenarios were created for 2006, 2025, and 2035. To calculate the zonal data for a target year, the following linear function was used:

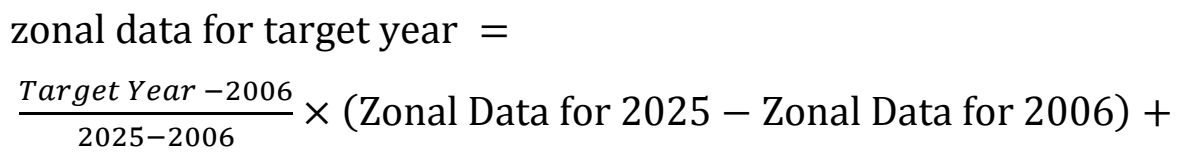

Zonal Data for 2006

The ZDATA1 and ZDATA2 were recalculated for 2010 using this equation and were imported into the TBRPM model to create a new scenario (2010BASE).

\section{- Retrieve Congested Skim}

The new scenario was executed to produce traffic costs and trips among origins and destinations. In this study, the traffic cost was defined as the zonal travel time during peak hours (congested) which can be retrieved from the "CONGSKIM_Ayy.MAT" after conducting trip distribution. The travel impedance (TIME2) in this matrix includes travel time, turn penalties, toll equivalent time, and acceleration / deceleration delay time. This matrix was transformed to a table that represents zone-to-zone congested travel time. 


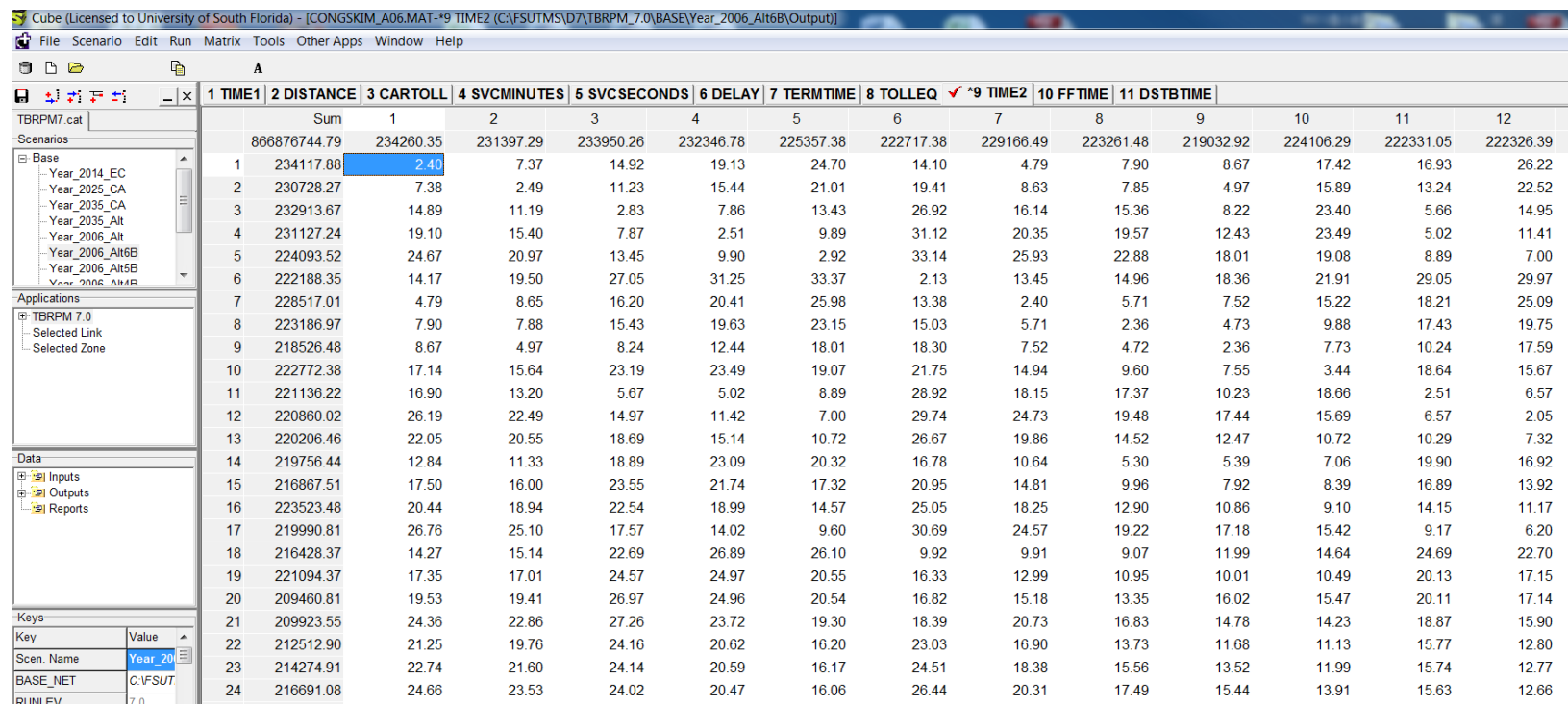

\section{Figure 3-18 Zone-to-Zone Travel Time in Hillsborough County}

As shown in Figure 3-19, TBRPM also produced zone-to-zone trips by purpose: HBW (homebased work), NHBW (non-home-based work), and so on. These trip matrices were retrieved from the output of the TBRPM model organized by travel purposes.

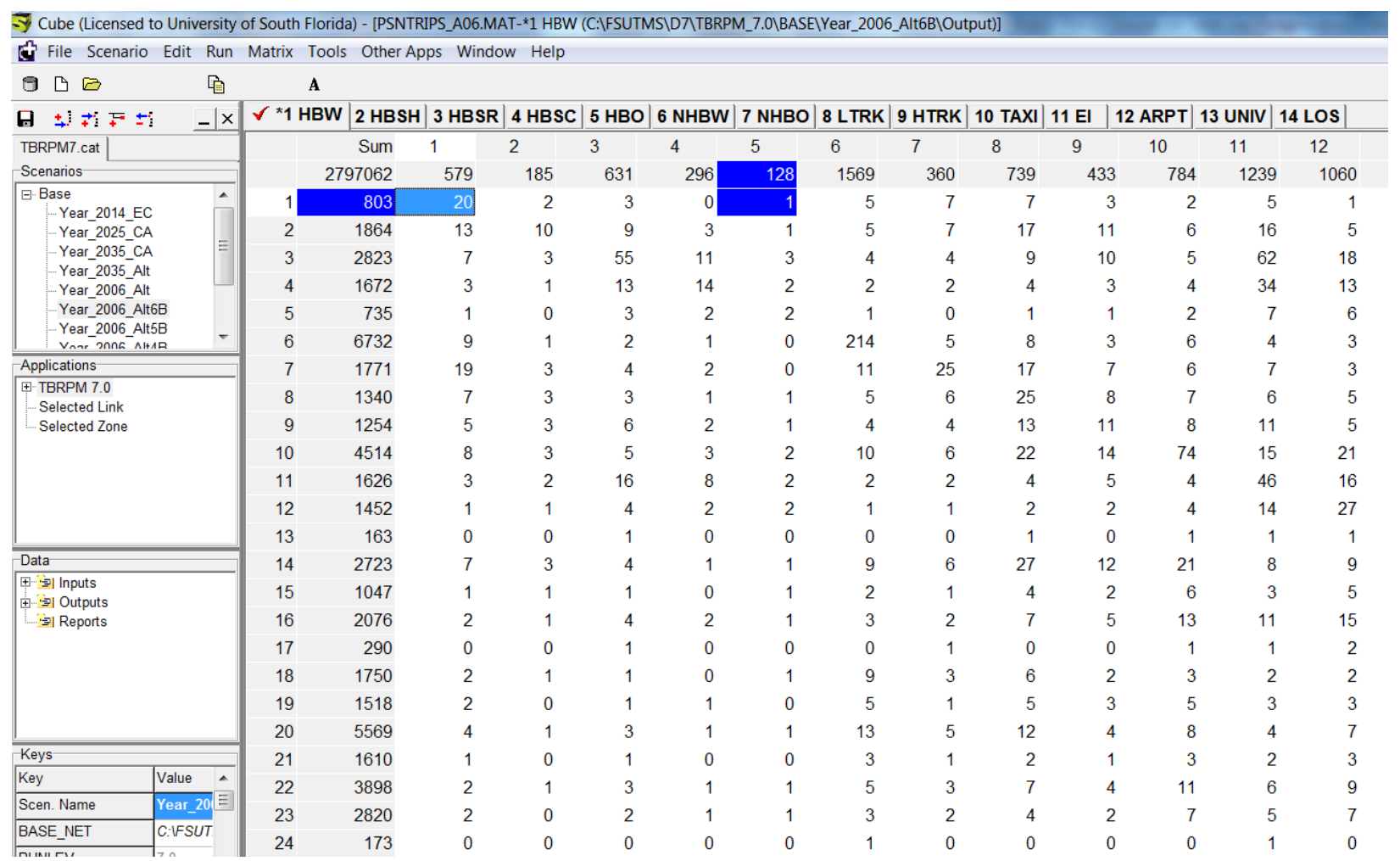

Figure 3-19 Zone-to-Zone Trips by Purpose in Hillsborough County 


\section{- Aggregate Zonal Traffic Pattern}

Six zonal traffic patterns were produced in this study: zone-to-zone congested traffic costs, weighted average zonal traffic time, weighted average zonal HBW traffic time, weighted average zonal NHBW traffic time, weighted average zone-to-CBD traffic time, and weighted average zone-to-Airport traffic time. The zone-to-zone congested traffic costs were retrieved from the TBRPM model output directly. The other patterns were calculated by following equations.

Weighted average zonal traffic time:

Traffic Time for Zone $i=\frac{\sum_{j=1}^{J} \text { (Trips for I to } \mathrm{j} \times \text { Traffic Time for I to } \mathrm{j} \text { ) }}{\sum_{j=1}^{J} \text { Trips for } i \text { to } j}$

$\mathrm{i} \neq \mathrm{j}, \mathrm{J}=$ Number of Zones

Weighted average zonal HBW traffic time:

Traffic Time for Zone $i=\frac{\sum_{j=1}^{J} \text { (HBW Trips for } \mathrm{i} \text { to } \mathrm{j} \times \text { Traffic Time for } \mathrm{i} \text { to } \mathrm{j} \text { ) }}{\sum_{j=1}^{J} \text { HBW Trips for } i \text { to } j}$

$\mathrm{i} \neq \mathrm{j}, \mathrm{J}=$ Number of Zones

Weighted average zonal NHBW traffic time:

Traffic Time for Zone $i=\frac{\sum_{j=1}^{J}(\text { NHBW Trips for i to } \mathrm{j} \times \text { Traffic Time for } \mathrm{i} \text { to } \mathrm{j})}{\sum_{j=1}^{J} \text { NHBW Trips for } i \text { to } j}$

$\mathrm{i} \neq \mathrm{j}, \mathrm{J}=$ Number of Zones

Weighted average zone-to-CBD traffic time:

Traffic Time for Zone $i=\frac{\sum_{j=1}^{J} \text { (Trips for I to } \mathrm{j} \times \text { Traffic Time for I to } \mathrm{j} \text { ) }}{\sum_{j=1}^{J} \text { Trips for } i \text { to } j}$

$$
\mathrm{i} \neq \mathrm{j}, \mathrm{j} \in \text { CDB Zones, } \mathrm{J}=\text { Number of CBD Zones }
$$


The CBD Zones are shown in Figure 3-20.

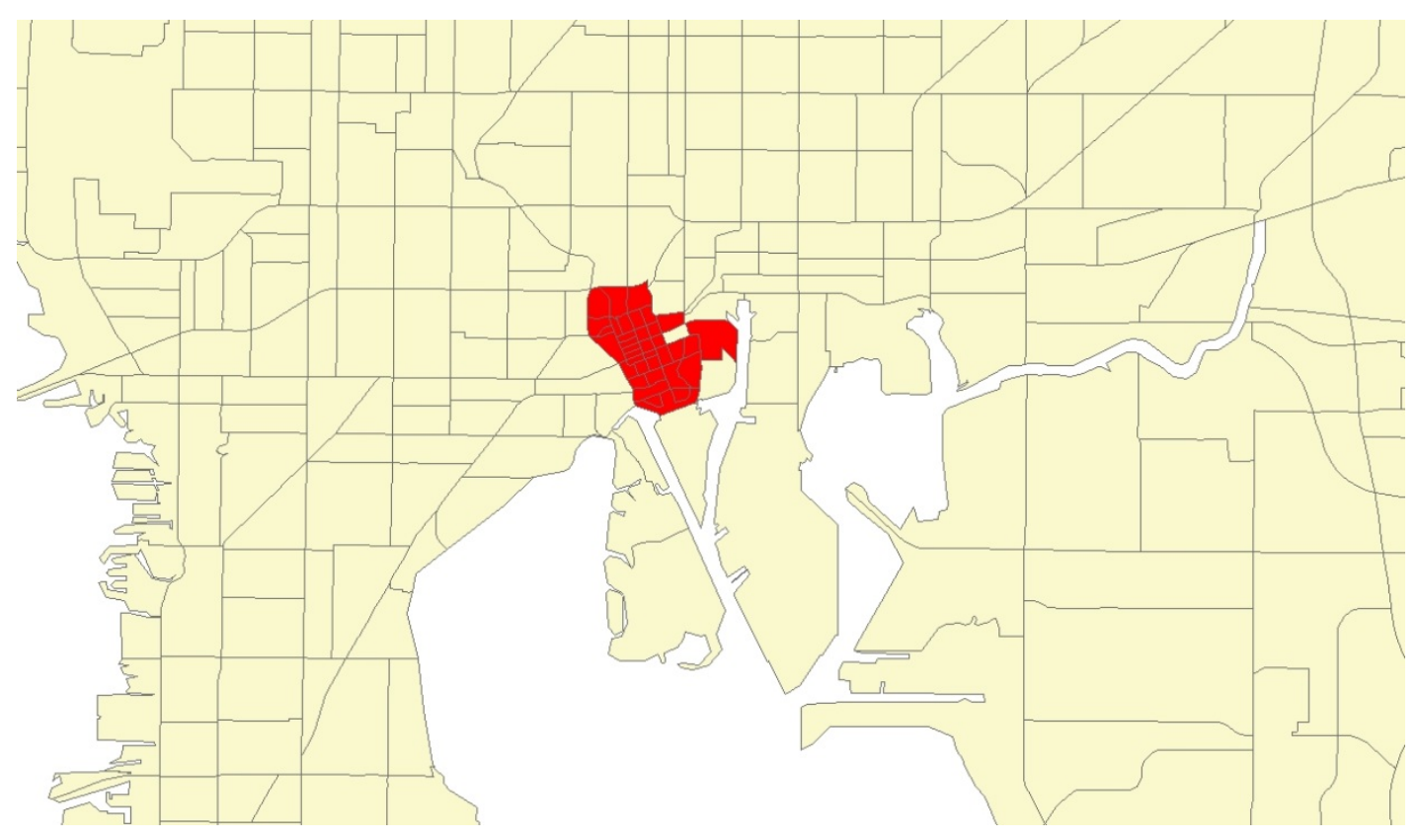

Figure 3-20 Zones in Tampa CBD Area

Weighted average zone-to-AirPort traffic time:

Traffic Time for Zone $i=\frac{\sum_{j=1}^{J} \text { (Trips for I to } \mathrm{j} \times \text { Traffic Time for I to } \mathrm{j} \text { ) }}{\sum_{j=1}^{J} \text { Trips for } i \text { to } j}$

$i \neq j, j \in$ Air Port Zones, $J=$ Number of Air Port Zones 


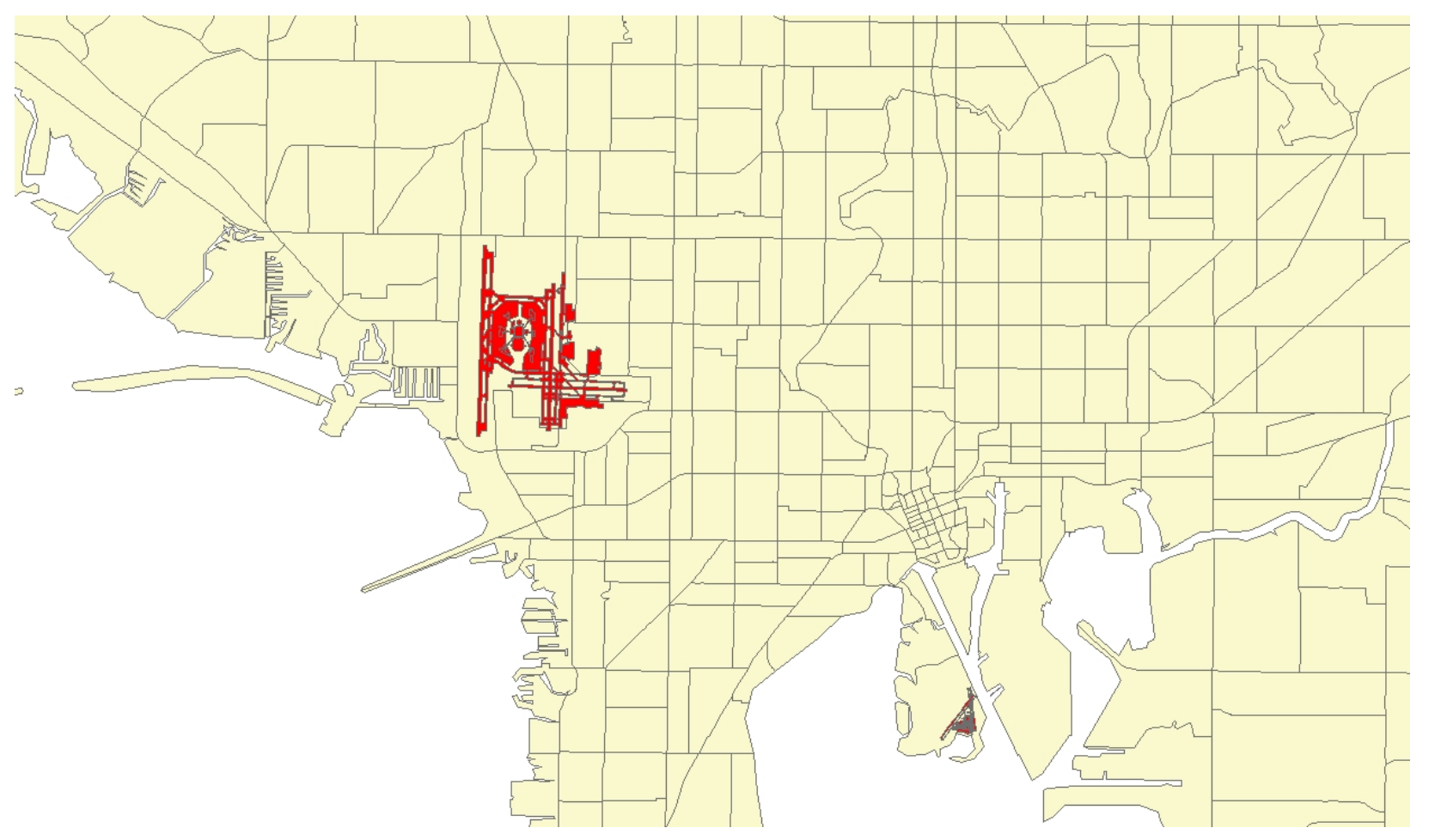

Figure 3-21 Air Port (Tampa International Airport) Zones

\section{- Output Data Tables}

Two data tables were produced to represent the traffic patterns. "Traffic_data" is used to describe zone-to-zone congested travel time in seconds. "Zones" contain weighted average zonal traffic time, weighted average zonal HBW traffic time, weighted average zonal NHBW traffic time, weighted average zone-to-CBD traffic time, and weighted average zone-to-Airport traffic time for each zone in Hillsborough County. 


\subsection{Data Compilation}

After the data were prepared, they were compiled to generate input tables for the UrbanSim model. The data compilation included converting the data to UrbanSim format, producing data tables, connecting data tables by "key" variables, and outputting UrbanSim input files (CSV format). Detailed information on the format of input tables is provided in Appendix I. The input tables are listed below.

- ANNUAL_EMPLOYMENT_CONTROL_TOTALS - employment forecasts, by location (home-based or non-home based) for each simulated year;

- ANNUAL_HOUSEHOLD_CONTROL_TOTALS - households forecasts, by household size for each simulated year;

- ANNUAL_RELOCATION_RATES_FOR_HOUSEHOLDS - relocation rates of households, by household head age, and by household income;

- ANNUAL_RELOCATION_RATES_FOR_JOBS - relocation rates of jobs, by sector;

- BUILDING_SQFT_PER_JOB - amount of space each job will take in a particular building type, by zone;

- BUILDING_TYPES - unique building types used to classify buildings;

- BUILDINGS - individual building located on a parcel;

- $\quad$ CITIES - the name of cities included in the study area;

- $\quad$ COUNTIES - the name of counties included in the study area;

- DEMOLITION_COST_PER_SQFT - costs of demolition by building type;

- DEVELOPMENT_CONSTRAINTS - constraints to restrict development on parcels;

- DEVELOPMENT_TEMPLATE_COMPONENTS - buildings or parts of buildings included in a particular template;

- EMPLOYMENT_SECTORS - employment sectors used to classify jobs by industrial sector;

- GENERIC_LAND_USE_TYPES - generalized land use classification used for models; 
- HOUSEHOLD_CHARACTERISTICS_FOR_HT - classification used in the annual_household_control_totals table to determine how many households of particular categories will be in the region in a simulation year;

- HOUSEHOLDS - synthesized households for the region. It typically reflects an expansion of the Public Use Microdata Samples (PUMS) to approximate a 100\% sample of households;

- JOBS - inventory of jobs for the region;

- LAND_USE_TYPES - land use classification for all parcels in the region;

- PARCELS - attributes of individual parcels;

- PERSONS - synthesized population for the region;

- PLAN_TYPES - classification of land use regulations defining permissible uses and densities of future development;

- TARGET_VACANCIES - structural or target vacancies - trigger development when vacancies fall below this, by building type for each simulated year;

- TRAVEL_DATA - zone-to-zone skims from the travel demand models, for accessibility variables;

- ZONES - attributes of traffic analysis zones used in the travel demand models. 


\section{Model Development}

UrbanSim is a model system to support land use, transportation planning, and environmental planning. It is a full micro-simulation model system, simulating choices of agents: households, businesses, and developers. UrbanSim is based on the following theories:

- Random Utility Theory (McFadden)

$\checkmark$ Theoretical basis for discrete choice models (such as mode choice): agents choose among alternatives based on the relative utility of the available options

$\checkmark$ Multinomial and nested logit models, more general forms relaxing the Irrelevant Alternatives (IIA) property

- Urban Economics/Bid Rent Theory (Alonso, Mills, Muth)

$\checkmark$ Explains land use outcomes (density, rents, etc.) as outcomes of bidding processes based on willingness to pay for locational amenities: trade-off travel time vs. housing cost

- Hedonic Price Theory (Rosen)

$\checkmark$ Observed prices of composite goods, like housing, can be 'decomposed' to the implicit prices of their attributes; widely used to measure the market valuation of locational amenities or disamenities.

- Dynamic Market Equilibrium, Price Adjustment, Disequilibrium

$\checkmark$ Markets are rarely in equilibrium, especially real estate due to supply lags and high transactions costs; information is imperfect and speculation can lead to bubbles

$\checkmark$ Current housing market crisis is an excellent example of market disequilibrium

- Micro-simulation (Orcutt)

$\checkmark$ Initially a computational framework to explore individual level impacts of policies; later found more computationally efficient than complex aggregate models 
Strong empirical support for micro-simulation to avoid aggregation bias and ecological fallacy (attributing to individuals behavior from aggregate patterns)

- Geographic Information Systems and Spatial Analysis (Tobler, Anselin)

$\checkmark$ Radical advance in spatial analysis capabilities;

$\checkmark$ Representation of walking scale accessibility

The interaction of UrbanSim model agents in urban markets is shown in Figure 4-1.

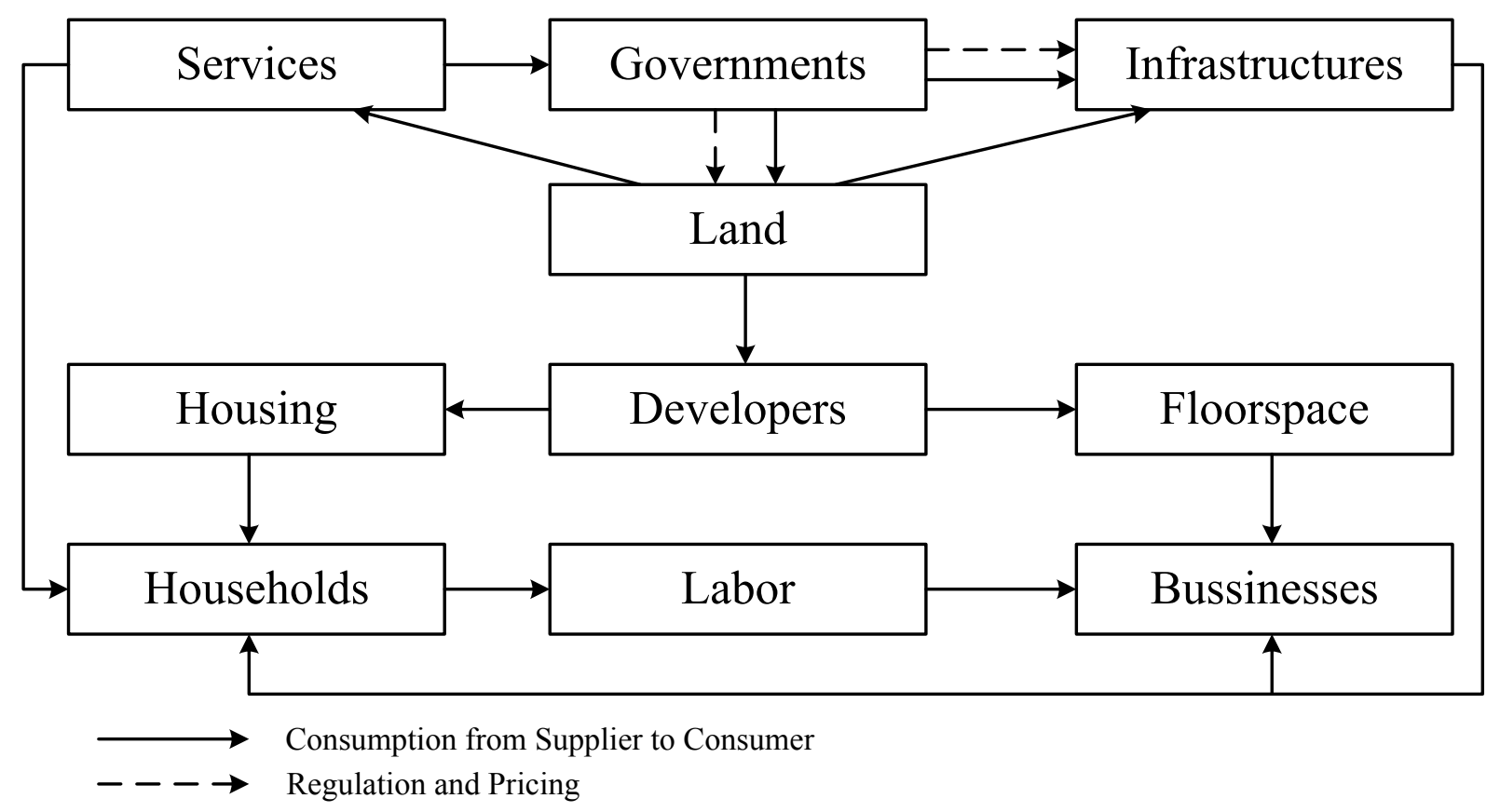

Figure 4-1 UrbanSim Model Agents Interacting in Urban Markets

As a micro-simulation system, UrbanSim simulates agents making a series of choices in urban markets: households making residence location choices, businesses locating jobs, and persons choosing shopping destinations. These choice activities are based on comparing relative utility of the available options using Multinomial Logit Models (MNLs), which have several advantages:

- Closed form, easy to compute

- Probabilities sum to 1

- Independence of Irrelevant Alternatives (IIA) allows consistent estimation using sample of alternatives 
The process of agent choice in urban markets is shown in Figure 4-2.

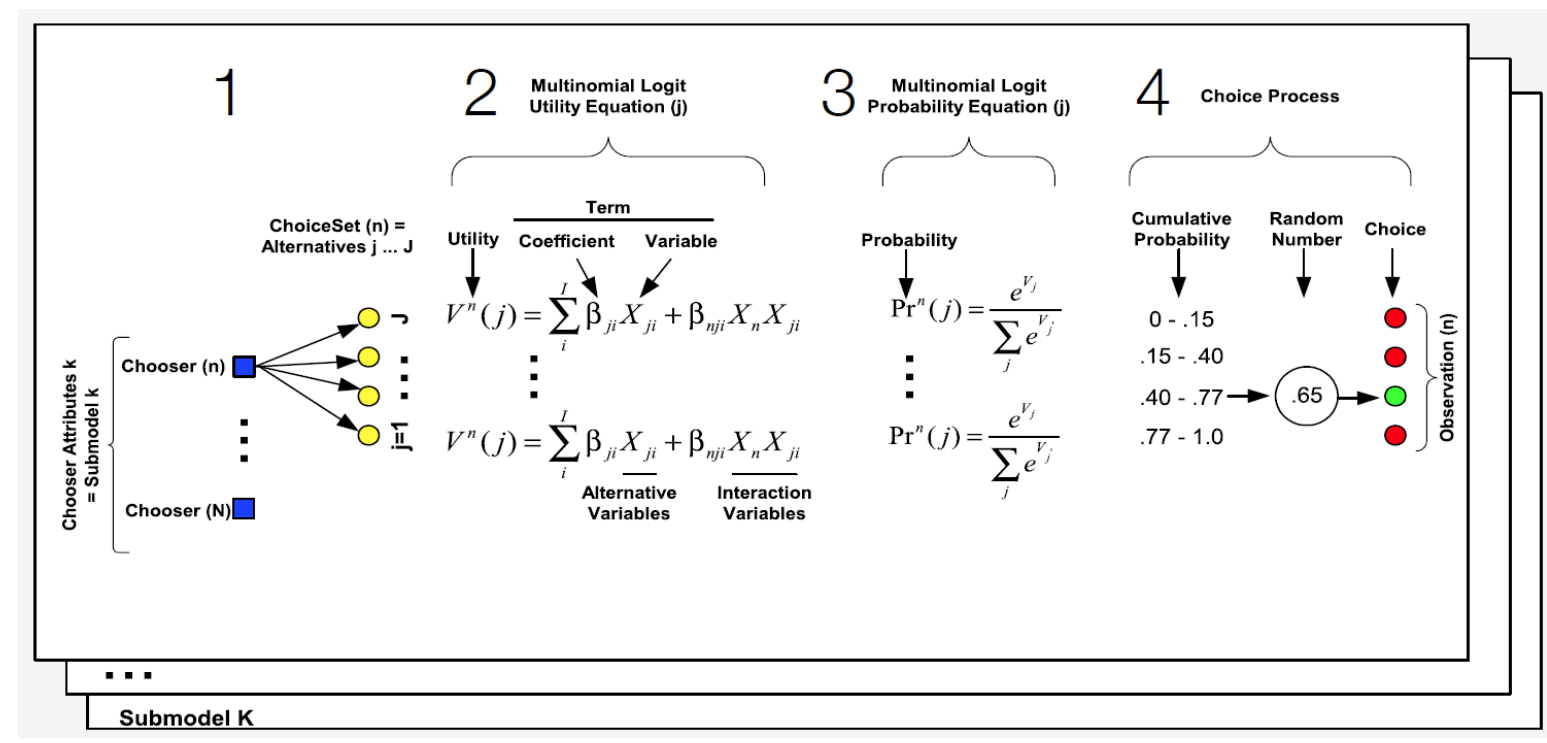

Figure 4-2 Agent Choice in UrbanSim

(source: www.urbansim.org)

\subsection{UrbanSim Sub-Models Structure}

UrbanSim provides a flexible strategy to allow users to select sub-models from a candidate list consisting of 35 sub-models, and even create new models. By considering feasibility, necessity, and cost, ten sub-models were selected to develop in this study, as shown in Figure 4-3. UrbanSim runs the sub-models in the sequence shown in Figure 4-3 and allows researchers to calibrate the real estate price model, household location choice model, and employment location choice model using local data. 
Real Estate Price Model

Expected Sale Price Model

Development Proposal Choice Model

Building Construction Model

Household Transition Model

Employment Transition Model

Household Relocation Model

Household Location Choice Model

Employment Relocation Model

Employment Location Choice Model
Predicts price of land if vacant, price of land + buildings if parcel is developed

Generates possible development proposals for each eligible parcel, and the predicted return on investment

Selects proposals based on return on investment, current vacancy rates

Adds new buildings / demolishes redeveloped ones

Adds or subtracts households to the region to match the annual control totals from the user - subtractions are randomly selected, additions are not yet placed in a parcel or building. Employment same as Household with controls at the sector level

Selects households that will move based on user's probability inputs

Chooses vacant dwelling units for households added through Transition model and households moving via the Relocation model

Same function as Household Relocation model

Same function as Household Location Choice model, but jobs choose building spaces (ie cubicles)

\section{Figure 4-3 Developed Sub-Models in UrbanSim}

\section{Real Estate Price Model (REPM)}

UrbanSim uses real estate prices as the indicator of a match between demand and supply of land at different locations and with different land use types. It also uses real estate prices for relative market valuations for attributes of housing, nonresidential space, and location. This role is important to the rationing of land and buildings to consumers based on preferences and the ability to pay, and is a reflection of the operation of actual real estate markets. Since prices enter the location choice utility functions for jobs and households, an adjustment in prices will alter location preferences. All else being equal, this will in turn cause higher price alternatives to 
become more likely to be chosen by occupants who have lower price elasticity of demand. Similarly, any adjustment in land prices alters the preferences of developers to build new construction by the type of space and the density of the construction.

Real estate prices are modeled using a hedonic regression of the log-transformed property value per square foot on attributes of the parcel and its environment, including land use mix; density of development; proximity of highways and other infrastructure; land use plan or zoning constraints; and neighborhood effects. The hedonic regression equation encapsulates interactions between market demand and supply, revealing an envelope of implicit valuations for location and structural characteristics. The independent variables influencing land prices can be organized into site characteristics, regional accessibility, and urban-design scale effects, including development type; land use plan; environmental constraints; access to population and employment; land use mix and density; and proximity to highway and arterials.

- buildings

- zones

- travel_data

- households

- jobs

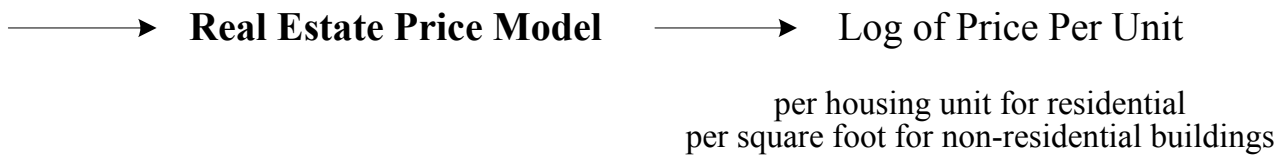

Figure 4-4 Input and Output of Real Estate Price Model

\section{Expected Sales Price Model (ESPM)}

The Expected Sales Price Model (ESPM) predicts the price per unit of each proposed development project. The model uses the same specifications and estimated parameters from the Real Estate Price Model to predict expected prices. The dependent variable is the Log of the price per unit (per housing unit for residential, per square foot for non-residential buildings). The independent variables include attributes of the building: density, accessibility, and zonal composition of households and employment.

- buildings

- zones

- travel_data

- households

- jobs

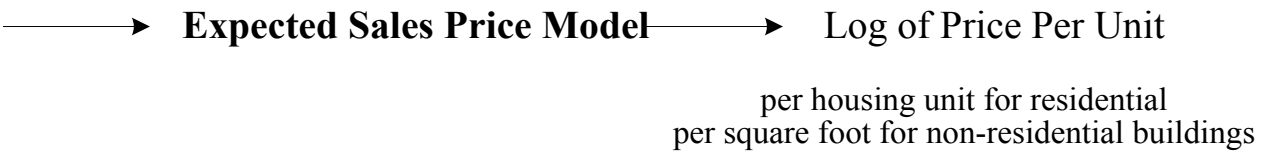

Figure 4-5 Input and Output of Expected Sales Price Model 


\section{Development Proposal Choice Model (DPCM)}

The Development Proposal Choice Model predicts the selection of proposed development projects to be constructed on parcels. This model can be seen as a choice being made by a financial agent, determining whether to approve construction financing for possible projects. The model begins by evaluating each parcel, based on its remaining vacant land and the plan type that is on the parcel. It then makes an assessment for each of the "development templates" as to whether that template would be permitted by land use regulations, and would fit on the parcel. Any of the templates that pass both of these tests are then configured as development proposals. Once all parcels have been evaluated and a full list of proposals has been generated, the model uses the Expected Sales Price Model to predict the market value for the proposal. The development costs for constructing the proposal are also calculated, and a resulting Return on Investment (ROI) is computed. The model treats the ROI as the profit (the counterpart of utility for firms) based on a Multinomial Logit formulation.

- building_sqft_per_job

- development constraints

- demolition_cost_per_square_feet

- development_project_proposals

- development_templates

$\longrightarrow$ Development Proposal Choice Model $\longrightarrow$ Predicted development projects

- development_template_components

- target_vacancies

- velocity_functions

\section{Figure 4-6 Input and Output of Development Proposal Choice Model}

\section{Building Construction Model (BCM)}

The Building Construction Model (BCM) constructs (adds) buildings based on projects selected by the Development Proposal Choice Model and the velocity functions that specify the rate at which development occurs. It uses a customized algorithm to load development projects, compare them to time-tables specified in velocity functions, and to add records to the building dataset with an appropriate quantity of the development within each project.

The output of the BCM is to add records to this buildings dataset; the inputs have buildings, development projects, and velocity functions. The data tables used by the BCM are given in Table 4-3. 
- buildings

- velocity_functions $\longrightarrow$ Building Construction Model $\longrightarrow$ added buildings

\section{Figure 4-7 Input and Output of Building Construction Model}

\section{Household Transition Model (HTM)}

The Household Transition Model (HTM) predicts new households migrating into the region, or the loss of households, migrating out of the region. The model compares the total number of households (possibly by type) in the households table at the beginning of a simulation year, to the total number of households (by type) specified by the user in the annual household control totals for that year. If the control total value is higher, the model adds the necessary number of households to the household table by sampling existing households (of the same type) and duplicating them. If the control totals indicate a declining household count (by type) then the appropriate number of households in the data are selected at random and removed. The role of this model is to keep the household data in the simulation synchronized with aggregate expectations of population and households. Note that the model can be configured by the user's choice of specification of the annual control totals. If no household characteristics are included in the control totals, then the synchronization is done for the total number of households. Otherwise it is done by the categories present in the control totals.

- annual_household_control_totals

- households

- persons

Household Transition Model $\longrightarrow$ added/removed households

Figure 4-8 Input and Output Household Transition Model

\section{Employment Transition Model (ETM)}

The Employment Transition Model predicts new jobs being created within, or moved to, the region by businesses, or the loss of jobs from businesses in the region - either through 
downsizing, closure of a business, or relocation out of the region. The model compares the total number of jobs by sector in the jobs table at the beginning of a simulation year to the total number of jobs by sector specified by the user in the annual employment control totals for that year. If the control total value is higher, the model adds the necessary number of jobs to the jobs table by sampling existing jobs of the same sector and duplicating them. If the control totals indicate a declining job count for a sector, then the appropriate number of jobs in the data are selected at random and removed. The role of this model is to keep the jobs data in the simulation synchronized with aggregate expectations of employment in the region. In most current applications, control totals are separately specified for each sector and split by a proportion that is assumed to be home-based employment vs. non-home-based employment. These two are handled by different model groups in the employment location choice model.

- annual_employment_control_totals

- jobs

Employment Transition Model $\longrightarrow$ added/removed jobs

Figure 4-9 Input and Output of Employment Transition Model

\section{Household Relocation Model (HRM)}

The Household Relocation Model predicts the relocation of households within the region during each simulation year. The Household Relocation Model is implemented as a cross-classification rate-based model, with a probability of moving by age and income category applied to each household in the synthetic population, each simulation year. The outcome of the model is implemented as follows: If a household is determined to be a mover because the random draw is greater than 1 (their move probability), then they are moved out of their current location. In practical terms, their "building_id", which identifies where they are located, is simply reset to a null value. They remain in the household table but do not have a location.

- annual_household_relocation_rates

- households

Household Relocation Model probability of a household relocation

Figure 4-10 Input and Output of Household Relocation Model 


\section{Household Location Choice Model (HLCM)}

The Household Location Choice Model predicts the probability that a household that is either new (from the transition component) or has decided to move within the region (from the mobility component), will choose a particular location defined by a residential building. The form of the model is specified as multinomial logit, with random sampling of alternatives from the universe of available (vacant) housing units, including those units vacated by movers in the current year. Once a household has chosen a location, that location is committed to the household (like a rental contract or closing on a purchase of a house) and the residential unit becomes unavailable for any other households until the time that the occupying household is predicted to move.

The independent variables can be organized into housing characteristics, regional accessibility, and urban-design scale effects, including prices (interacted with income), development types (density, land use mix), housing age, job accessibility by auto-ownership group, travel time to CBD/airport, neighborhood land use mix/density, and neighborhood employment.

- households

- builidngs

- zones

$\longrightarrow$ Household Location Choice Model $\longrightarrow$ location of each household

- travel_data

\section{Figure 4-11 Input and Output of Household Location Choice Model}

\section{Employment Relocation Model (ERM)}

The Employment Relocation Model predicts the relocation of households within the region during each simulation year. The model is implemented as a cross-classification rate-based model, with a probability of moving by employment sector applied to each job and each simulation year. The outcome of the model is implemented as follows: if a job is determined to be a mover because the random draw is greater than 1 (their move probability), then they are moved out of their current location. In practical terms, their "building_id", which identifies where they are located, is simply reset to a null value. They remain in the jobs table but do not have a location. 
- annual_job_relocation_rates

- jobs

Employment Relocation Model

probability of a job relocation

\section{Figure 4-12 Input and Output of Employment Relocation Model}

\section{Employment Location Choice Model (ELCM)}

The Employment Location Choice Model (ELCM) predicts the probability that a job that is either new (from the Economic Transition Model) or has moved within the region (from the Employment Mobility Model), will be located at a particular site. Buildings are used as the basic geographic unit of analysis in the current model implementation. Each job has an attribute of space it needs, and this provides a simple accounting framework for space utilization within buildings. The number of locations available for a job to locate within a building will depend mainly on the total square footage of nonresidential floor space in the building, and on the density of the use of space (square feet per employee). The model is specified as a multinomial logit model, with separate equations estimated for each employment sector.

The independent variables used in the employment location choice model can be grouped into the categories of real estate characteristics, regional accessibility, and urban-design scale effects, including prices, development type (land use mix, density), access to population, travel time to $\mathrm{CBD} /$ airport, and proximity to highway and arterials.

- jobs

- employment_sectors

- buildings

$\longrightarrow$ Employment Location Choice Model $\longrightarrow$ location of each job

- zones

- travel_data

Figure 4-13 Input and Output of Employment Location Choice Model

\subsection{Model Specifications}

Three sub-models, including the Real Estate Price Model, Household Location Choice Model, and Employment Location Choice Model, can be re-estimated by users based on local data. In 
this study, the three aforementioned sub-models were used with the system default specifications due to the following reasons:

- The data sets for model calibration need "real" geographic data, demographic data, and employment data at the parcel level. These data are usually derived from surveys to collect samples of households, jobs, and buildings. It is difficult to obtain the "real" data in Hillsborough County. In particular, the location information is required at the parcel level and the historic price information is required at the building level. This information could not be obtained from the current travel survey.

- The base year data (2010) contains many synthesized data, for example, households and buildings. The matching algorithm between these data was randomly assigned (households-to-buildings, jobs-to-buildings, etc.) because the marginal distributions were unavailable. Thus, the base year data could not be used for model estimation.

Thus, the system default model specifications and coefficients were used in this study.

\subsection{UrbanSim Model Assembly and Debug}

After preparing base year data and configuring model specifications, the UrbanSim model was assembled in the Open Platform for Urban Simulation (OPUS) platform. The process of model assembly is given as follows:

- Install the UrbanSim/OPUS platform on computers

- Test the UrbanSim/OPUS platform using the sample dataset

- Import the base year data and model specifications

- Create the base year scenario

- Debug the UrbanSim model

\section{Install UrbanSim}

The UrbanSim package is powered by Python and its math library has been run and tested on Windows, Linux, and Mac OS X systems. The current version is 4.4 and can be downloaded from www.urbansim.org. In this study, the UrbanSim package for Windows 64-bit was used to 
simulate the land use in Hillsborough County. Since no binary installer for 64-bit Windows is available, all supporting packages were installed manually.

\section{Test with Sample Dataset}

To ensure the installed UrbanSim package was fully functional, a sample dataset provided by the authors was used to test the installed UrbanSim.

\section{Import the base year data and model specifications}

A parcel-based UrbanSim project was created based on a project template, as shown in Figure 414. The template defines the project directory, variable library, and model templates as XML files. These configurations were revised according to the needs in this study.

When the project was created, the prepared data tables (as shown in Section 3.11) were imported in the project using the UrbanSim CSV importing tool, as shown in Figure 4-15.

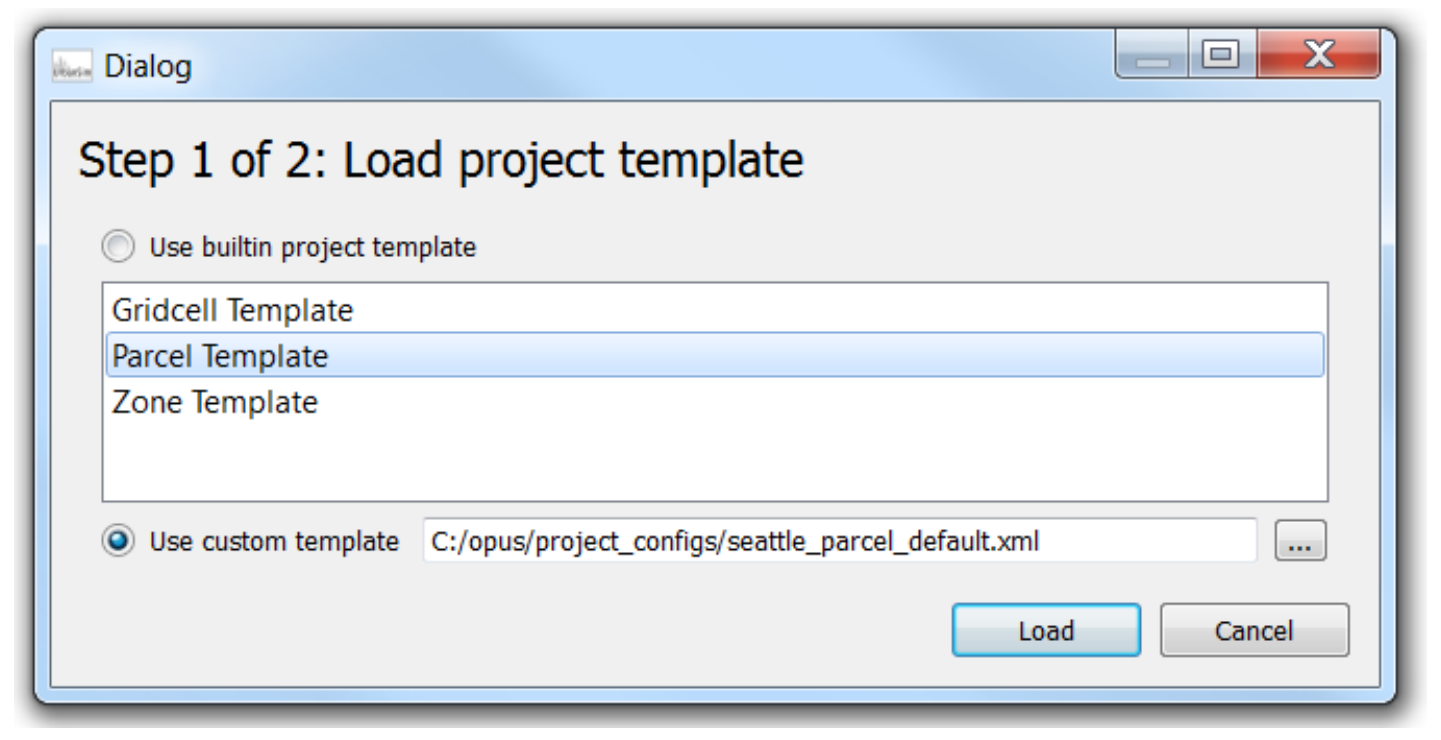

Figure 4-14 Create Parcel-Based UrbanSim Project 


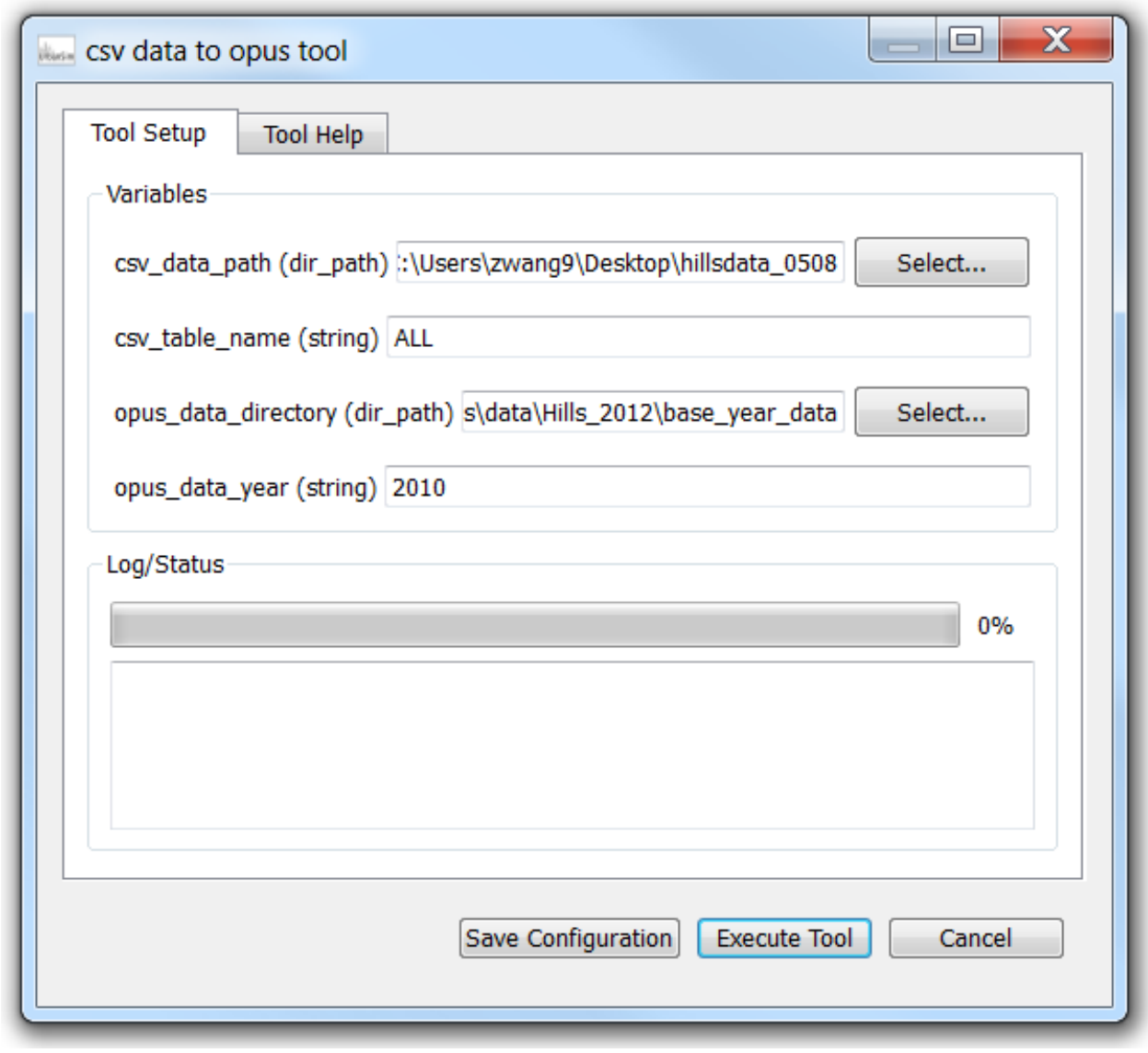

Figure 4-15 CSV Data Importing Tool 


\section{Create Base Year Scenario}

After importing data and models, researchers selected and specified the ten sub-models in UrbanSim, as shown in Figure 4-16. This scenario was used as the baseline to create new scenarios.

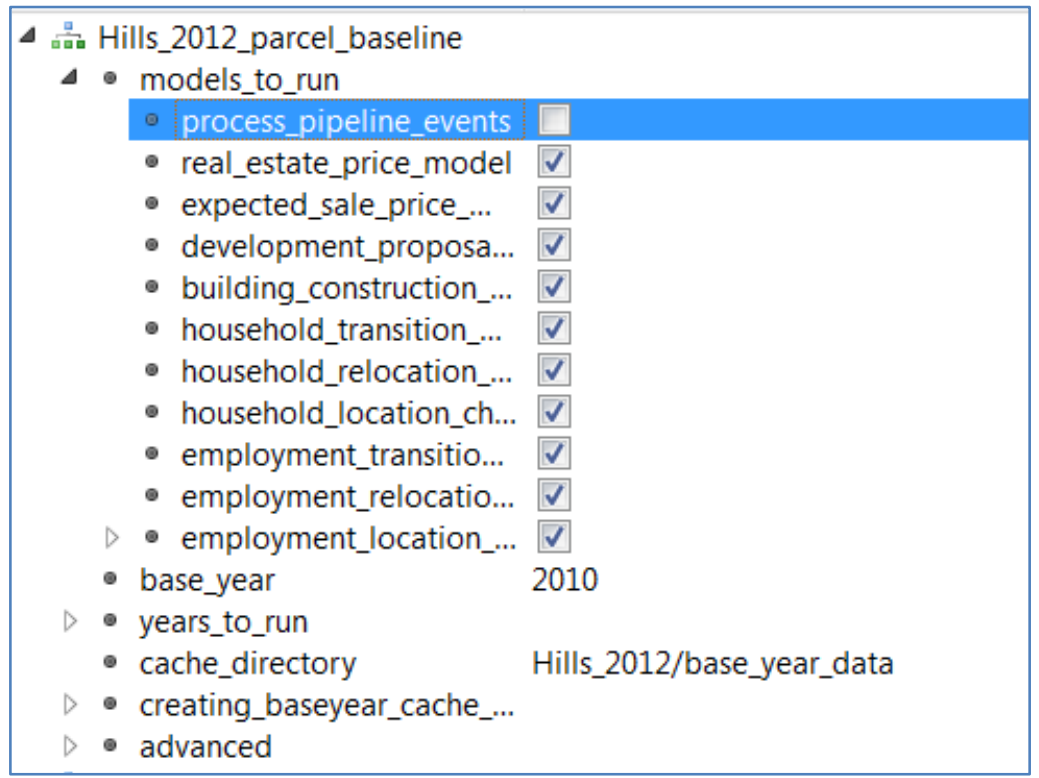

\section{Figure 4-16 Base Year Scenario}

\section{Debug UrbanSim Model}

The developed UrbanSim Model was tested using the base year scenario (2010). It was a challenging task because UrbanSim is an open source platform and still in development. Unlike commercial software, lack of documents and technical support was an obstacle in implementation. In addition, UrbanSim has high requirements for data formatting and error messages are weak in assisting users to address errors. Researchers had to spend a significant amount of time to add the data tables and models one by one to address the errors using exclusive methods.

Finally, all bugs were eliminated from the UrbanSim model. The base year scenario was ready for validation. 


\section{MODEL VALIDATION}

Model validation was conducted to verify the simulation accuracy based on the scenarios of the base year (2010) and forecasted years (2016 and 2020). For validation purposes, the assembled UrbanSim model was run with the scenarios, and the associated traffic patterns were generated by the TBRPM model. The forecasted number of households was compared with the number of households which were projected in the 2035 LRTP on the study zones. The comparisons with the number of households were made for the years of 2010 (Base Year), 2016, and 2020.

The zonal population was compared between the simulation in UrbanSim prediction and the projection in the 2035 LRTP. The comparison process is given as follows:

\section{Produce household projection}

In the 2035 LRTP, zonal population projections are available in 2006 and 2025. The target years of validation are 2010, 2016, and 2025. The zonal household projections for the three years were calculated by

Zonal Households for Target Year $=$

$\left\{\frac{\text { Target Year-2006 }}{2025-2006} \times(\right.$ Zonal Population for $2025-$ Zonal Population for 2006) + Zonal Population for 2006\}/2.55

\section{Prepare scenarios}

The base year (2010) scenario was created during data collection and model assembly. Two new scenarios (2016 and 2020) were created based on the base scenario. Since socioeconomic and demographic data were controlled by two data tables: ANNUAL_EMPLOYMENT_CONTROL_TOTALS and ANNUAL_HOUSEHOLD_CONTROL_TOTALS, only traffic patterns needed to be revised. The TBRPM model was executed for 2016 and 2020 using the method described in Section 3-10. The traffic patterns were imported into the UrbanSim model to produce the scenarios for 2016 and 2020. 


\section{Generate household indicator}

The scenarios were executed, and the population indicators were created, to aggregate households from parcels to zones based on the running results.

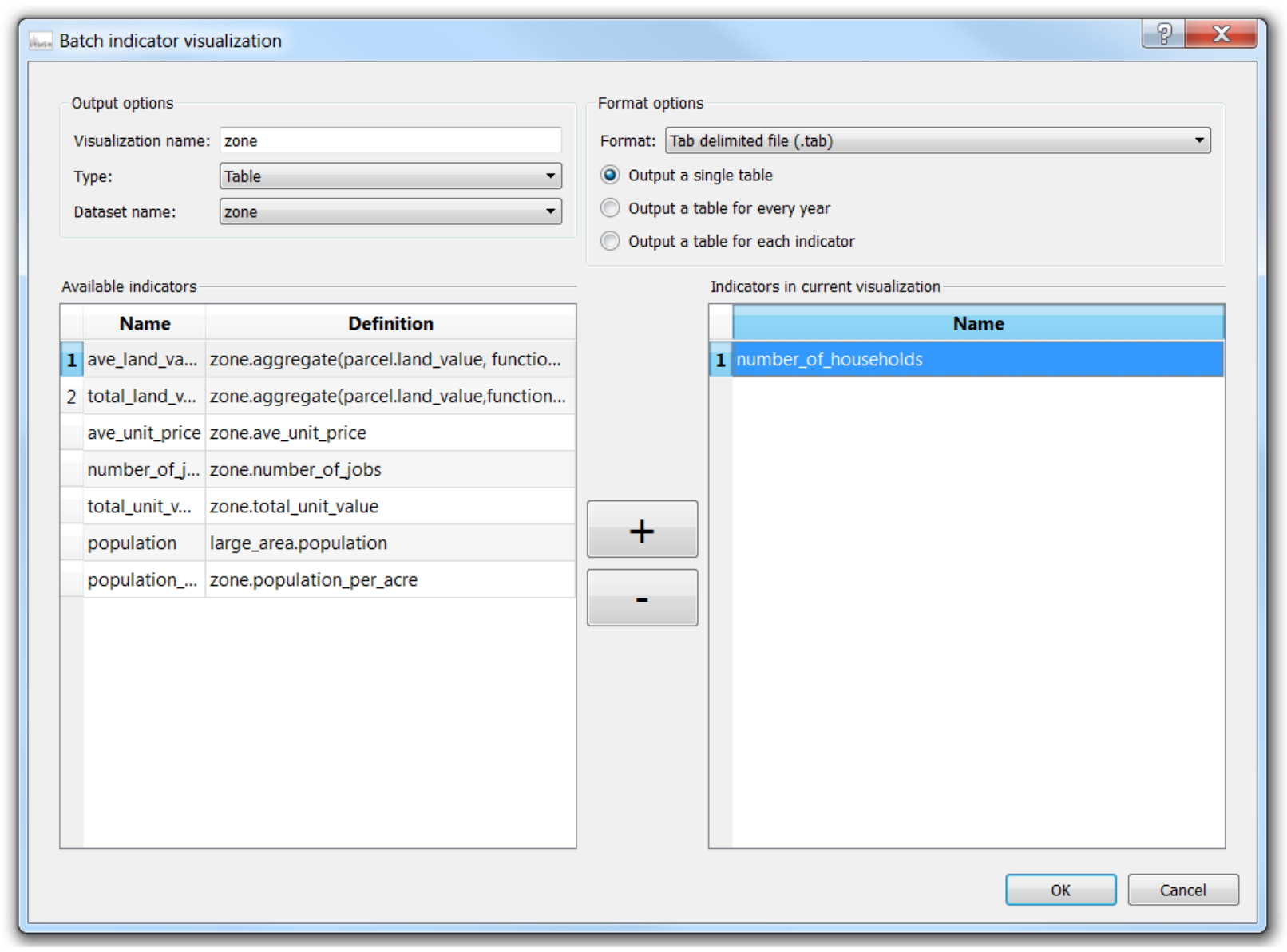

Figure 5-1 UrbanSim Indicators

IV. Calculate cumulative percentage of household difference between 2035 LRTP and UrbanSim

The zonal households predicted by UrbanSim were compared to those produced from the 2035 LRTP. Since the control totals are the same as those adopted in the 2035 LRTP, the total population number from UrbanSim was very close to that of the socioeconomic and demographic data for the 2035 LRTP. The cumulative percentage of TAZs is graphed against the household differences between UrbanSim forecasts and the 2035 LRTP (Difference $=$ Households in UrbanSim - Households in LRTP) in Figure 5-2. This study found that the differences of zonal households between UrbanSim and the LRTP are very similar for the three 
years. The errors at the zonal level range from -200 to 200 and represent over 70 percent of the TAZs. The spatial distributions of zonal household differences in the study zones for 2010, 2016, and 2020 are shown in Figures 5-3, 5-4, and 5-5 respectively.

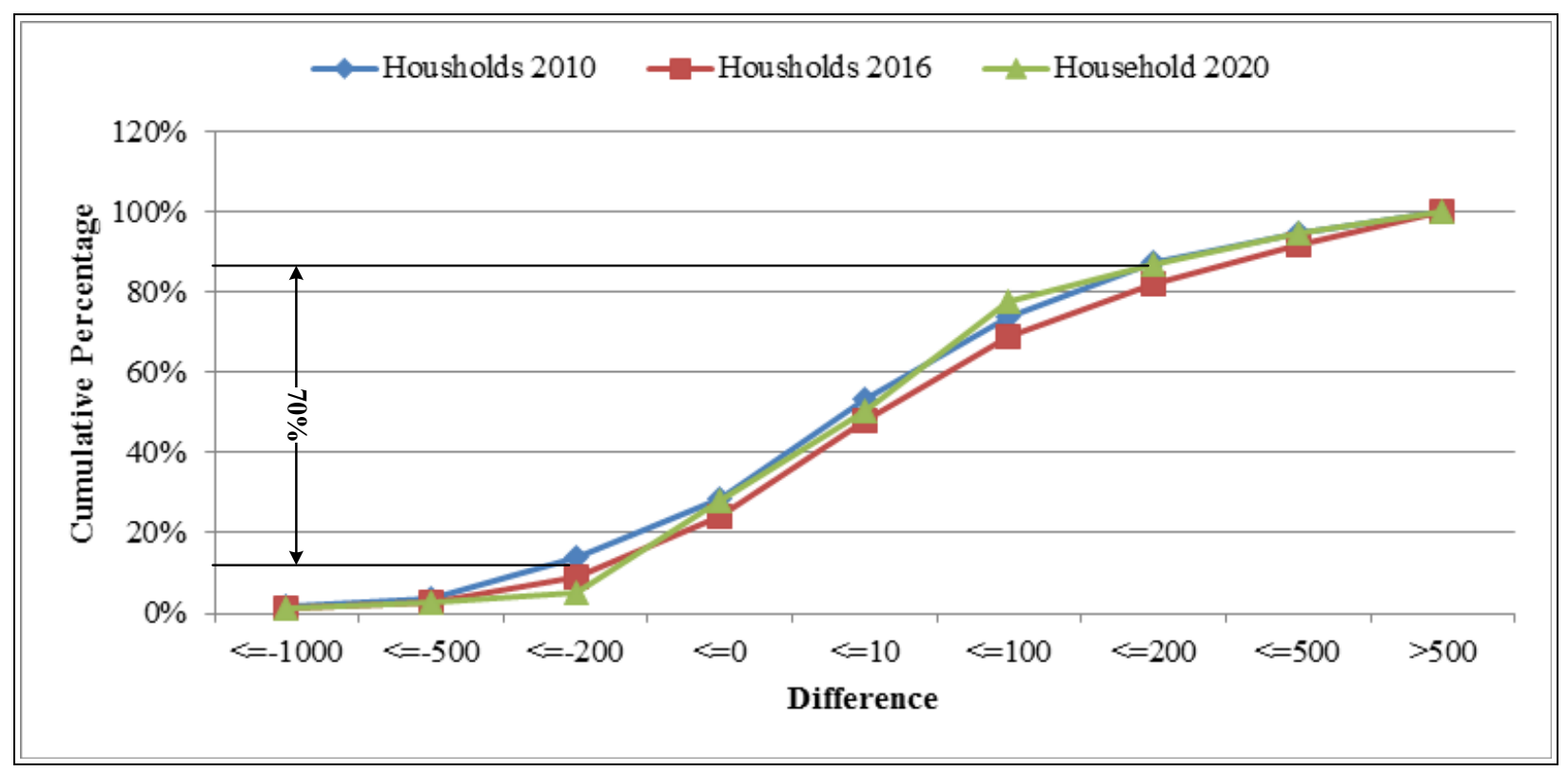

Figure 5-2 Cumulative Percentage of Household Difference 


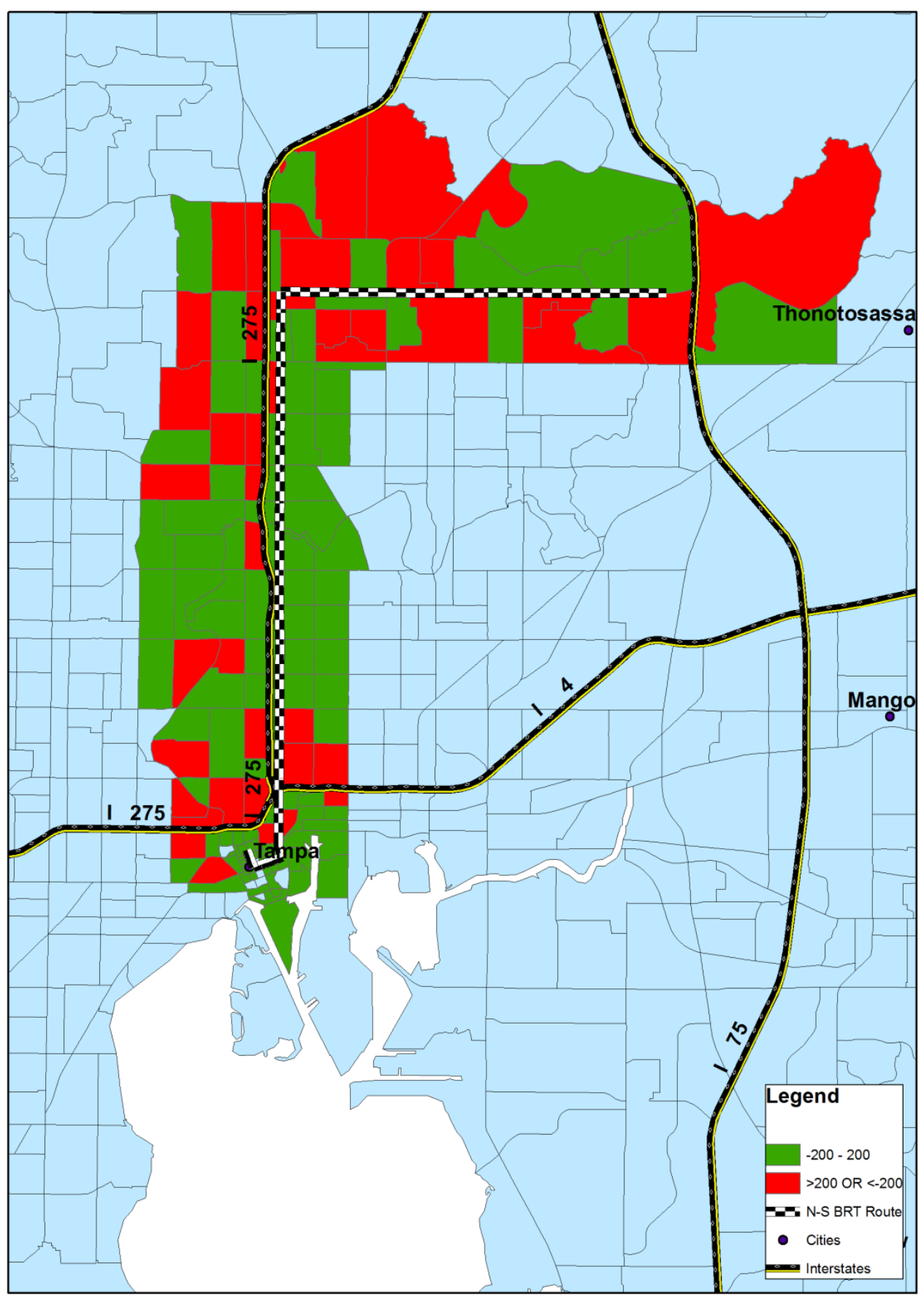

Figure 5-3 Zonal Household Difference between UrbanSim and 2035 LRTP in 2010 


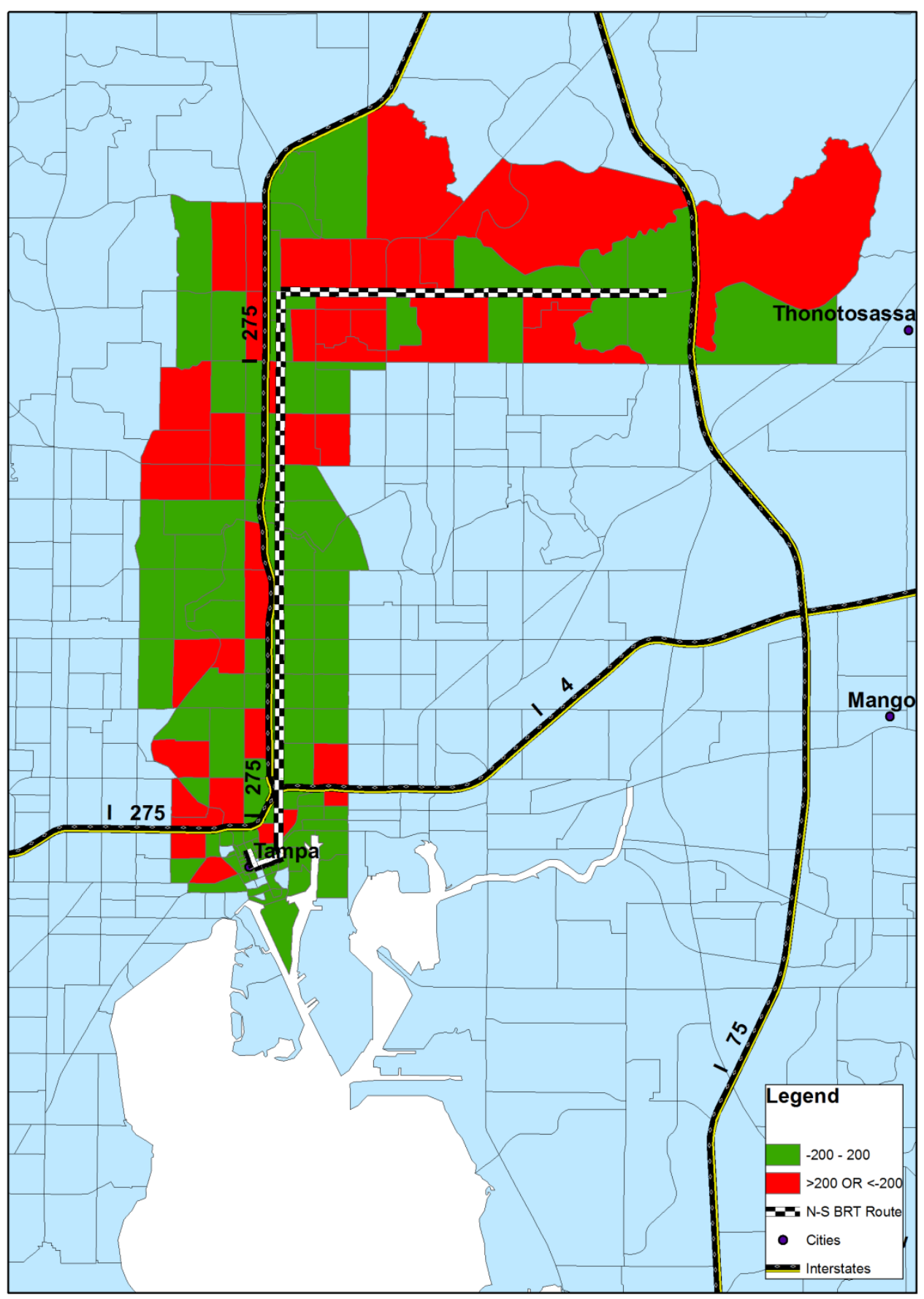

Figure 5-4 Zonal Household Difference between UrbanSim and 2035 LRTP in 2016 


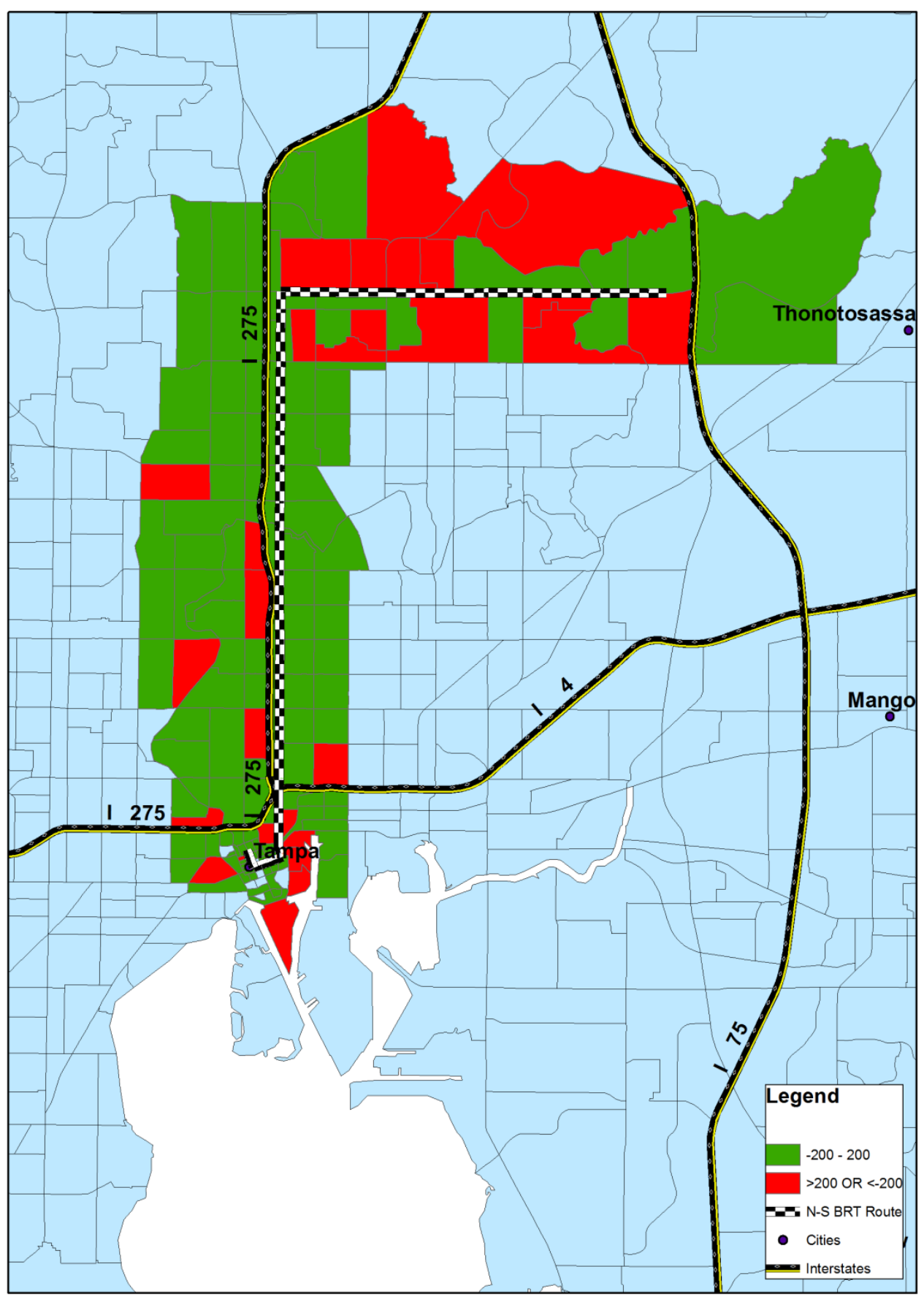

Figure 5-5 Zonal Household Difference between UrbanSim and 2035 LRTP in 2020 


\section{SCENARIO TESTING (BRT)}

The objective of this study is to evaluate the impact of a proposed transit investment on the land use pattern using the developed UrbanSim model. The HART North-South BRT route was selected for evaluation. The basic idea was to compare the land use pattern of the study area with and without implementing the BRT route. Accessibility is a significant factor influencing a person's choices on the location of their household and employment. Implementation of the BRT route may attract more persons to take trips by transit systems, rather than by auto; this attraction, consequently, changes the traffic pattern and the accessibility of properties in its influence area. Thus, land use patterns, such as populations, households, employments, and/or land prices, are impacted by introducing a BRT route.

The typical method of obtaining a change in traffic patterns due to implementing a transit route is using the travel planning model to forecast the ridership of the transit route. However, the BRT mode is not available in current versions of transportation planning models for Hillsborough County, in either TBRPM or TBEST. Thus, the research team assumed that the BRT route attracts a certain percentage of trips from auto mode and compared the land use patterns between the scenario with the BRT service and the scenario without the BRT service. Four scenarios were created and examined as follows:

- Scenario 1: The BRT route with a one percent trip attraction in a short-period projection (2012)

- Scenario 2: The BRT route with a five percent trip attraction in a short-period projection (2012)

- Scenario 3: The BRT route with a one percent trip attraction in a long-period projection (2020)

- Scenario 4: The BRT route with a five percent trip attraction in a long-period projection (2020) 


\subsection{Scenario 1 (The BRT route with a one percent trip attraction in a short-period projection)}

In Scenario 1, it was assumed that the BRT route attracted one percent of trips from the auto mode within the study zones. The following variables representing accessibility were recalculated based on the BRT attraction:

Weighted average zonal traffic time:

Traffic Time for Zone $i=\frac{\sum_{j=1}^{J} \text { (Trips for I to } \mathrm{j} \times \text { Traffic Time for I to } \mathrm{j} \text { ) }}{\sum_{j=1}^{J} \text { Trips for } i \text { to } j}$

$\mathrm{i} \neq \mathrm{j}, \mathrm{J}=$ Number of Zones

Weighted average zonal HBW traffic time:

Traffic Time for Zone $i=\frac{\left.\sum_{j=1}^{J} \text { (HBW Trips for } \mathrm{i} \text { to } \mathrm{j} \times \text { Traffic Time for } \mathrm{i} \text { to } \mathrm{j}\right)}{\sum_{j=1}^{J} \text { HBW Trips for } i \text { to } j}$

$\mathrm{i} \neq \mathrm{j}, \mathrm{J}=$ Number of Zones

Weighted average zonal NHBW traffic time:

Traffic Time for Zone $i=\frac{\left.\sum_{j=1}^{J} \text { (NHBW Trips for } \mathrm{i} \text { to } \mathrm{j} \times \text { Traffic Time for } \mathrm{i} \text { to } \mathrm{j}\right)}{\sum_{j=1}^{J} \text { NHBW Trips for } i \text { to } j}$

$\mathrm{i} \neq \mathrm{j}, \mathrm{J}=$ Number of Zones

Weighted average zone-to-CBD traffic time:

Traffic Time for Zone $i=\frac{\left.\sum_{j=1}^{J} \text { (Trips for } \mathrm{i} \text { to } \mathrm{j} \times \text { Traffic Time for } \mathrm{i} \text { to } \mathrm{j}\right)}{\sum_{j=1}^{J} \text { Trips for } i \text { to } j}$

$\mathrm{i} \neq \mathrm{j}, \mathrm{j} \in$ CDB Zones, $\mathrm{J}=$ Number of CBD Zones 
Weighted average zone-to-AirPort traffic time:

Traffic Time for Zone $i=\frac{\sum_{j=1}^{J} \text { (Trips for } \mathrm{i} \text { to } \mathrm{j} \times \text { Traffic Time for } \mathrm{i} \text { to } \mathrm{j} \text { ) }}{\sum_{j=1}^{J} \text { Trips for } i \text { to } j}$

$$
\mathrm{i} \neq \mathrm{j}, \mathrm{j} \in \text { Air Port Zones, } \mathrm{J}=\text { Number of Air Port Zones }
$$

Based on the original traffic pattern data, the trips from zone $i$ to zone $j$ were reduced by one percent. The variables were recalculated by substituting the new zonal trips, and a new traffic pattern data table was produced. The new traffic table was imported into the UrbanSim model to create a scenario with the impact of BRT. (Note: only the zones within the study area were recalculated in this study) The UrbanSim model ran for the target year (2012) and the land use patterns were extracted from the model output (indicators) as follows:

- Zonal Population

- Zonal Household

- Zonal Jobs

- Zonal Unit Price

The four measures with the BRT impact were compared with those without the BRT impact and summarized in Figure 6-1. 

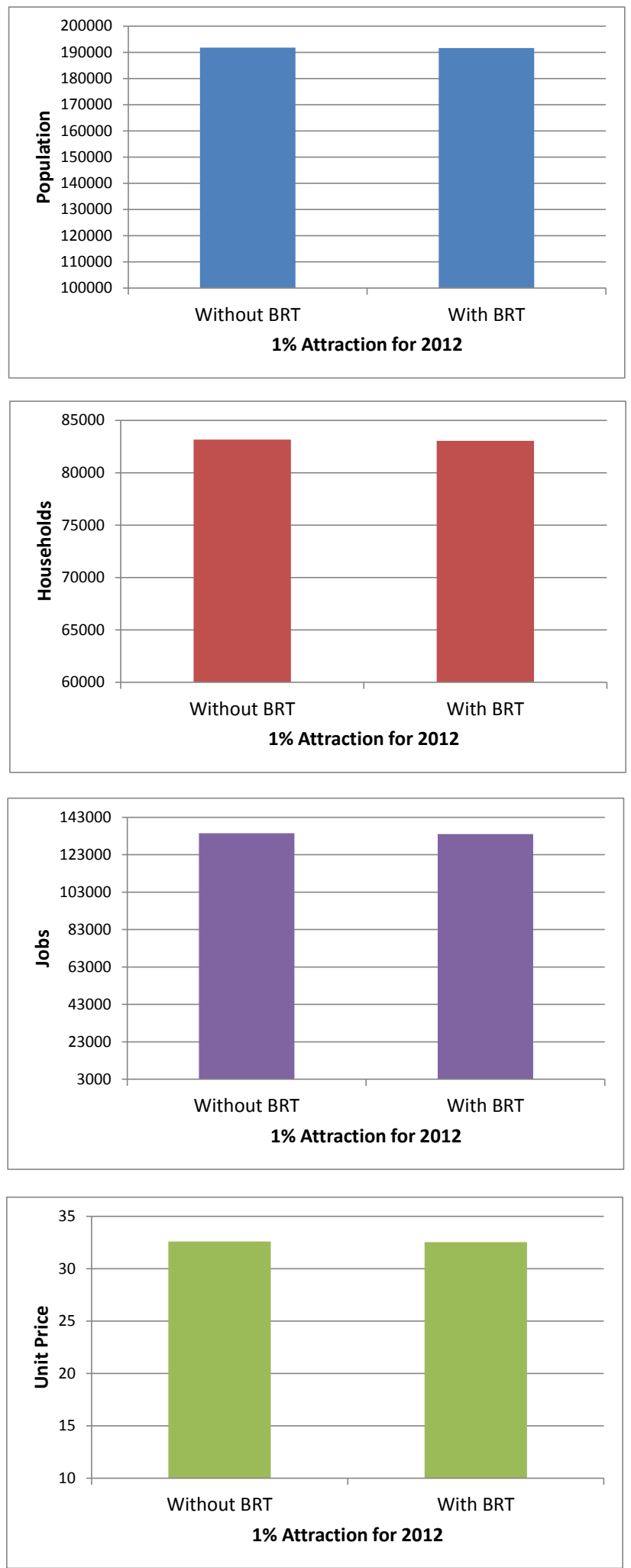

Figure 6-1 Land Use Patterns With and Without Implementation of BRT (1\% Trip Attraction) in 2012 
Figure 6-1 shows that implementing the BRT route (assuming 1\% trip attraction) had no significant impact on land use patterns in the study zones in 2012. The population, households, jobs, and unit price were almost equal (difference $<1 \%$ ) with and without implementing the BRT route with 1\% trip attraction in a short-term period (2010-2012).

The spatial difference of land use patterns (population, household, jobs) due to implementing the BRT service in 2012 is shown in Figures 6-2 to 6-5. The calculation equation is given as:

$$
\text { Difference }=\text { Measure with BRT }(x \% \text { Trip Attraction })-\text { Measure without BRT }
$$

where $\mathrm{x}=1$ or 5

The variety of population, households, and jobs due to the BRT service is complex: the measures may increase in some zones, decrease in other zones, or remain constant with and without implementing the BRT service. The measure of unit price is the same in a great portion of the zones with and without the BRT service. 


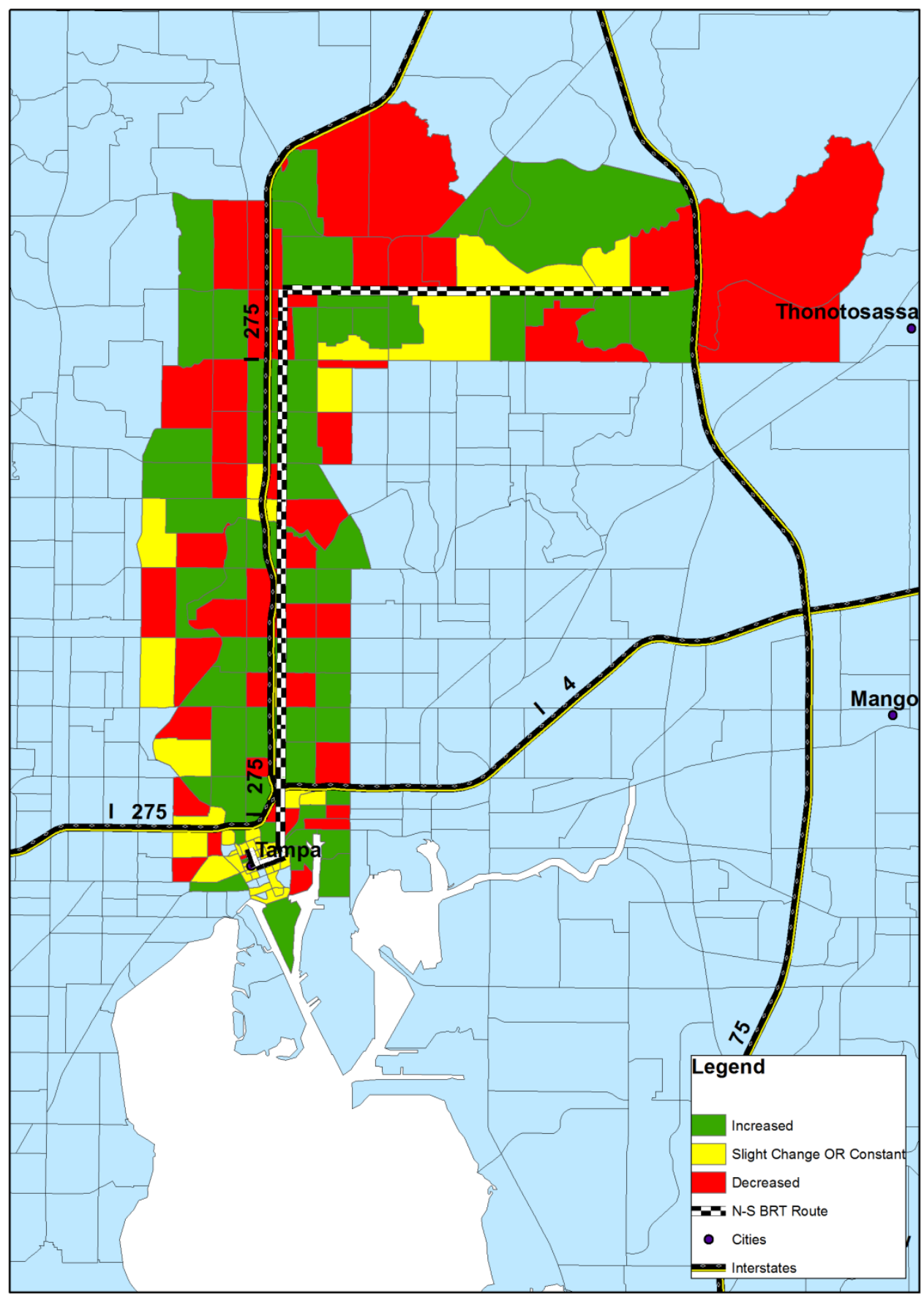

Figure 6-2 Zonal Change in Population due to Implementation of BRT (1\% Trip Attraction) in 2012 


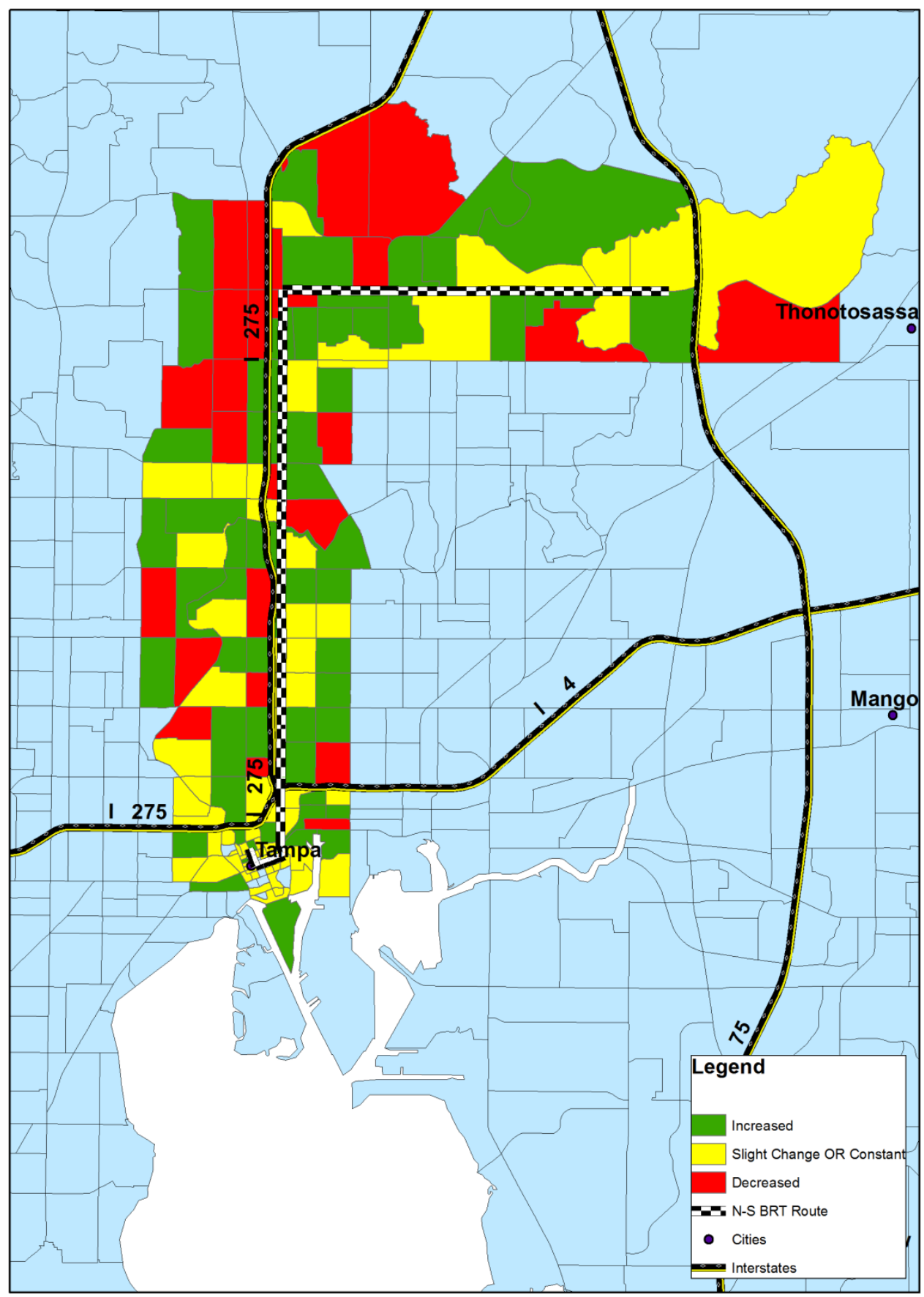

Figure 6-3 Zonal Change in Households Due to Implementation of BRT (1\% Trip Attraction) in 2012 


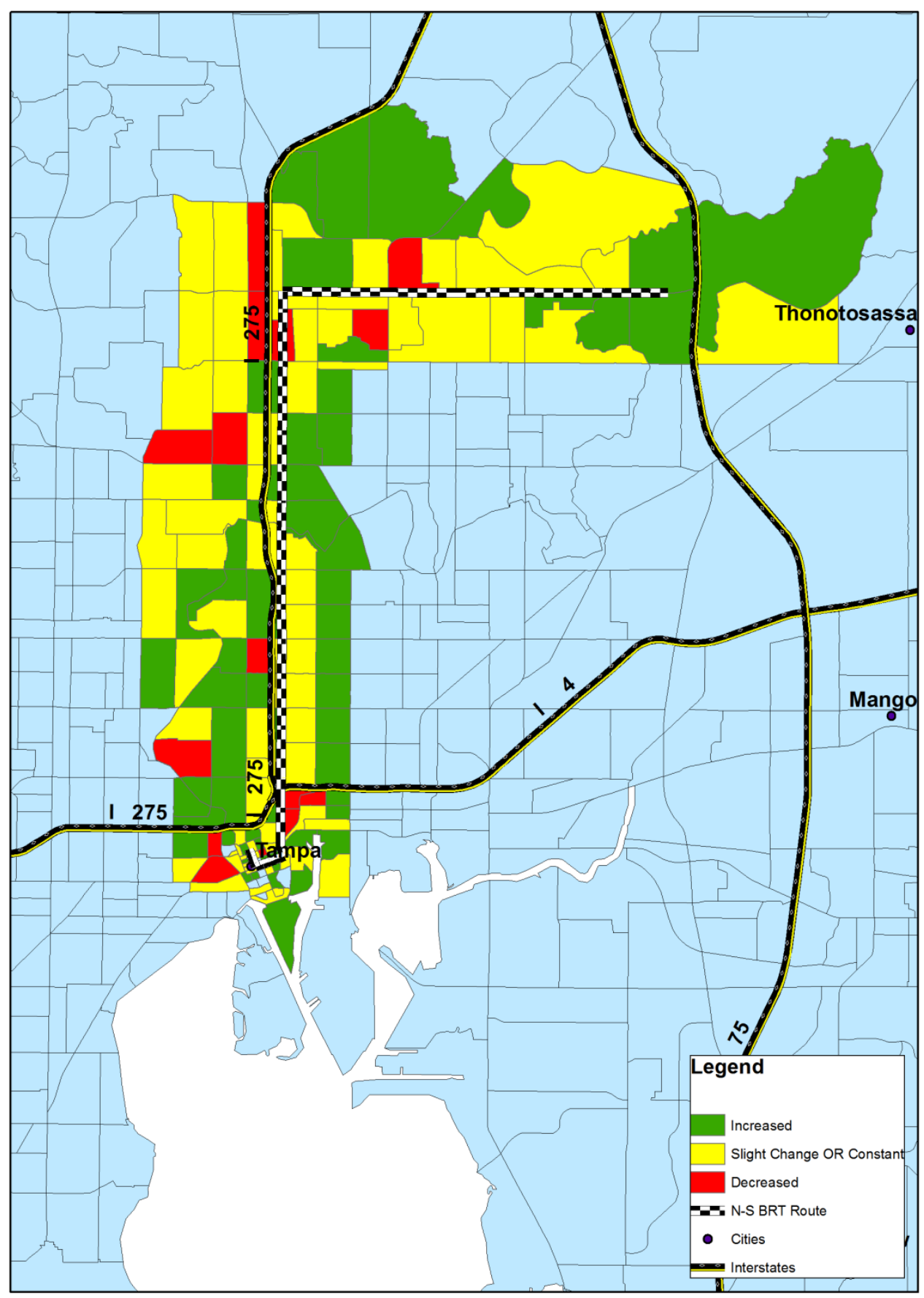

Figure 6-4 Zonal Change in Jobs due to Implementation of BRT (1\% Trip Attraction) in 2012 


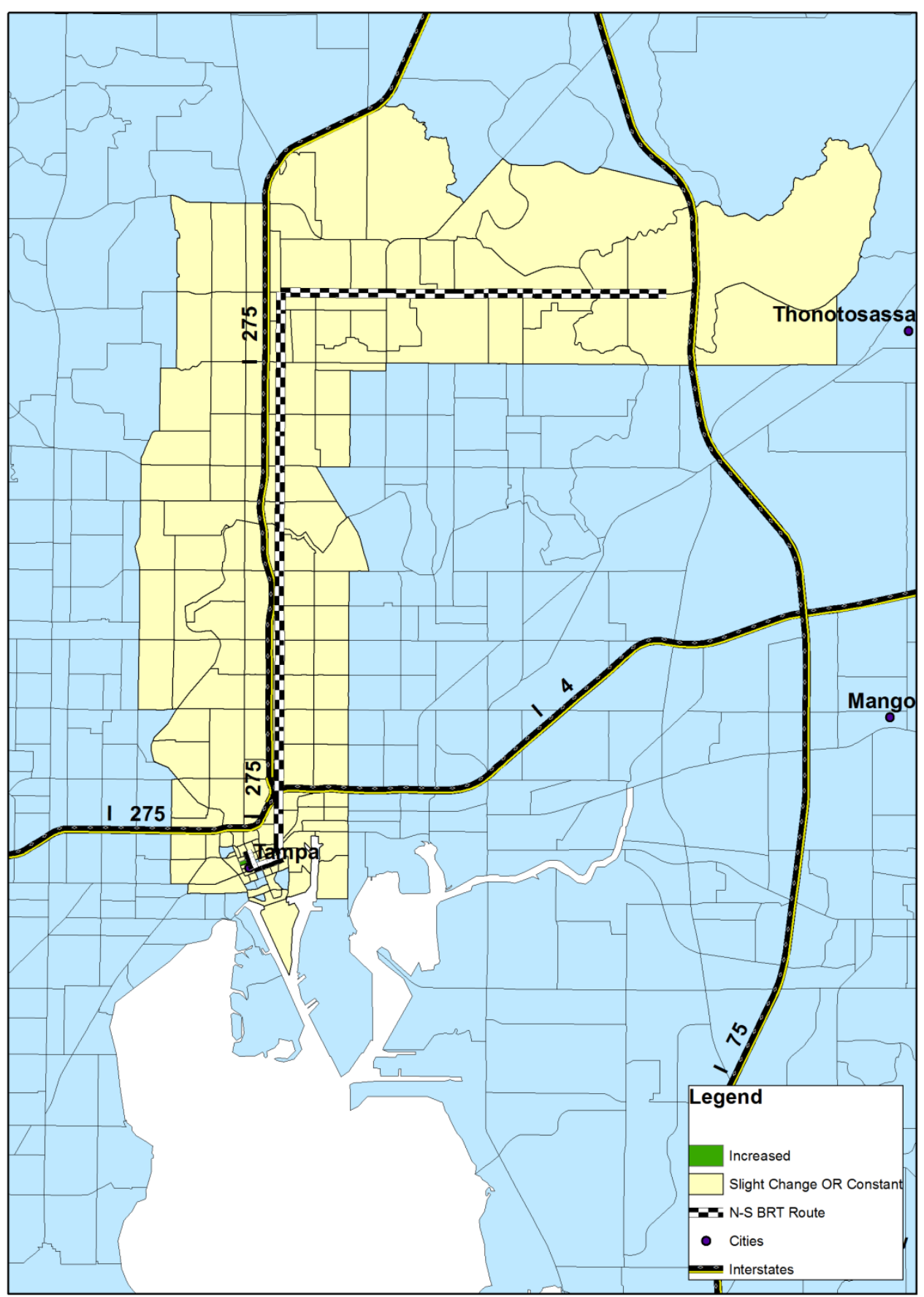

Figure 6-5 Zonal Change in Unit Price due to Implementation of BRT (1\% Trip Attraction) in 2012 


\subsection{Scenario 2 (The BRT route with a five percent trip attraction in a short-period projection)}

The 2012 traffic patterns were revised using the method described in Section 6.1 assuming that the BRT route attracted five percent of trips from auto trips within the study zones. The scenario of the BRT with a five percent trip attraction in a short-period projection (2010-2012) was created and examined using the UrbanSim model. The comparison of population, households, jobs, and unit price with and without implementation of the BRT route (5\% trip attraction) for 2012 is shown in Figure 6-6. 

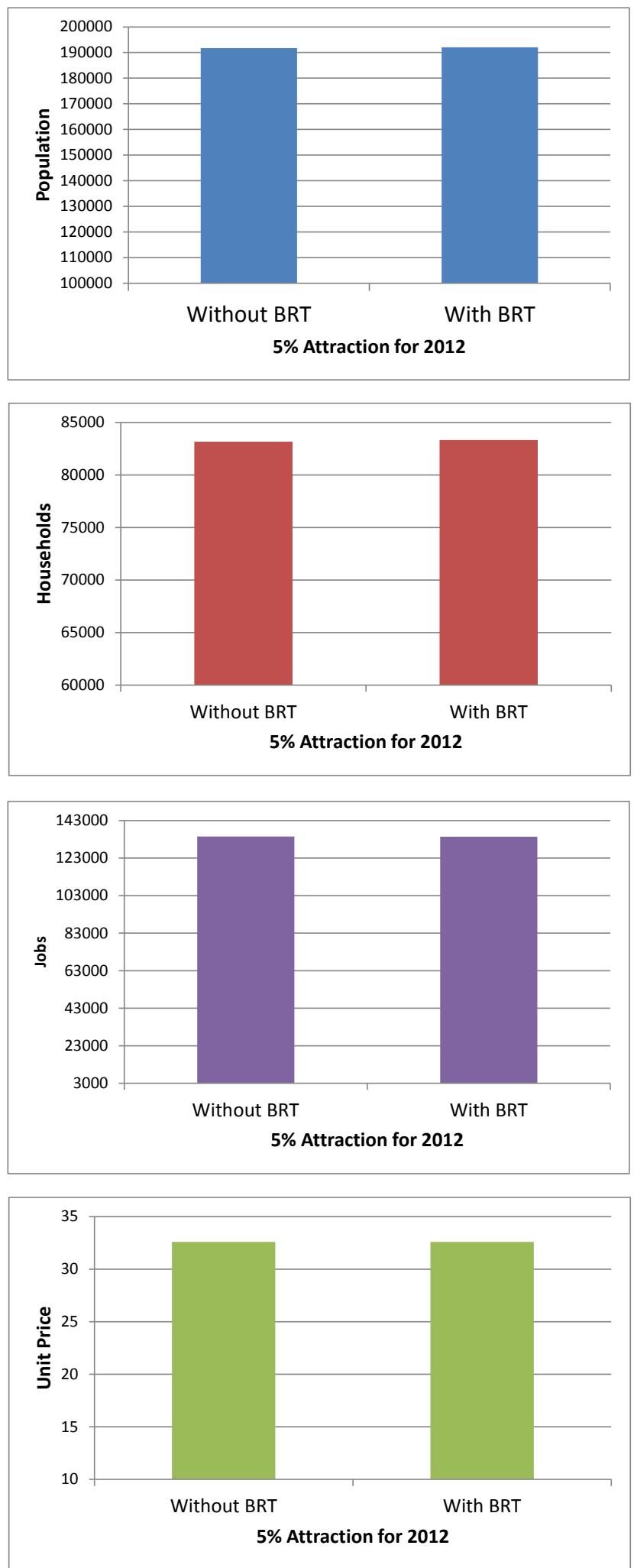

Figure 6-6 Land Use Patterns With and Without Implementation of BRT (5\% Trip Attraction) in 2012 
Figure 6-6 shows that implementation of the BRT route increases population and households in the study zones in 2012; however, the increase is very small and can be ignored (the population increases by $0.1 \%$, and the households increase by $0.2 \%$ ). The jobs and unit price with and without implementation the BRT route with 5\% trip attraction are almost equal.

The spatial changes in zonal population, households, and jobs due to the BRT service are displayed in Figures 6-7 to 6-10. It can be seen that with a five percent trip attraction, there are more zones that have an increase in population, households, jobs, and housing unit price than the zones with a one percent trip attraction. It can also be seen that with a five percent trip attraction, the number of zones that have a decrease in population, households, jobs and land unit price is less than those with one percent trip attraction. . 


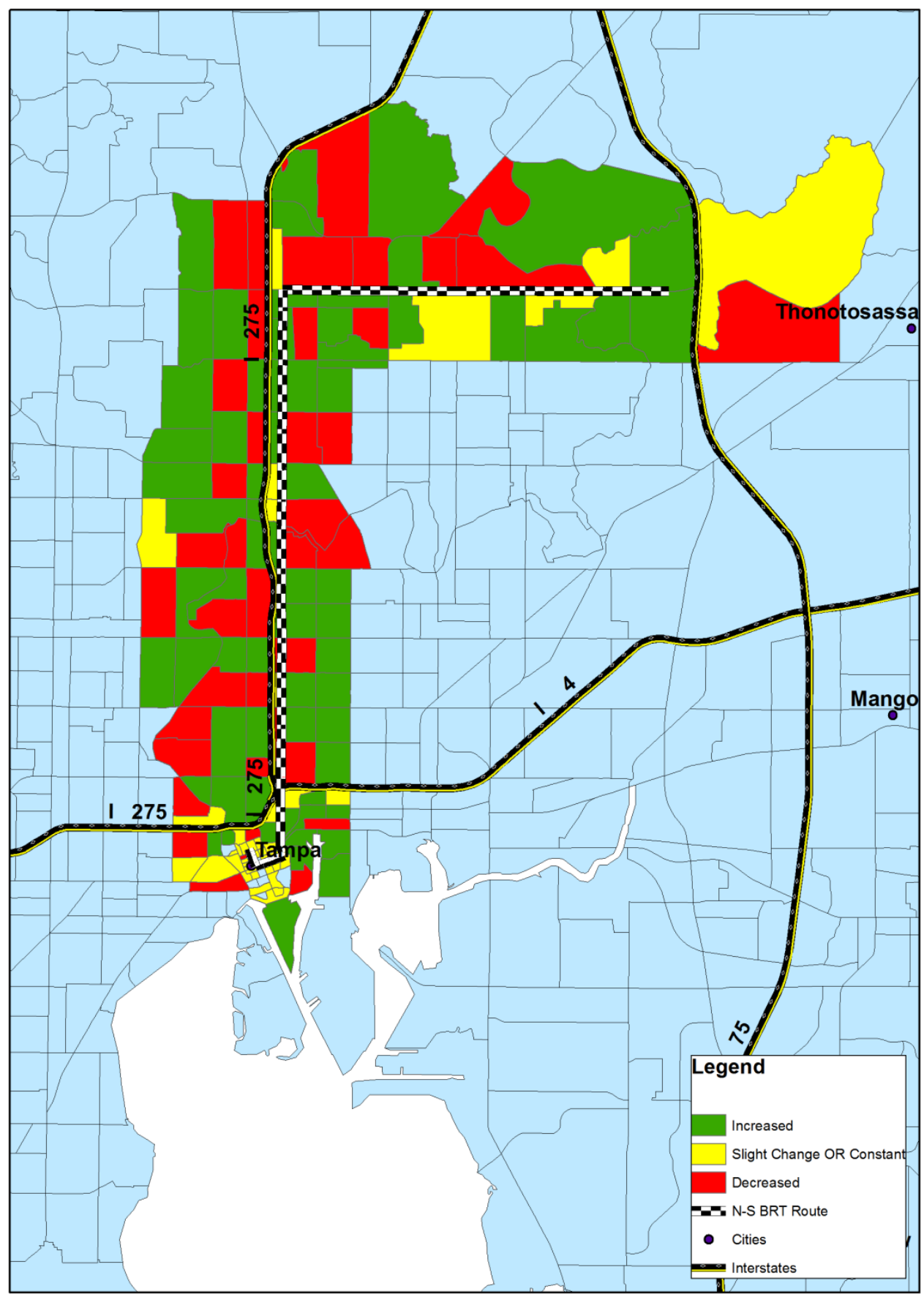

Figure 6-7 Zonal Change in Population due to Implementation of BRT (5\% Trip Attraction) in 2012 


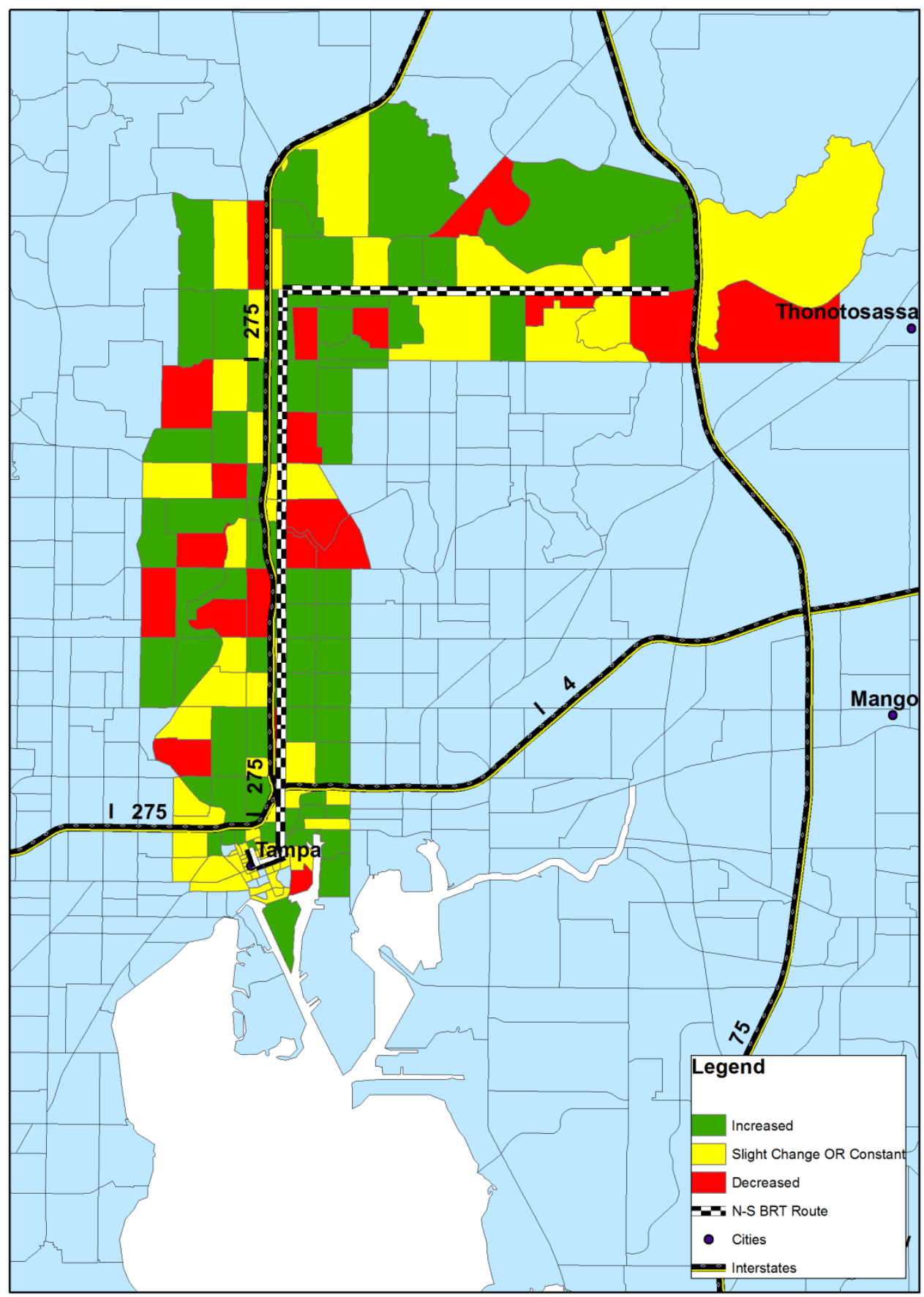

Figure 6-8 Zonal Change in Households due to Implementation of BRT (5\% Trip Attraction) in 2012 


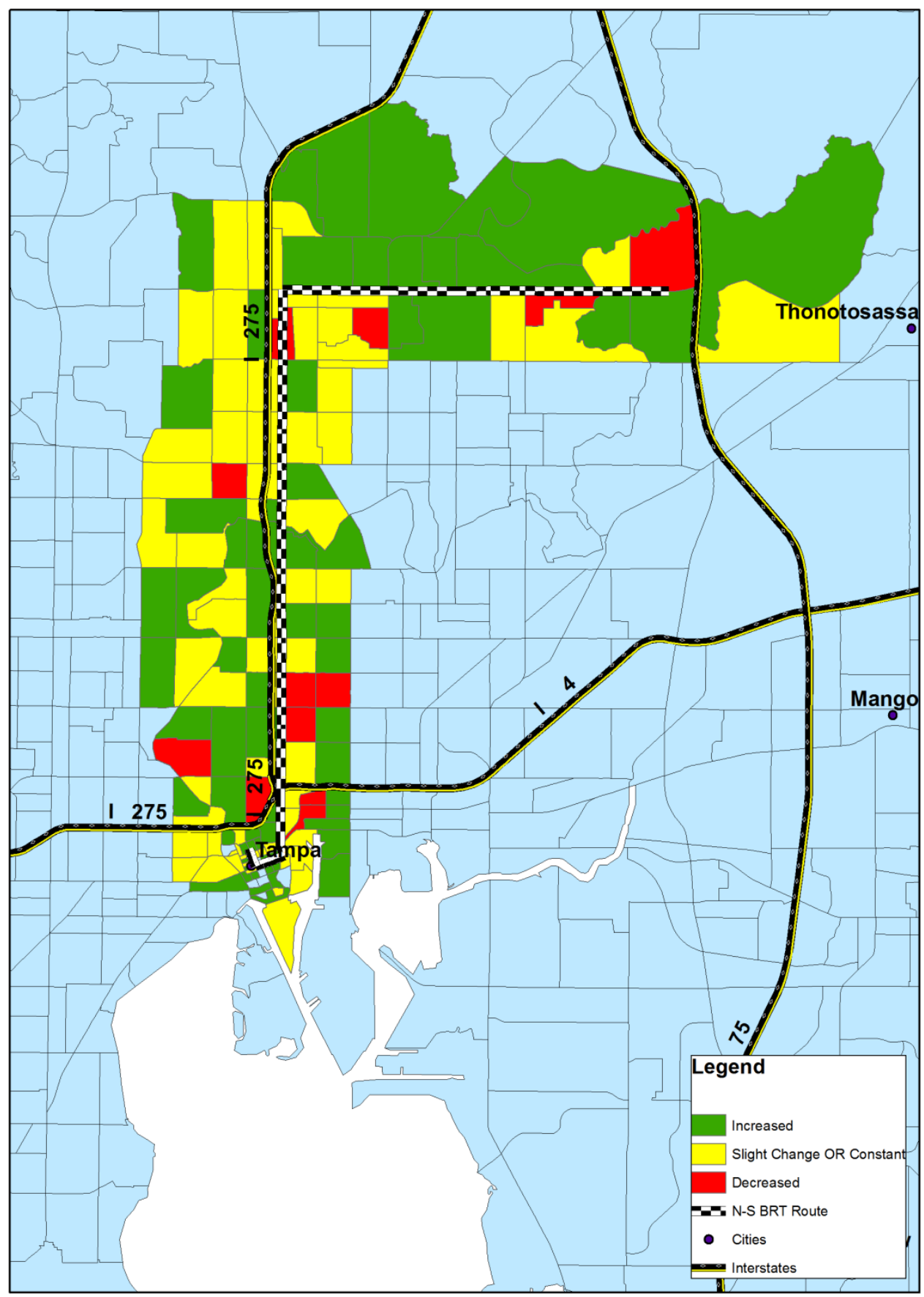

Figure 6-9 Zonal Change in Jobs due to Implementation of BRT (5\% Trip Attraction) in 2012 


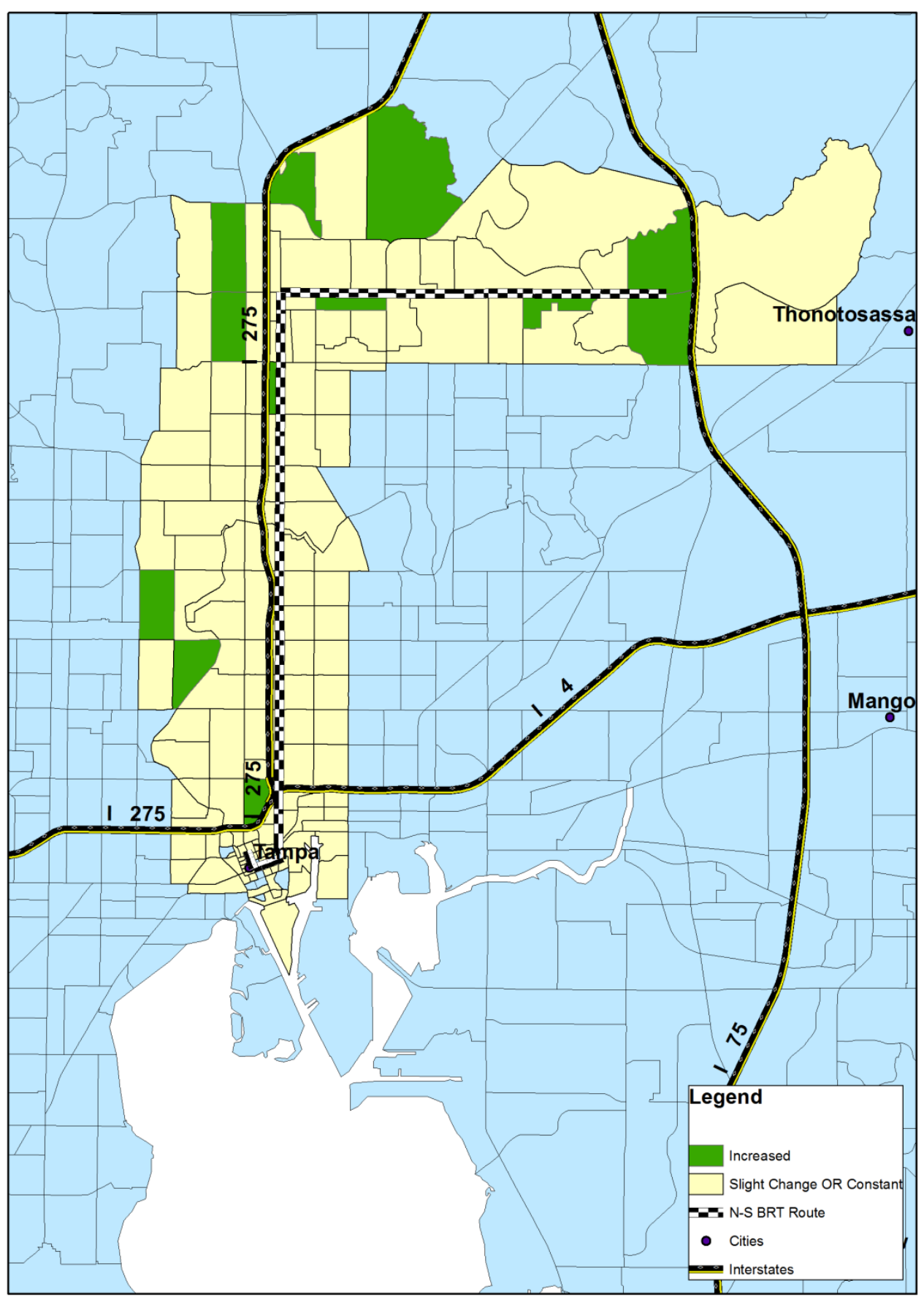

Figure 6-10 Zonal Change in Unit Price due to Implementation of BRT (5\% Trip Attraction) in 2012 


\subsection{Scenario 3 (The BRT route with a one percent trip attraction in a long-period projection)}

The traffic patterns of 2020 were revised using the method described in Section 6.1 assuming that the BRT route attracted one percent of the trips from auto trips within the study zones. The scenario of the BRT with a one percent trip attraction in a long-period projection was created and examined using the UrbanSim model. The comparison of population, households, jobs, and unit price with and without implementation of the BRT route (1\% trip attraction) for a long-term period (2010-2020) is shown in Figure 6-11. 

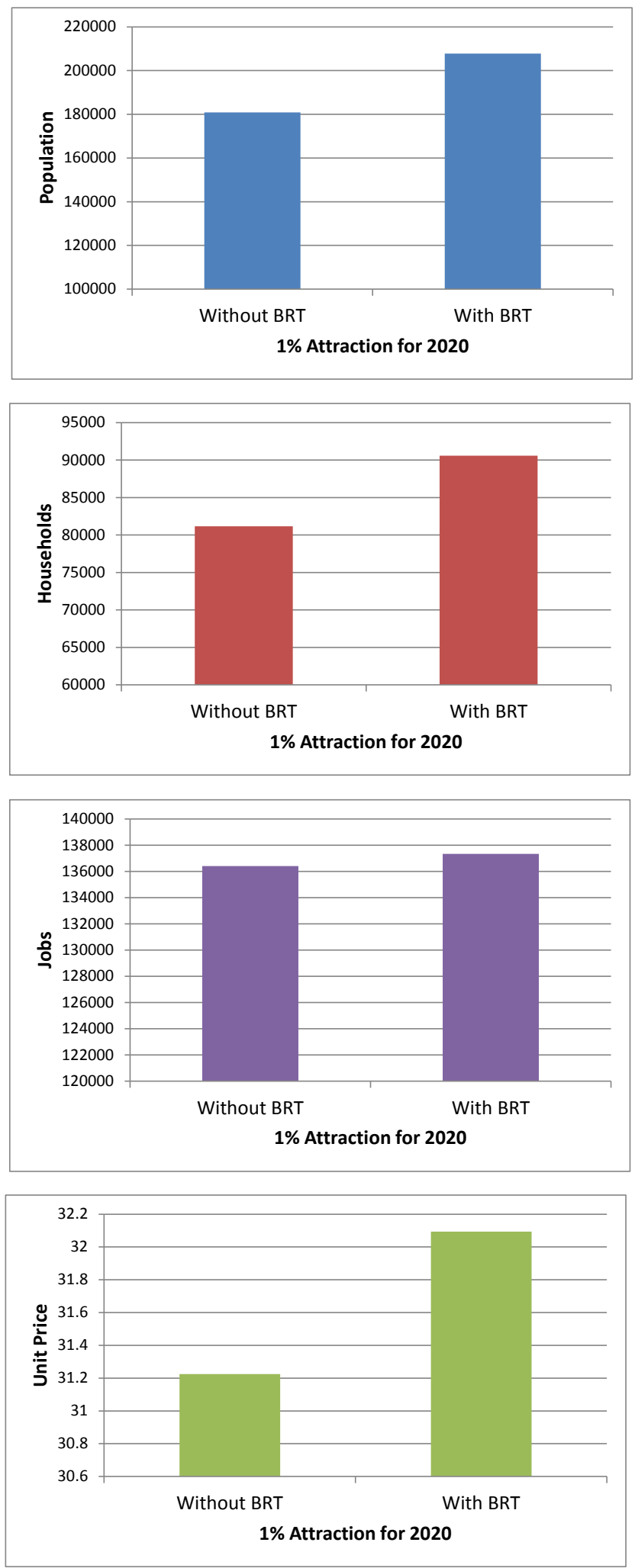

Figure 6-11 Land Use Patterns With and Without Implementation of BRT (1\% Trip attraction) in 2020 
Figure 6-11 shows that implementation of the BRT route (assuming 1\% trip attraction) increases population, households, unit price, and jobs in the study zones in 2020. The population increased by $15 \%$; households increased by $12 \%$; unit price increased by $3 \%$; and jobs increased by $0.68 \%$. The spatial differences of the four zonal land use patterns are displayed in Figures 6-12 to 6-15. 


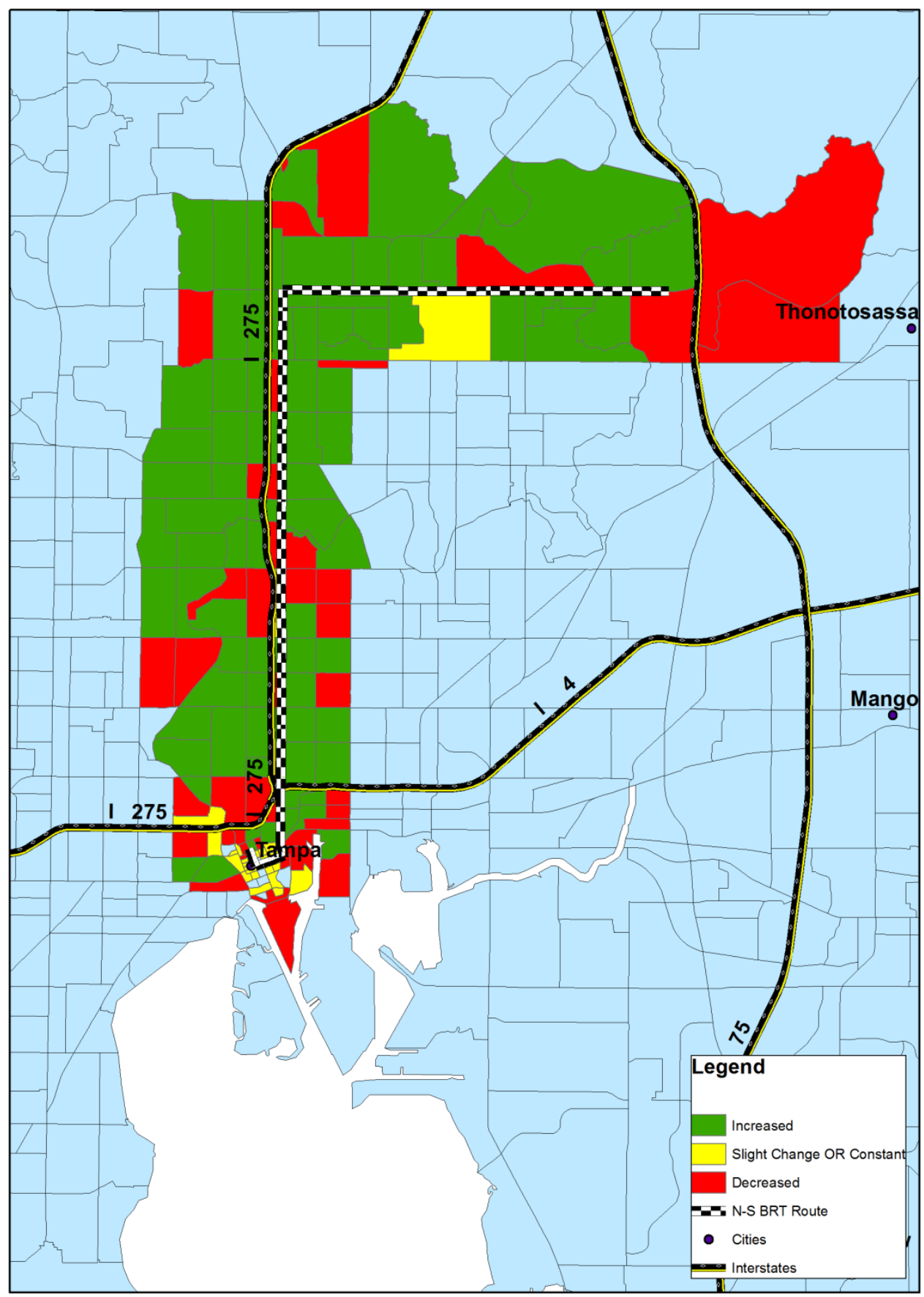

Figure 6-12 Zonal Change in Population due to Implementation of BRT (1\% Trip Attraction) in $\mathbf{2 0 2 0}$ 


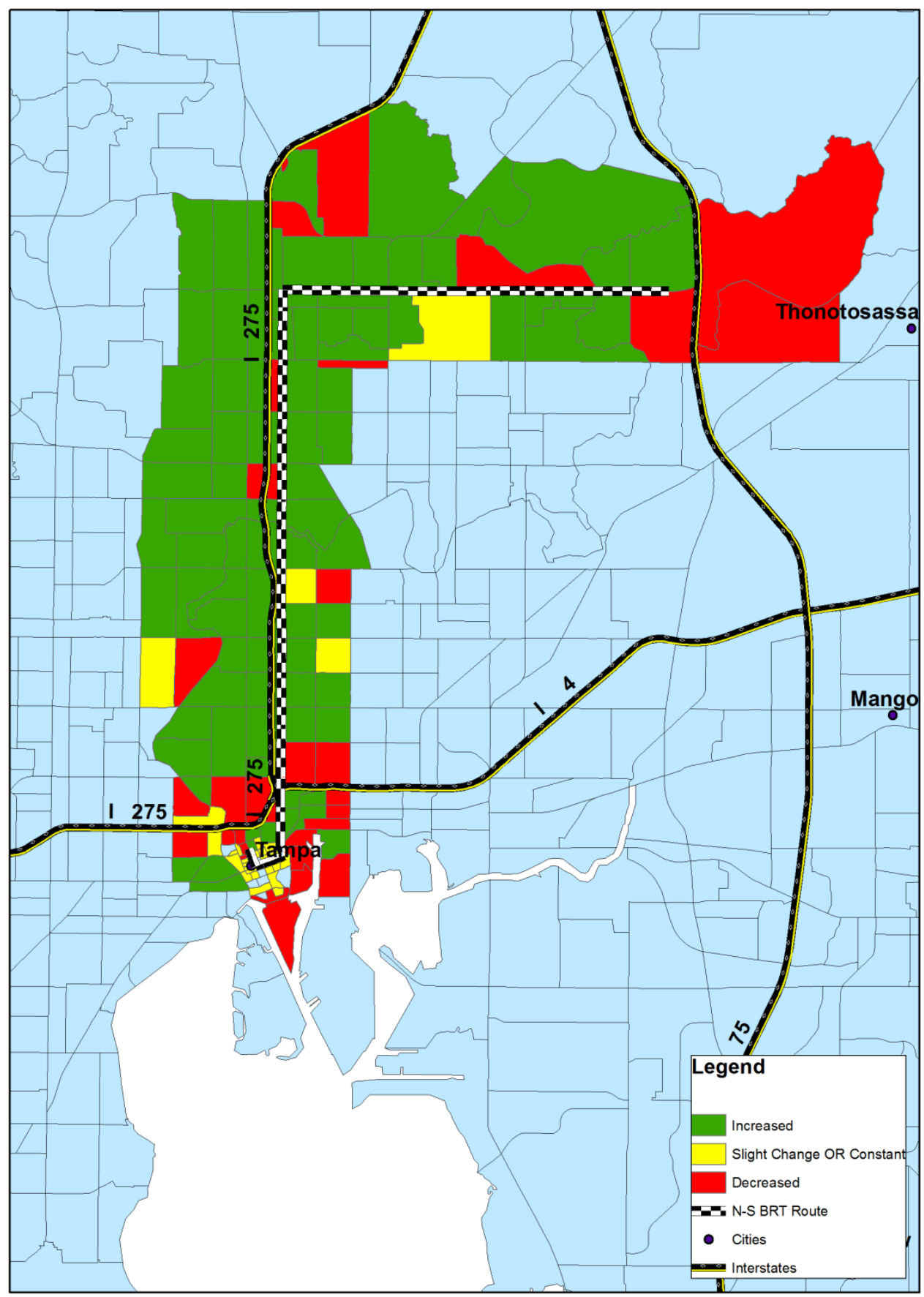

Figure 6-13 Zonal Change in Households due to Implementation of BRT (1\% Trip Attraction) in 2020 


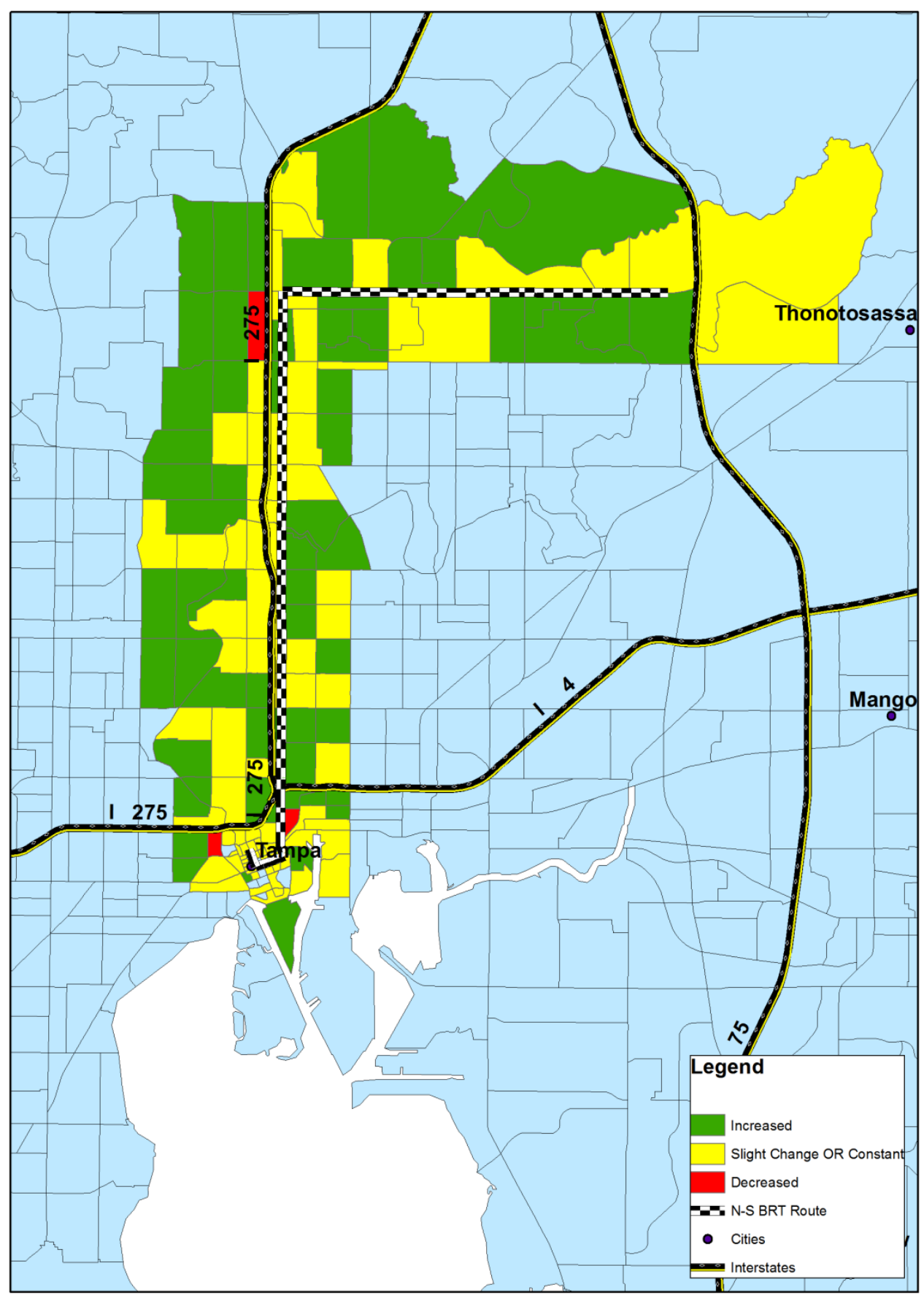

Figure 6-14 Zonal Change in Jobs due to Implementation of BRT (1\% Trip Attraction) in 2020 


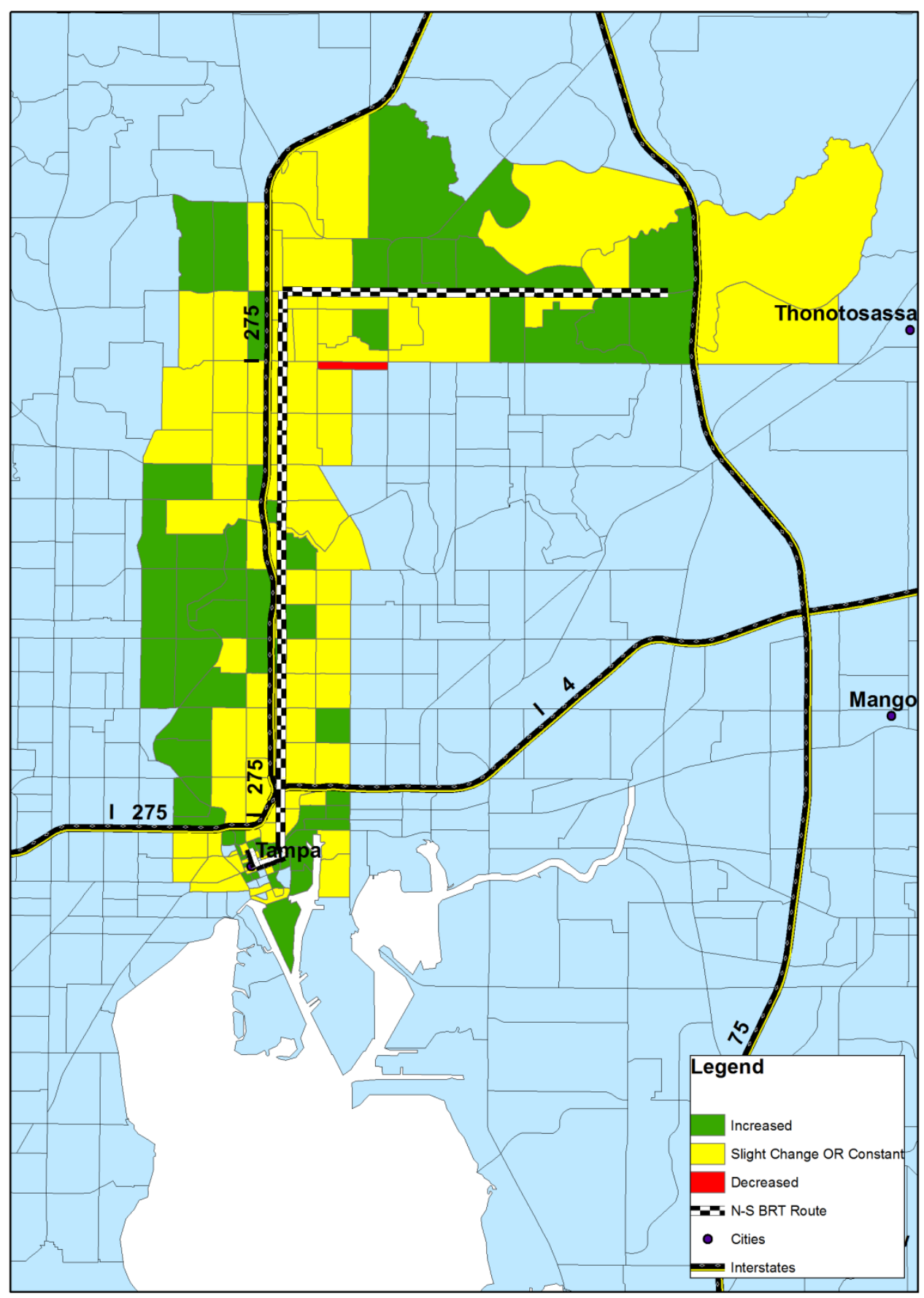

Figure 6-15 Zonal Change in Unit Price due to Implementation of BRT (1\% Trip Attraction) in 2020 


\subsection{Scenario 4 (The BRT route with a five percent trip attraction in a long-period projection)}

The traffic patterns of 2020 were revised using the method described in Section 6.1 assuming that the BRT route attracted five percent of the trips from auto trips within the study zones. The scenario of the BRT with a five percent trip attraction in a long-period projection was created and examined using the UrbanSim model. The comparison of population, households, jobs, and unit price with and without implementation of the BRT route (5\% trip attraction) for 2020 is shown in Figure 6-16. 

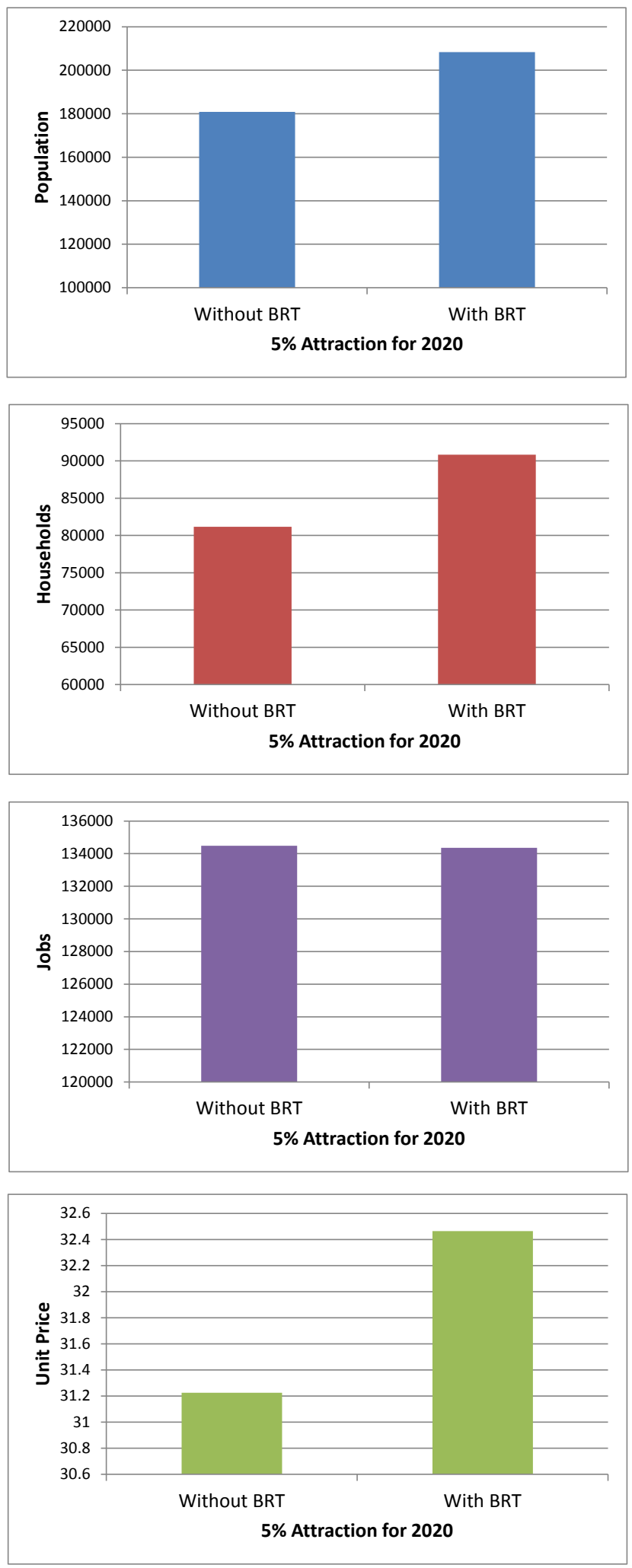

Figure 6-16 Land Use Patterns With and Without Implementation of BRT (5\% Trip Attraction) in 2020 
Figure 6-16 shows that implementation of the BRT route (assuming 5\% trip attraction) increases population, households, and jobs in the study zones in 2020 . The population increased by $15 \%$; households increased by $12 \%$; unit price increased by $4 \%$; and jobs increased by $0.85 \%$. The spatial differences of zonal land use patterns are displayed in Figures 6-17 to 6-20. 


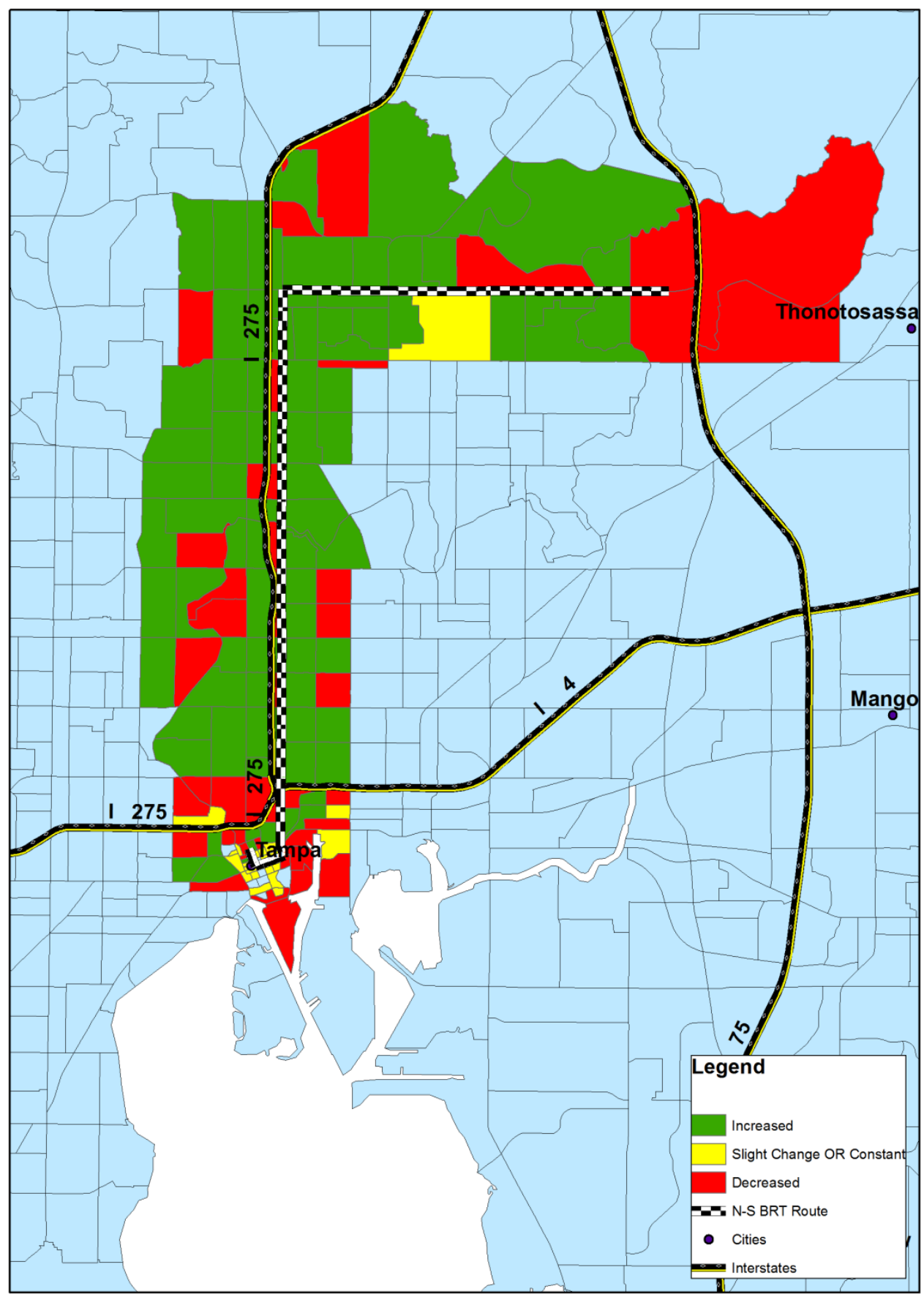

Figure 6-17 Zonal Change in Population due to Implementation of BRT (5\% Trip Attraction) in $\mathbf{2 0 2 0}$ 


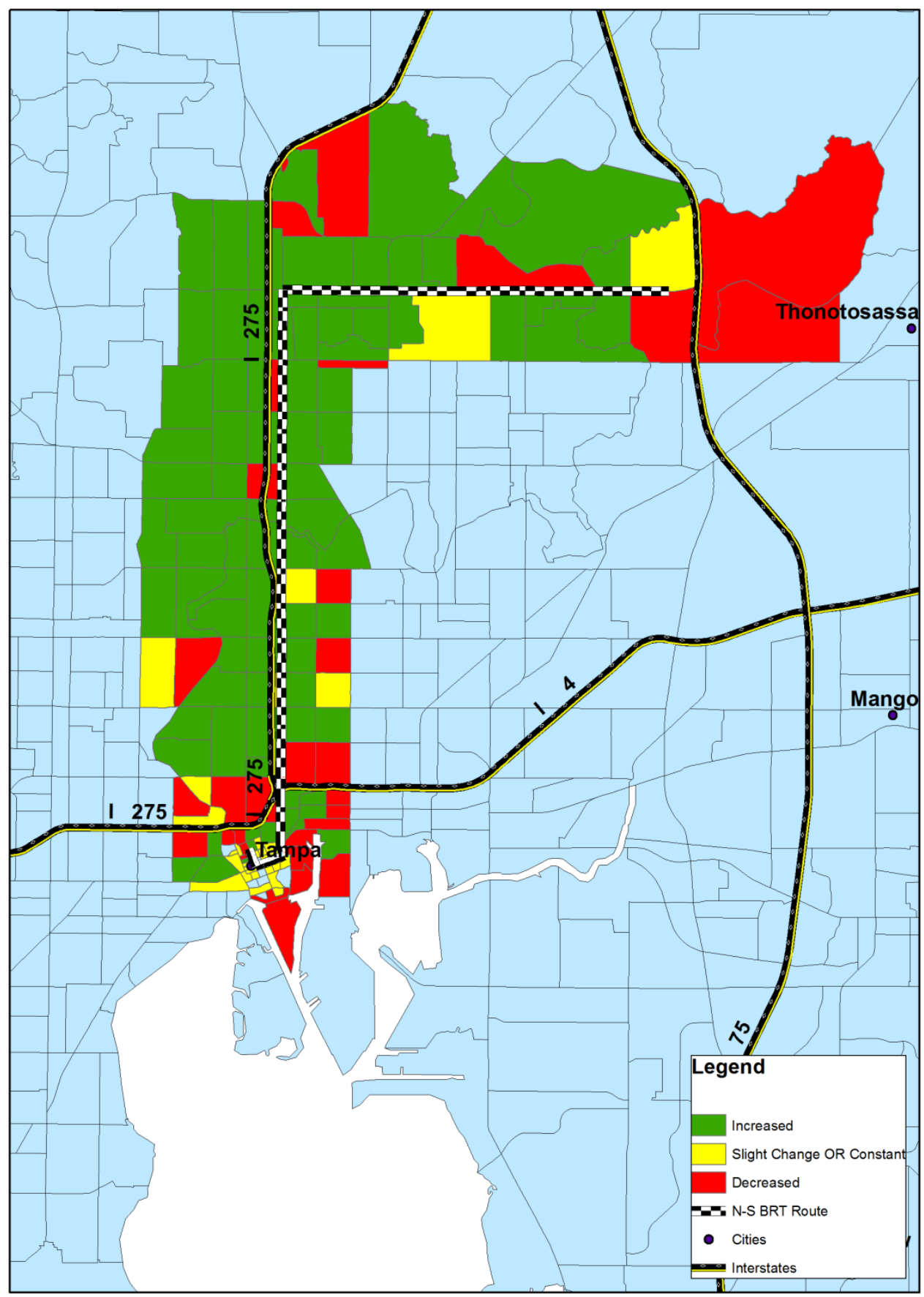

Figure 6-18 Zonal Change in Households due to Implementation of BRT (5\% Trip Attraction) in 2020 


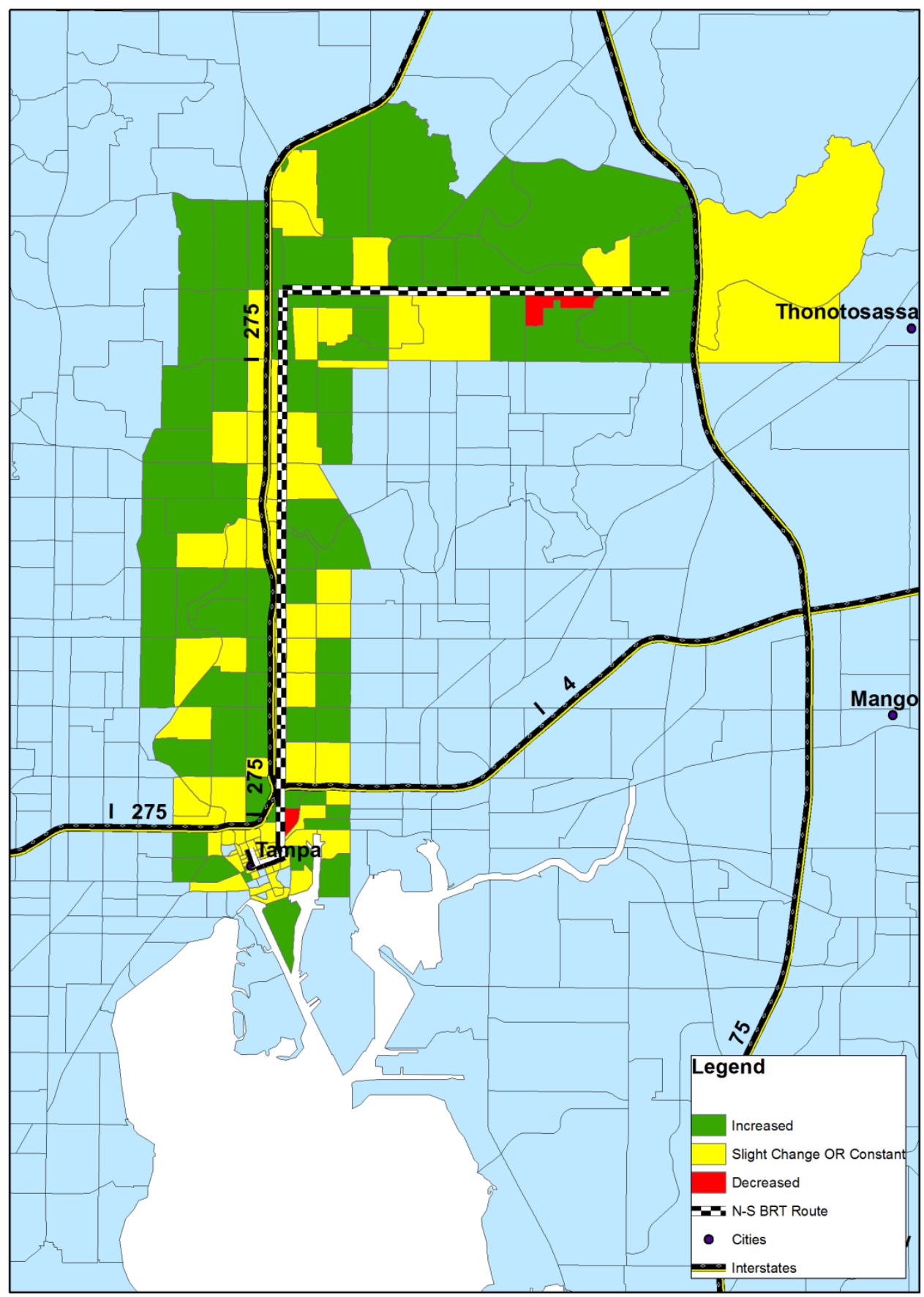

Figure 6-19 Zonal Change in in Jobs due to Implementation of BRT (5\% Trip Attraction) in 2020 


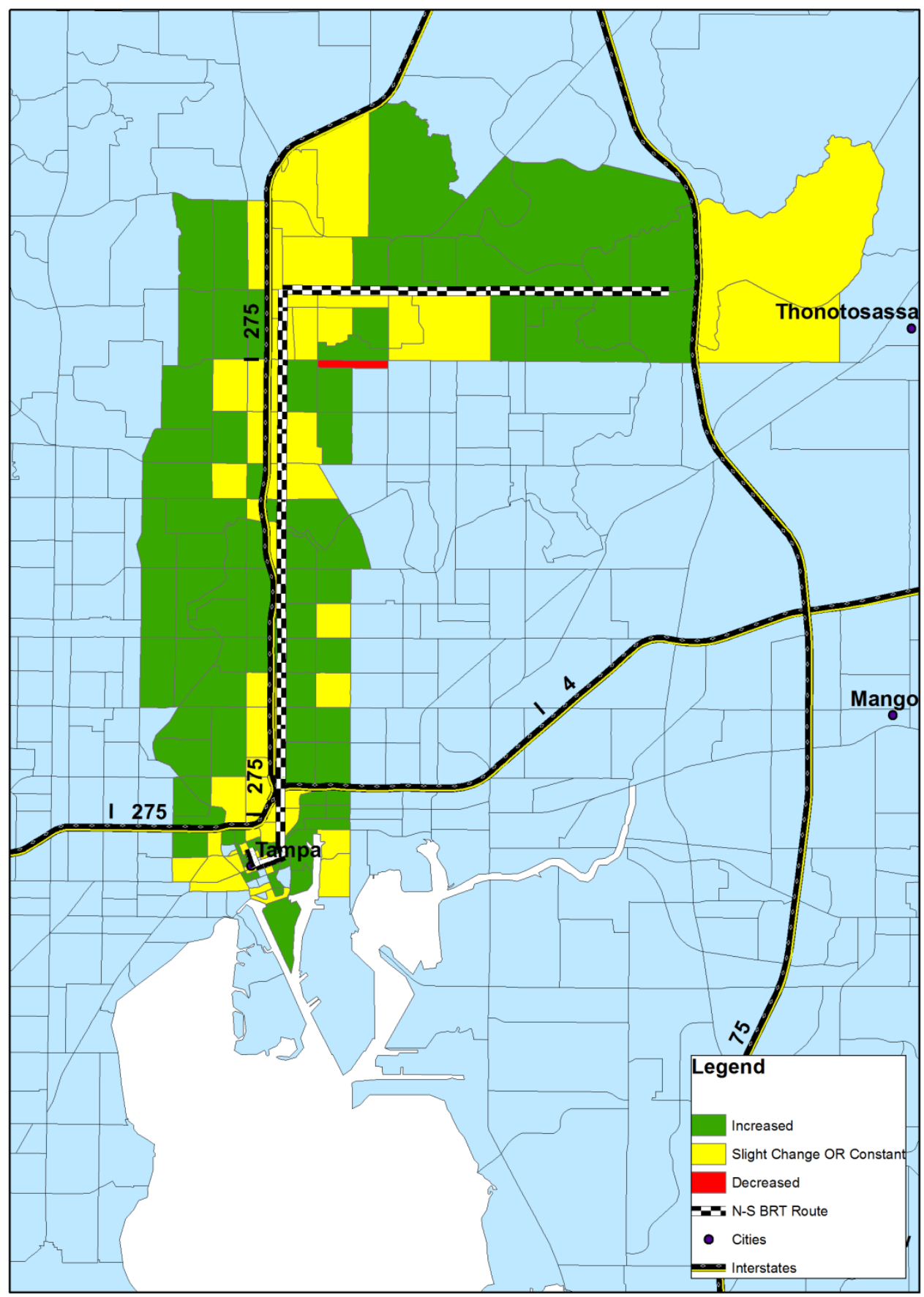

Figure 6-20 Zonal Change in Unit Price due to Implementation of BRT (5\% Trip Attraction) in 2020 


\subsection{Analysis}

Based on the simulation results, it was learned that implementation of the North-South BRT route will introduce a complex transformation in land use patterns. Time is the most important factor contributing to the land use transformation. As shown in Figure 6-21, the changes in population, households, unit price, and jobs due to implementation of the BRT service are close to zero $(<1 \%)$ in 2012, assuming one percent and five percent trip attraction. It appears that land use patterns are not sensitive to the implementation of the BRT service in a short-term period.

However, in 2020, the differences in population, households, and unit price due to implementation of the BRT service are significant. The average increases in percentages are $15 \%$ (population), 12\% (households), and 3.57\% (unit price) within the study zones. The increasing percentages of jobs due to the BRT service in 2020 are $0.68 \%$ (1\% trip attraction) and $0.85 \%$ (5\% trip attraction). From these results, it can be said that the BRT service has a significant impact on the land use patterns (population, households, and unit price) in a long-term period.

Compared to the impacts of the BRT investment on jobs and housing unit prices $(4 \%$ and less than $1 \%$ respectively), the impacts on population and households in 2020 were larger (15\% and $12 \%$ respectively). In UrbanSim, population and households are predicted by the Household Location Choice Model which adopted a system default structure and coefficients in this study due to the lack of survey data for Hillsborough County. A possible reason for the "large" impacts on population and households is the "non-localized" Household Location Choice Model. To improve the estimation accuracy, the Household Location Choice Model needs to be redeveloped using localized structure and coefficients for Hillsborough County. 


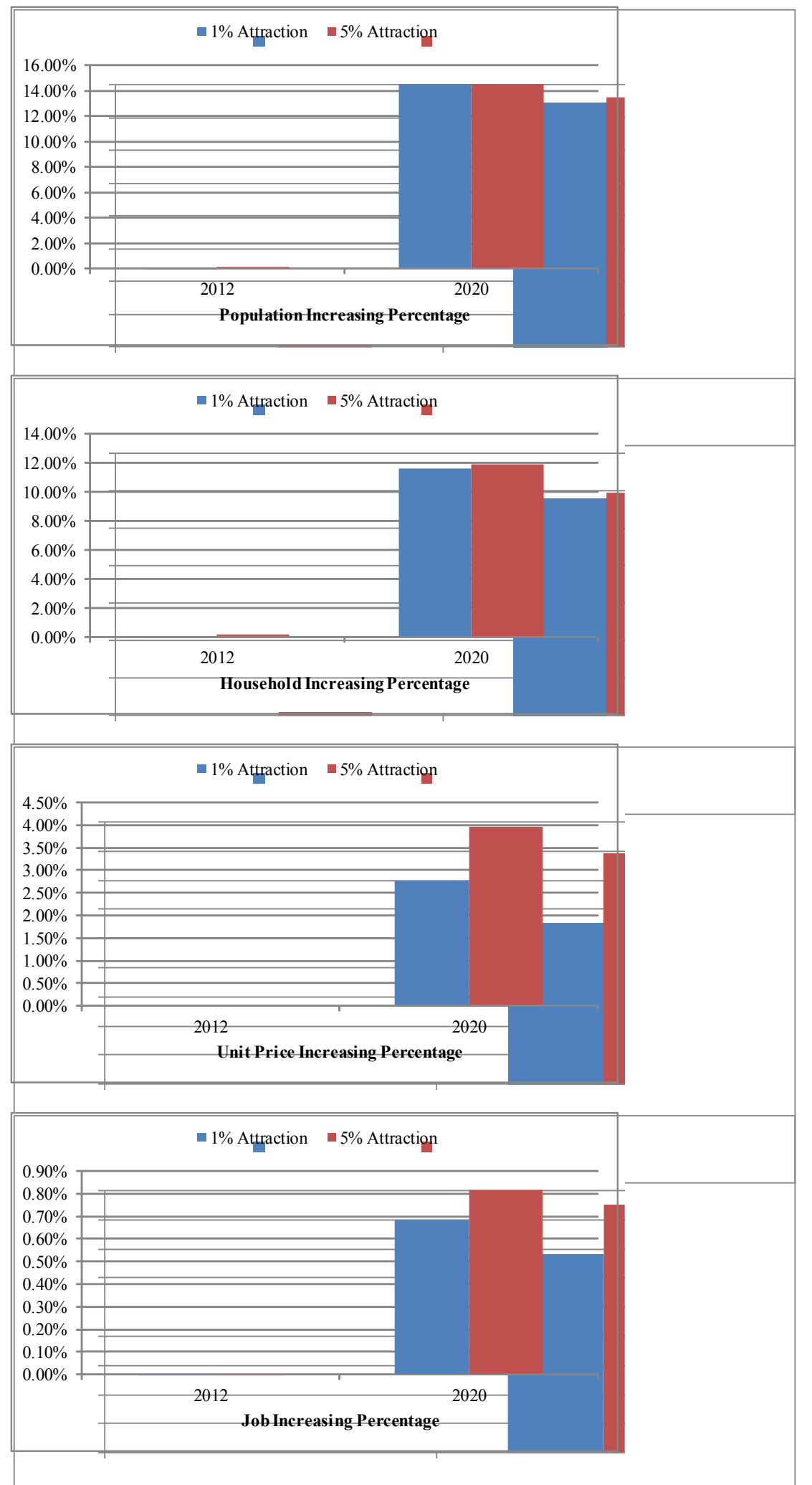

Figure 6-21 Changes in Land Use Pattern due to Implementation of BRT Service 


\section{Scenario Testing II (HART Route 2)}

Another scenario testing was conducted to assess the impact of an upgrade of a bus route on land use in Hillsborough County. The HART Route 2, as shown in Figure 7-1, was selected for this test. The HART Route 2 includes two lines (North-to-South and South-to-North) that connect the two central ends: University Area Transit Center and Marion Transit Center, along the Nebraska corridor. In this study, it was assumed that Route 2 was upgraded to an express bus from its current mode. The major upgrades are shown in Table 7-1.

Table 7-1 Upgrade of Route 2

\begin{tabular}{|c|c|c|}
\hline Item & Current & Upgrade \\
\hline Mode & Local Bus & Express Bus \\
\hline Peak Hour Headway & $15 \mathrm{~min}$ & $10 \mathrm{~min}$ \\
\hline Peak-Off Headway & $30 \mathrm{~min}$ & $15 \mathrm{~min}$ \\
\hline
\end{tabular}

The Transit Network module of the TBRPM model was changed based on the upgrade plan. The TBRPM model was executed with the upgraded transit network to forecast the travel patterns for two target years (2012 and 2020). These travel patterns were imported into the UrbanSim model to predict the land use patterns in the two target years. The land use patterns were compared to those in the same years without the upgrade travel patterns to assess the impact of the upgrade on land use. 


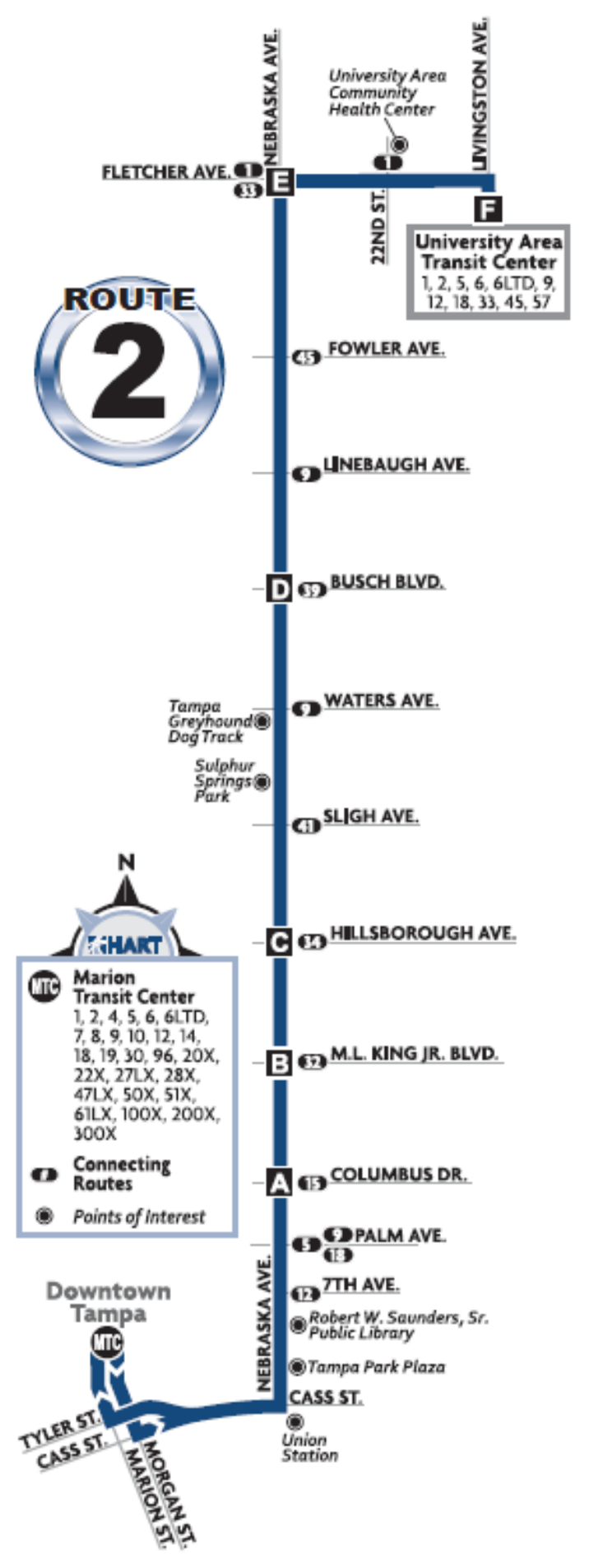

Figure 7-1 HART Route 2 (Source: http://www.gohart.org) 


\subsection{Study Zones}

This study evaluated the impact of the HART Route 2 on its adjacent areas. These areas were delimited as the traffic analysis zones that are influenced by the route, as shown in Figure 7-2. The influence area is defined as the zones within a 2-mile radius around the route. In total, 70 zones were defined as the study zones. 


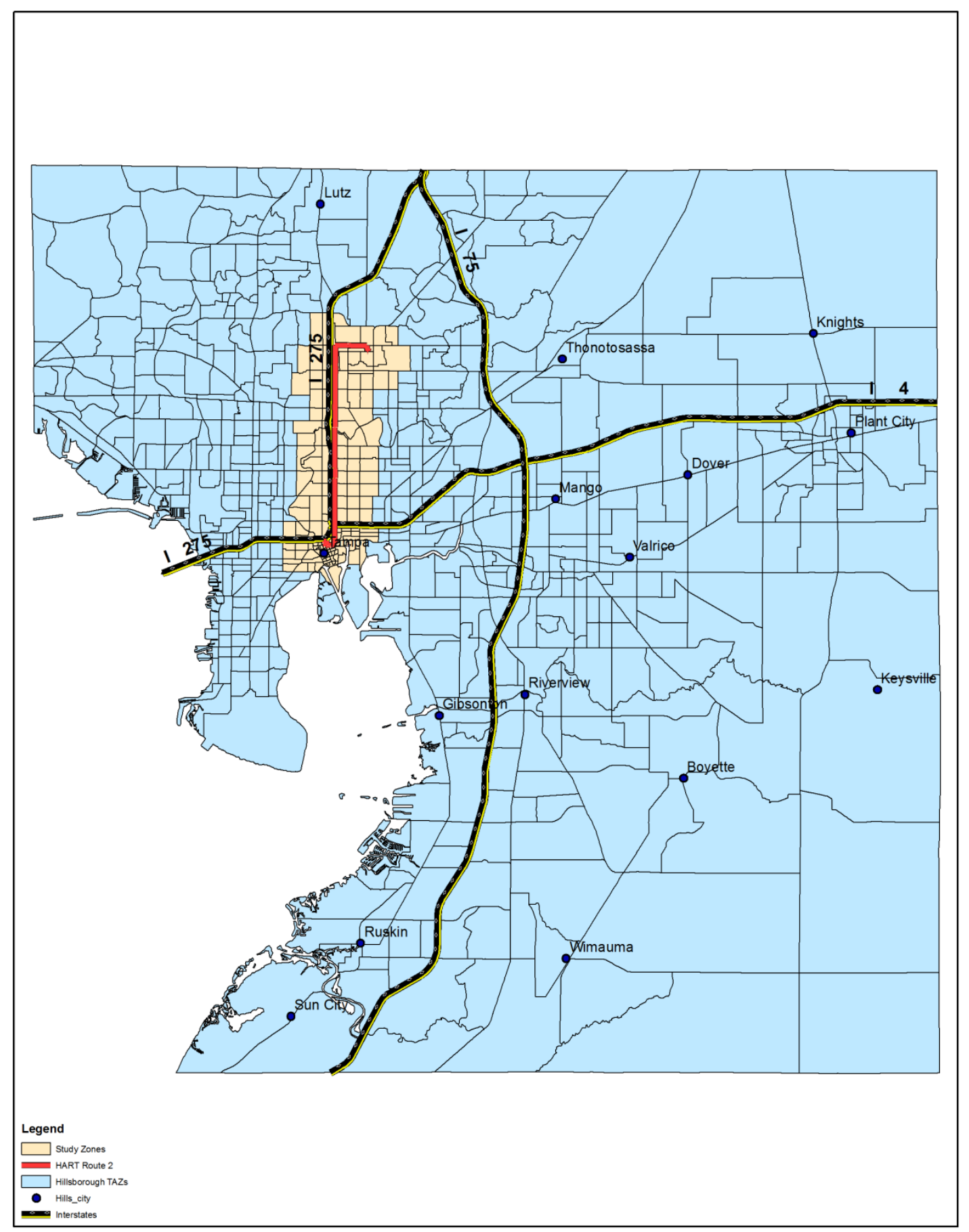

Figure 7-2 Influence Zones of HART Route 2 (2-mile buffer) 


\subsection{Land Use Pattern in 2012}

The UrbanSim model, with the upgraded Route 2, ran for the target year (2012) and the land use patterns were extracted from the model output (indicators), including:

- Zonal Population

- Zonal Household

- Zonal Jobs

- Zonal Unit Price

The four measures with the express bus upgrade impact were compared with those without the upgrade and are summarized in Figure 7-3. 

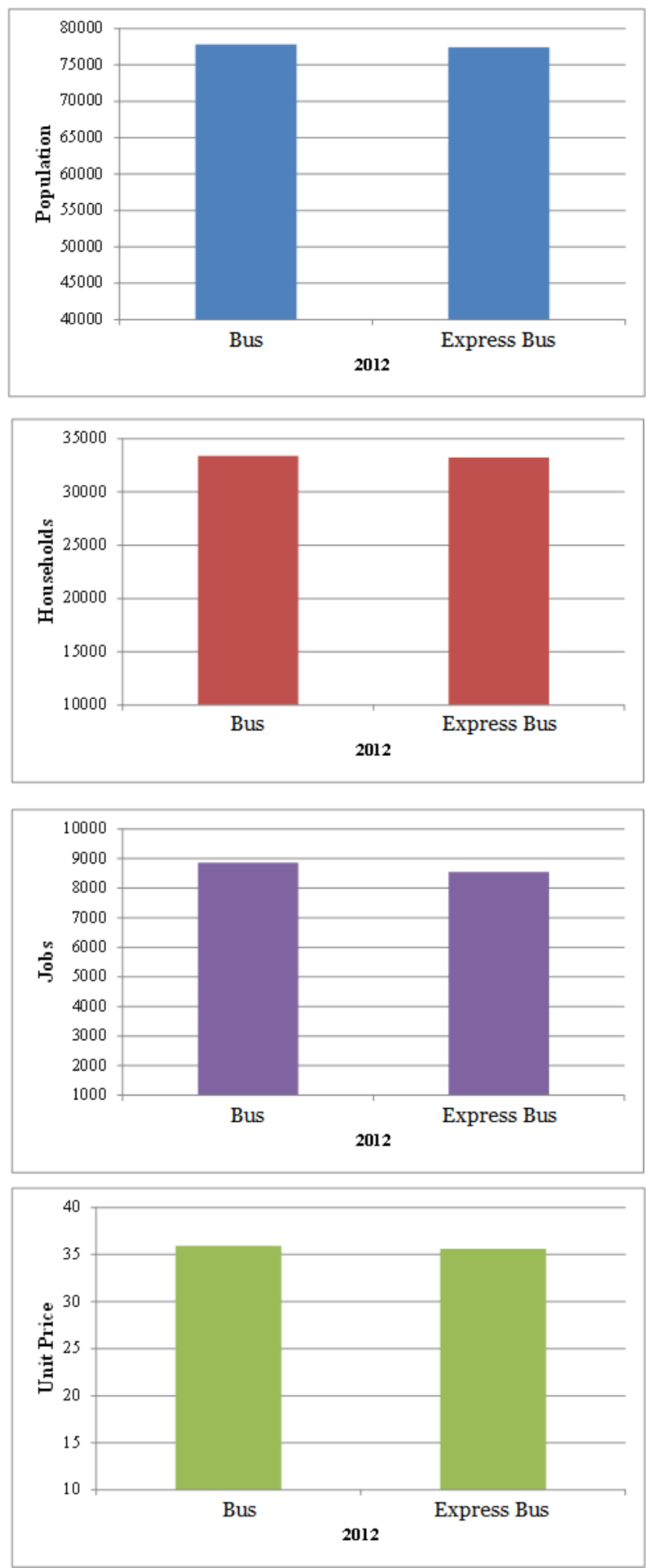

Figure 7-3 Land Use Patterns With and Without Upgrading HART Route 2 in 2012 
Figure 7-3 shows that upgrading HART Route 2 to an express bus has no significant impact on land use patterns in the study zones in a short-term period (2012-2020). The population, households, jobs, and unit price are almost equal (difference $<1 \%$ ) with and without upgrading the HART route in 2012.

\subsection{Land Use Pattern in 2020}

The scenario of the upgraded HART Route 2 in 2020 was created and examined using the UrbanSim model. The comparison of population, households, jobs, and unit price with and without upgrading the HART route for 2020 is displayed in Figure 7-4. 

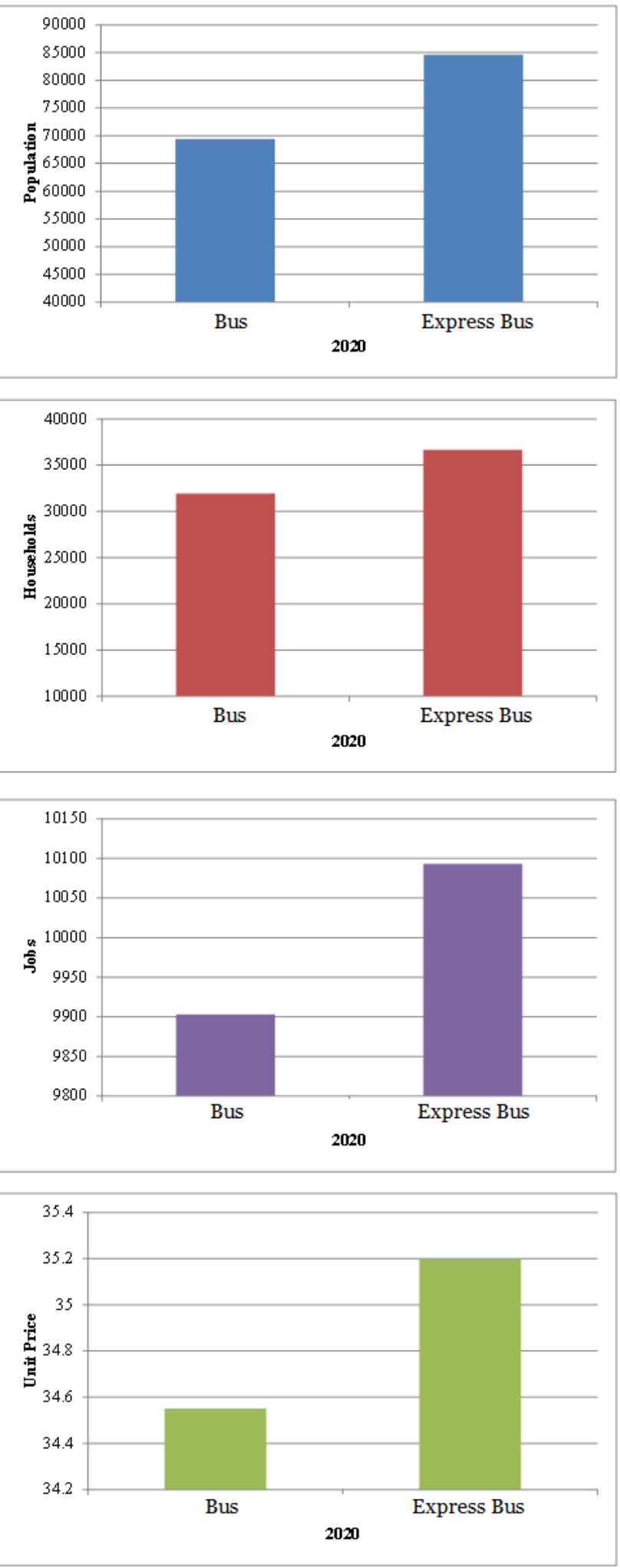

Figure 7-4 Land Use Patterns With and Without Upgrading HART Route 2 in 2020 
Figure 7-4 shows that upgrading HART Route 2 to an express bus has a significant impact on the land use pattern of the influence zones in a long-term period. The population, households, jobs, and unit price increase by $22 \%, 15 \%, 2 \%$, and $2 \%$ respectively due to upgrading the HART Route 2 in 2020. This finding confirms the conclusion derived from Chapter 6 that improving transit service will impact the land use pattern positively in the long-term, especially for population and household. 


\section{CONCLUSIONS AND RECOMMENDATIONS}

This study applied the UrbanSim package to evaluate the impact of transit investments on land use patterns in Hillsborough County, Florida. The socioeconomic, demographic, and geographic data were collected from various data sources for the base year (2010). These data and the specified sub-models were assembled in the UrbanSim platform to create a simulation model. The TBRPM model was used to forecast traffic patterns in target years. Based on the base year data, four scenarios with assumed BRT ridership (trip attraction from auto mode) were examined to simulate the choice behavior of individual agents (persons, households, companies, etc.) with and without a proposed BRT service. With and without comparisons were conducted on land use patterns (population, households, jobs, and unit price) based on the simulation results. The following conclusions were found from this study:

- UrbanSim is a powerful tool to simulate land use changes. It is based on theories of market economics and discrete choice behavior, and captures both the impacts of market forces as well individuals' choices on land development processes. The household and job-based simulation makes its forecasting more realistic spatially and temporally. The UrbanSim model provides a reasonable prediction based on the difference between simulated land use patterns using UrbanSim and the projections in the 2035 LRTP. It is necessary to point out that differences are expected since these projections are produced by using different methods.

- The proposed BRT service has significant impacts on land use patterns in a longterm period (2010-2020). The population and households in the study area would increase by about $15 \%$ and $12 \%$, respectively, due to implementing the BRT service in 2020; the housing unit price in the study area would increase by $4 \%$ due to implementing the BRT service in 2020.

- Compared to the impacts of the BRT investment on jobs and housing unit prices (4\% and less than $1 \%$ respectively), the impacts on population and households in 2020 were larger (15\% and 12\% respectively). In UrbanSim, population and households are predicted by the Household Location Choice Model, which adopted system default structure and coefficients in this study due to lack of survey data for 
Hillsborough County. A possible reason for the "large" impacts on population and households is the "non-localized" Household Location Choice Model.

- The change in land use patterns is complex due to implementing the BRT service, in both a short-term and a long-term period. For example, as shown in Figure 6-17, about $20 \%$ of zones decrease in population assuming five percent trip attraction by the BRT service, although the total population in the study will increase by $15 \%$. It can be said that individuals' choices are complicated and impacted by several joint factors.

Some recommendations are provided as follows:

- Data preparation is the key step in implementation of the UrbanSim model. In particular, household data and building data were synthesized using the IPU algorithm. Since the resolution of the algorithm is Census Blockgroup, which is larger than TAZ and parcel, researchers had to randomly assign the synthesized households and persons to zones, parcels, and buildings because of the lack of marginal distributions at zone and parcel levels. The random assignment may influence the accuracy of the UrbanSim simulation. In the future, it would be necessary to develop a new assignment algorithm considering relationships between household characteristics and parcel attributes; for example, households with higher incomes tend to take the higher value parcels/buildings.

- The study adopted the system default coefficients for the sub-models because the "real" data at parcel level are unavailable in Hillsborough County. In the future, a comprehensive survey is recommended to calibrate the coefficients of household/employment location choice models. Models localized for Hillsborough County would improve the accuracy of the UrbanSim model.

- In the UrbanSim model developed in this study, the impact of BRT services on traffic patterns are represented by the number of trips attracted from the auto mode, since only the variable of auto mode is included in the sub-models. A new model structure should be developed to contain additional transit variables in order to represent transit impacts directly. 
- In the current travel planning model for Hillsborough County (TBRPM or TBEST), the BRT mode is not available. Thus, researchers had to assume the ridership of the proposed BRT route to create scenarios. The scenarios should be updated with the availability of the BRT mode in travel planning models to provide a more reasonable assessment on the impacts of the proposed BRT route. 


\section{References}

1. Cambridge Systematics Inc., "TCRP Report 35: Economic Impact Analysis of Transit Investment: Guidebook for Practitioners", National Academy Press, Washington, DC, 1998.

2. McDonald, J.F. and C.I. Osuji, "The Effect of Anticipated Transportation Improvement on Residential Land Values", Regional Science and Urban Economics, vol. 25, no. 3, pp. 261-278, 1995.

3. McMillen, D.P. and J. McDonald, "Reaction of House Prices to a New Rapid Transit Line: Chicago's Midway Line, 1983-1999", Real Estate Economics, vol. 32, no. 3, pp. 463-486, 2004.

4. Noland, R., S. DiPetrillo, and M. Lahr, "Residential Property Values and the New Jersey Transit Village Program", presented at the $90^{\text {th }}$ Annual Meeting of Transportation Research Board, 2011.

5. Chatman, D.G., N.G. Tulach and K. Kim, "Evaluating the Economic Impacts of Light Rail by Measuring Home Appreciation: A first look at New Jersey's River Line", Urban Studies, vol. 43, no. 3, pp. 467-487, 2010.

6. Kyeongsu, K. and M. Lahr, "The Impact of Hudson-Bergen Light Rail on Residential Property Appreciation", presented at the $89^{\text {th }}$ Annual Meeting of Transportation Research Board, 2010

7. Wang, F. and P. Zorn, "Estimating house price growth with repeat sales data: What's the aim of the game?", Journal of Housing Economics, vol. 6, pp. 93-118, 1997.

8. Can, A. and I. Megbologbe, "Spatial Dependence and House Price Index Construction", Journal of Real Estate Finance and Economic, vol. 14, no. 1-2, pp. 203-222, 1997.

9. Haider, M. and E. Miller, "Effects of Transportation Infrastructure and Location on Residential Real Estate Values: Application of Spatial Autoregressive Techniques", Transportation Research Record, no.1722, pp. 1-8, 2000.

10. Goetz, Ed, K. Kate, A. Hagar and T. Hoang, "Differential Impact of the Hiawatha Light Rail Line on Property Values in Minneapolis" Presented at the $88^{\text {th }}$ Annual Meeting of Transportation Research Board, 2009.

11. Löchl, M. and K. W. Axhausen. "Modeling Hedonic Residential Rents for Land Use and Transport Simulation while Considering Spatial Effects", Journal of Transport and Land Use, vol. 3, no. 2, pp. 39-63, 2010.

12. Picard, N., C. Antoniou, and A. de Palma. "Econometric Models", SustainCity Working Paper, 2.4, THEMA, Université de Cergy-Pontoise, 2010.

13. Economic Development Research Group and Cambridge Systematics, Inc., "TCRP Project J-11(7): Economic Impact of Public Transportation Investment", prepared for the American Public Transportation Association, October 2009.

14. Skolnik J. and R. Chami, "The Economic Impact of the Greater Lynchburg Transit Company on the Lynchburg, Virginia Region", presented at the $90^{\text {th }}$ Annual Meeting of Transportation Research Board, 2011. 
15. Timmermans, H., "The Saga of Integrated land Use-Transport Modeling: How Many More Dreams before We Wake Up?" presented at 10th International Conference on Travel Behavior Research Lucerne, Switzerland, 2003.

16. Miller, E. J., D. Kriger and J. Hunt, "TCRP Report (48): Integrated Urban Models for Simulation of Transit and Land Use Policies: Guidelines for Implementation and Use", Transportation Research Board of the National Academies, Washington, D.C., 1999

17. Johnston, A. R. and C. M. Mccoy, "Assessment of Integrated Transportation Land Use Models", Technical Report, Caltrans Contract 65A0186, Davis, CA, 2006

18. Zhao, F. and S. Chung, "A Study of Alternative Land Use Forecasting Models", Technical Report, prepared for the Florida Department of Transportation, 2006.

19. Hunt, D. J. and E. J. Abraham, "Design and Application of PECAS Land Use Modeling System", presented at the 8th Computers in Urban Planning and Urban Management Conference, Sendai, Japan, 2003

20. Munoz-Raskin, R., "Walking accessibility to bus rapid transit in Latin America: Does it affect property values? The case of Bogotá, Colombia", presented in the $86^{\text {th }}$ Annual Meeting of Transportation Research Board, 2006

21. Breakthrough Technologies Institute, "Bus Rapid Transit and Transit Oriented Development: Case Studies on Transit Oriented Development around Bus Rapid Transit Systems in North America and Australia", Technical Report, 2008

22. Rodriguez, D. A. and C. H. Mojica. "Capitalization of BRT Network Effects into Land Prices," presented at the 88th Annual Meeting of the Transportation Research Board, Washington, D.C., 2009

23. Diaz, R. and D. Hinebaugh "Characteristics of Bus Rapid Transit for Decision-Making, Federal Transit Administration, Office of Research, Demonstration, and Innovation", Technical Report, prepared for U.S. Department of Transportation, Washington, D.C., 2009

24. Rodriguez, D. A. and F. Targa. "Value of Accessibility to Bogotá's Bus Rapid Transit System," Transport Reviews, vol.2 4, no. 5, 587-610, 2004

25. Kittelson \& Associates, Inc., "TCRP Report (118): Bus Rapid Transit Practitioners Guide", Transportation Research Board, 2007.

26. Parsons Brinckerhoff Quade \& Douglas, Inc. et al, "Public Policy and Transit Oriented Development: Six International Case Studies. Transit Cooperative Research Program”, Techincal Report, 1996.

27. Perdomo, J. A., J. C. Mendieta, C. A. Mendoza, and A. F. Baquero. "Investigación Sobre el Impacto del Proyecto de Transporte Masivo TransMilenio Sobre el Valor de Las Propiedades en Bogotá, Colombia. Cambridge, MA: Lincoln Institute of Land Policy", 2007

28. Kaplowitz, W., "Bus Rapid Transit: A Powerful Real Estate Development Tool”, Urban and Regional Planning Economic Development Handbook”, 2005

29. Waddell, P and G. F. Ulfarsson, "Introduction to Urban Simulation: Design and Development of Operational Models," Handbook of Transport, Volume 5: Transport Geography and Spatial Systems, P. Stopher, K. Button, K. Haynes, and D. Hensher, eds., 
Pergamon Press, New York, NY, Preprint available from http://www.urbansim.org/papers., 2005

30. Kakaraparthi, S. K. and K.M. Kockelman. "An Application of Urbansim to the Austin, Texas Region: Integrated-Model Forecasts for the Year 2030”, Journal of Urban Planning and Development, vol. 137, no. 3, pp. 238-247, 2011.

31. Waddell, P. "Documentation: Puget Sound UrbanSim Application”, Technical Report, Puget Sound Regional Council, 2008

32. Schirmer, P., C. Zöllig, K. Müller, B.R. Bodenmann and K.W. Axhausen, "The Zurich Case Study of UrbanSim", presented at the 51st European Congress of the Regional Science Association, Barcelona, 2011

33. Ye, X., K. C. Konduri, R. M. Pendyala, B. Sana, and P. Waddell, "Methodology to Match Distributions of Both Household and Person Attributes in Generation of Synthetic Populations", presented at the $88^{\text {th }}$ Annual Meeting of the Transportation Research Board, Washington, D.C., 2009.

34. Waddell, P. "The Open Platform for Urban Simulation, Users Guide and Reference Manual", available from http://www.urbansim.org/ 
Appendices 


\section{Appendix I Input Files for Parcel-Based UrbanSim}

\section{annual_employment_control_totals}

The "annual_employment_control_totals" table contains the control totals, or aggregate quantities, of employment that will be used to set the total employment in the model system for each year. Totals by employment sector are split into home-based and non-home based components, on separate records.

Table A-1 annual_employment_control totals

\begin{tabular}{|l|c|c|l|}
\hline \multicolumn{1}{|c|}{ Column Name } & Data Type & Required & \multicolumn{1}{|c|}{ Description } \\
\hline year & Integer & $\mathrm{Y}$ & simulation year \\
\hline sector_id & Integer & $\mathrm{Y}$ & unique id for the employment sector \\
\hline home_based_status & Integer & $\mathrm{Y}$ & flag for home-based employment \\
\hline number_of_jobs & Integer & $\mathrm{Y}$ & control total \\
\hline
\end{tabular}

\section{annual_household_control_totals}

The "annual_household_control_totals" table contains the control totals, or aggregate targets, for the number of households for each year.

Table A-2 annual household control totals

\begin{tabular}{|l|c|c|l|}
\hline \multicolumn{1}{|c|}{ Column Name } & Data Type & Required & \multicolumn{1}{c|}{ Description } \\
\hline year & Integer & Y & simulation year \\
\hline age_of_head & Integer & N & Optional age of head category \\
\hline persons & Integer & N & $\begin{array}{l}\text { Optional number of persons } \\
\text { category }\end{array}$ \\
\hline income & Integer & N & Optional income category \\
\hline total_number_of_households & Integer & Y & total number of households \\
\hline
\end{tabular}




\section{annual_household_relocation_rates}

The "annual_household_relocation_rates" table contains estimates of the probabilities of moving within the region during a one-year time frame. The rates can be obtained from analyzing Current Population Survey data. Users can use any range or categorical variable (primary or computed) defined for households. By default, it includes households of different incomes and ages of head of household categories.

Table A-3 annual_household_relocation_rates

\begin{tabular}{|l|c|c|l|}
\hline \multicolumn{1}{|c|}{ Column Name } & Data Type & Required & \multicolumn{1}{c|}{ Description } \\
\hline age_of_head_min & Integer & Y & Start of age range. Optionally age_min \\
\hline age_of_head_max & Integer & Y & End of age range. Optionally age_max \\
\hline income_min & Integer & Y & Start of income range \\
\hline income_max & Integer & Y & End of income range \\
\hline probability_of_relocating & Float & Y & $\begin{array}{l}\text { annual relocation probability (between 0 } \\
\text { and 1) }\end{array}$ \\
\hline
\end{tabular}

annual_job_relocation_rates

The "annual_job_relocation_rates" table contains the probabilities that a job in a sector will relocate within the region within a one-year time frame.

Table A-4 annual_job_relocation_rates

\begin{tabular}{|l|c|c|l|}
\hline \multicolumn{1}{|c|}{ Column Name } & Data Type & Required & \multicolumn{1}{c|}{ Description } \\
\hline sector_id & Integer & Y & Unique id of employment sector \\
\hline job_relocation_probability & Float & Y & $\begin{array}{l}\text { Probability of a job relocating within a } \\
\text { year (between 0 and 1) }\end{array}$ \\
\hline
\end{tabular}




\section{buildings}

The "buildings" table in the parcel version of the model system is an individual building located on a parcel. There can be multiple buildings on a parcel (a many to one relationship). Buildings that are mixed use, such as retail on the first floor and apartments above, can be represented as two separate buildings, on the same parcel. The land area would generally be assigned by the user to each component as a prorated amount.

Table A-5 buildings

\begin{tabular}{|c|c|c|c|}
\hline Column Name & Data Type & Required & Description \\
\hline building_id & Integer & Y & $\begin{array}{l}\text { Unique id of building (one per zone and } \\
\text { building type) }\end{array}$ \\
\hline building_quality_id & Integer & Y & $\begin{array}{l}\text { Building quality that can be used in } \\
\text { development templates }\end{array}$ \\
\hline building_type_id & Integer & Y & $\begin{array}{l}\text { Unique id of the building type of this } \\
\text { building }\end{array}$ \\
\hline improvement_value & Integer & $\mathrm{Y}$ & Value in dollars of buildings on parcel \\
\hline land_area & Integer & $\mathrm{Y}$ & Land area in sqft used by the building \\
\hline non_residential_sqft & Integer & $\mathrm{Y}$ & Total non-residential sqft in building \\
\hline parcel_id & Integer & Y & $\begin{array}{l}\text { Unique id of the parcel in which this building } \\
\text { is located }\end{array}$ \\
\hline residential_units & Integer & $\mathrm{Y}$ & Total residential units in building \\
\hline sqft_per_unit & Integer & $\mathrm{Y}$ & $\begin{array}{l}\text { Average square feet per residential unit in } \\
\text { building }\end{array}$ \\
\hline stories & Integer & $\mathrm{N}$ & Number of stories in the building \\
\hline tax_exempt & Integer & $\mathrm{N}$ & 1 if tax-exempt building, 0 otherwise \\
\hline year_built & Integer & Y & $\begin{array}{l}\text { Average year built of this aggregated } \\
\text { building }\end{array}$ \\
\hline
\end{tabular}




\section{building_sqft_per_job}

The "building_sqft_per_job" table contains information on the amount of space each job will take in a particular building type, by zone.

Table A-6 building_sqft_per_job

\begin{tabular}{|l|c|c|l|}
\hline \multicolumn{1}{|c|}{ Column Name } & Data Type & Required & \multicolumn{1}{c|}{ Description } \\
\hline zone_id & Integer & Y & The zone id of the record \\
\hline building_type_id & Integer & Y & The building type id of the record \\
\hline building_sqft_per_job & Integer & Y & $\begin{array}{l}\text { The number of sqft per job for jobs with the } \\
\text { corresponding zone_id and building_type_id }\end{array}$ \\
\hline
\end{tabular}

\section{building_types}

The "building_types" table provides a list of the unique building types used to classify buildings. These typically are derived from local land use codes or building typologies.

Table A-7 building_types

\begin{tabular}{|l|c|c|l|}
\hline \multicolumn{1}{|c|}{ Column Name } & Data Type & Required & \multicolumn{1}{|c|}{ Description } \\
\hline building_type_id & Integer & Y & Unique id for building types \\
\hline is_residential & Integer & Y & 1 if residential, 0 otherwise \\
\hline building_type_name & String & Y & Short name of the building type \\
\hline building_type_description & String & N & Description of the building type \\
\hline unit_name & String & Y & $\begin{array}{l}\text { Used to denominate per_unit } \\
\text { variables like price. Values: } \\
\text { building_sqft, parcel_sqft }\end{array}$ \\
\hline generic_building_type_id & Integer & Y & $\begin{array}{l}\text { Unique id for generic (aggregated) } \\
\text { building type }\end{array}$ \\
\hline generic_building_type_name & String & N & $\begin{array}{l}\text { Description of the generic building } \\
\text { type }\end{array}$ \\
\hline
\end{tabular}


cities

The "cities" table provides a list of cities in the region and is typically used for computing indicators by city.

Table A-8 cities

\begin{tabular}{|l|c|c|l|}
\hline \multicolumn{1}{|c|}{ Column Name } & Data Type & Required & Description \\
\hline city_id & Integer & Y & Unique id for each city \\
\hline city_name & String(50) & Y & Name of the city \\
\hline
\end{tabular}

\section{counties}

The "counties" table contains a unique list of the counties in the region. These are mainly used for computing indicators.

Table A-9 counties

\begin{tabular}{|l|c|c|l|}
\hline \multicolumn{1}{|c|}{ Column Name } & Data Type & Required & \multicolumn{1}{c|}{ Description } \\
\hline county_id & Integer & Y & Unique id for each county in the region \\
\hline county_name & String(50) & Y & Name for the county \\
\hline
\end{tabular}

\section{demolition_cost_per_sqft}

The "demolition_cost_per_sqft" table provides information to the developer model about the costs of demolition by building type. These numbers are used to calculate the cost of demolition of an existing development so that a more accurate cost of redevelopment can be calculated.

Table A-10 demolition_cost_per_sqft

\begin{tabular}{|l|c|c|l|}
\hline \multicolumn{1}{|c|}{ Column Name } & Data Type & Required & \multicolumn{1}{c|}{ Description } \\
\hline building_type_id & Integer & Y & The building type id \\
\hline building_type_name & String & N & A description of the building type \\
\hline demolition_cost_per_sqft & Integer & Y & $\begin{array}{l}\text { The cost in dollars to demolish one } \\
\text { square foot of the building type }\end{array}$ \\
\hline
\end{tabular}




\section{development_constraints}

The "development_constraints" table defines constraints to restrict development on parcels. Each row in the table defines a unique constraint. The Development Project Proposal Sampling Model (DPPSM) generates proposals for a parcel using the constraint(s) and by selecting appropriate records from the "development_templates_table" that will fit on the available land of the parcel. The DPPSM determines the applicable constraint(s) for a parcel by selecting a record in the "development_constraints" table based on the parcel's "plan_type_id" (not "generic_land_use_type_id"). A parcel may have a constraint for "far" and/or "units_per_acre". Note that this table is substantially different than its gridcell counterpart due to the differences in the real estate models of these versions.

Table A-11 development_constraints

\begin{tabular}{|c|c|c|c|}
\hline Column Name & Data Type & Required & Description \\
\hline constraint_id & Integer & Y & A unique id for the constraint \\
\hline constraint_type & String & Y & $\begin{array}{l}\text { The density measure for the } \\
\text { constraint. The value must be either } \\
\text { 'units_per_acre' for residential land or } \\
\text { 'far' for nonresidential land. }\end{array}$ \\
\hline generic_land_use_type_id & Integer & Y & The id of the generic land use. \\
\hline plan_type id & Integer & $\mathrm{Y}$ & The id of the plan type \\
\hline minimum & Integer & $\mathrm{Y}$ & $\begin{array}{l}\text { The minimum density allowed by the } \\
\text { constraint }\end{array}$ \\
\hline maximum & Integer & Y & $\begin{array}{l}\text { The maximum density allowed by the } \\
\text { constraint }\end{array}$ \\
\hline
\end{tabular}




\section{development_templates}

The "development_templates" table, along with the corresponding records in the "development_template_components" table, represents templates that can be used to define virtually any size and configuration of a development project. The template structure is robust enough to include projects from a single house on an infill lot to a large subdivision, to a mixed use project with retail on the first floor and condominiums above.

Templates are selected if the density and "land_use_type_id" fit within the constraints of a parcel with enough available land. Note that the "land_use_type_id" of a template does not need to match the "land_use_type_id" of a parcel. Instead, there must be a record in the "development_constraints" table with a "generic_land_use_type_id" that corresponds to the "land_use_type_id" of the template, and has a "plan_type_id" that matches the parcel.

Table A-12 development_templates

\begin{tabular}{|c|c|c|c|}
\hline Column Name & Data Type & Required & Description \\
\hline template_id & Integer & $\mathrm{Y}$ & A unique identifier for the template \\
\hline percent_land_overhead & Integer & $\mathrm{Y}$ & $\begin{array}{l}\text { The percent of land required for } \\
\text { purposes other than buildings, e.g. } \\
\text { landscaping, parking }\end{array}$ \\
\hline land_sqft_min & Integer & $\mathrm{Y}$ & $\begin{array}{l}\text { The minimum land area needed for } \\
\text { the template }\end{array}$ \\
\hline land_sqft_max & Integer & $\mathrm{Y}$ & $\begin{array}{l}\text { The maximum land area used by the } \\
\text { template }\end{array}$ \\
\hline density_type & String & $\mathrm{Y}$ & $\begin{array}{l}\text { The density measure for the template. } \\
\text { The value must be 'units_per_acre' or } \\
\text { 'far' }\end{array}$ \\
\hline density & Float & $\mathrm{Y}$ & The density of the template \\
\hline land_use_type_id & Integer & $\mathrm{Y}$ & The land use type id of the template \\
\hline development_type & String & $\mathrm{N}$ & $\begin{array}{l}\text { A description of the development } \\
\text { type, e.g. single-family residential, } \\
\text { retail, office }\end{array}$ \\
\hline
\end{tabular}




\section{development_template_components}

The "development_template_components" table represents buildings or parts of buildings included in a particular template. The records in this table are combined with the records in the “development templates" table to generate project proposals. By breaking development templates into components, development project templates can be configured as hierarchies or combinations of building blocks, providing a very flexible means of representing a wide variety of development types. Note that the templates can be generated using real or hypothetical data, since they will be compared to regulatory constraints and the size constraints of parcels. This table is roughly equivalent to the "development_project_proposal_components" table.

Table A-13 development_template_components

\begin{tabular}{|c|c|c|c|}
\hline Column Name & $\begin{array}{c}\text { Data } \\
\text { Type }\end{array}$ & Required & Description \\
\hline component_id & Integer & Y & A unique identifier for the component \\
\hline template_id & Integer & Y & $\begin{array}{c}\text { The id of the corresponding template in the } \\
\text { development _template table }\end{array}$ \\
\hline building_type_id & Integer & Y & The building type id of the component \\
\hline percent_building_sqft & Integer & Y & $\begin{array}{c}\text { The percent of the building area the } \\
\text { component constitutes }\end{array}$ \\
\hline construction_cost_per_unit & Integer & Y & The cost of the template per square foot \\
\hline building_sqft_per_unit & Integer & & $\begin{array}{c}\text { The square feet per unit for residential } \\
\text { buildings }\end{array}$ \\
\hline
\end{tabular}




\section{employment_sectors}

The "employment_sectors" table contains definitions for the employment sectors used to classify jobs by industrial sector. In the U.S., these are typically based on either the older Standard Industrial Classification (SIC) system or the newer NAICS (North American Industrial Classification System).

Table A-14 employment_sectors

\begin{tabular}{|c|c|c|c|}
\hline Column Name & Data Type & Required & Description \\
\hline sector_id & Integer & Y & Unique id for the employment sector \\
\hline name & String(20) & Y & Descriptive name for the employment sector \\
\hline
\end{tabular}

generic_land_use_types

The "generic_land_use_types" table contains the generalized land use classification used for models such as the Real Estate Price Model.

Table A-15 generic_land_use_types

\begin{tabular}{|l|c|c|l|}
\hline \multicolumn{1}{|c|}{ Column Name } & Data Type & Required & \multicolumn{1}{c|}{ Description } \\
\hline generic_land_use_type_id & Integer & Y & Unique id for the generic land use type \\
\hline generic_description & String(50) & Y & Descriptive name \\
\hline
\end{tabular}




\section{household_characteristics_for_ht}

The "household_characteristics_for_ht" table contains the classification used in the "annual_household_control_totals" table to determine how many households of particular categories will be in the region in a simulation year. Any attribute on the household table may be used.

Table A-16 household characteristics for ht

\begin{tabular}{|l|c|c|l|}
\hline $\begin{array}{c}\text { Column } \\
\text { Name }\end{array}$ & $\begin{array}{c}\text { Data } \\
\text { Type }\end{array}$ & Required & \multicolumn{1}{c|}{ Description } \\
\hline characteristic & String(11) & $\mathrm{Y}$ & $\begin{array}{l}\text { Name of the attribute on the household table (must } \\
\text { match exactly) }\end{array}$ \\
\hline $\min$ & Integer & $\mathrm{Y}$ & Start of user-defined class range \\
\hline $\max$ & Integer & $\mathrm{Y}$ & End of user-defined class range \\
\hline
\end{tabular}




\section{households}

The "households" table contains the synthesized households for the region. It typically reflects an expansion of the Public Use Microdata Sample (PUMS) to approximate a 100\% sample of households. Households may optionally be linked to individual persons, particularly for use in coupling to activity-based travel demand models.

Table A-17 households

\begin{tabular}{|l|c|c|l|}
\hline \multicolumn{1}{|c|}{$\begin{array}{c}\text { Column } \\
\text { Name }\end{array}$} & $\begin{array}{c}\text { Data } \\
\text { Type }\end{array}$ & Required & \multicolumn{1}{c|}{ Description } \\
\hline household_id & Integer & Y & Unique household id \\
\hline building_id & Integer & Y & $\begin{array}{l}\text { Unique id of the building in which the household is } \\
\text { located }\end{array}$ \\
\hline persons & Integer & Y & Number of persons in the household \\
\hline income & Integer & Y & Total annual income of the household \\
\hline age_of_head & Integer & Y & $\begin{array}{l}\text { Age of the head of the household (according to the } \\
\text { census) }\end{array}$ \\
\hline race_id & Integer & Y & Unique id of the race of the head of the household \\
\hline workers & Integer & Y & Number of workers in the household \\
\hline children & Integer & Y & 1 if children are present, 0 otherwise \\
\hline cars & Integer & Y & Number of cars owned by the household \\
\hline
\end{tabular}




\section{jobs}

The "jobs" table contains an inventory of jobs for the region. It is usually derived from either ES202 Unemployment Insurance data which monitors businesses by state for unemployment insurance purposes (and have had issues historically with under-reporting self-employed and proprietor employment, and also with headquarter reporting of jobs in multi-establishment firms) or from commercial sources such as InfoUSA (which have different issues of rolling updates).

Table A-18 jobs

\begin{tabular}{|c|c|c|c|}
\hline Column Name & $\begin{array}{c}\text { Data } \\
\text { Type }\end{array}$ & Required & Description \\
\hline job_id & Integer & $\mathrm{Y}$ & Unique id for each job \\
\hline building_id & Integer & $\mathrm{Y}$ & $\begin{array}{c}\text { Unique id for the building in which the job is } \\
\text { located }\end{array}$ \\
\hline home_based_status & Integer & $\mathrm{Y}$ & 1 if the job is home-based, 0 otherwise \\
\hline sector_id & Integer & $\mathrm{Y}$ & Unique id of the employment sector of the job \\
\hline
\end{tabular}

\section{land_use_types}

The "land_use_types" table contains the land use classification for all parcels in the region. It contains "unit_name" used to determine the type of unit to use in the "real estate price model".

Table A-19 land use types

\begin{tabular}{|l|l|c|l|}
\hline \multicolumn{1}{|c|}{ Column Name } & Data Type & Required & \multicolumn{1}{|c|}{ Description } \\
\hline land_use_type_id & Integer & Y & Unique id for the land use type \\
\hline description & String(40) & Y & Descriptive name \\
\hline land_use_name & String(25) & Y & Name \\
\hline unit_name & String(15) & Y & Unit type \\
\hline generic_land_use_type_id & Integer & Y & Plan type \\
\hline
\end{tabular}




\section{parcels}

The "parcels" table contains attributes of individual parcels.

Table A-20 parcels

\begin{tabular}{|c|c|c|c|}
\hline Column Name & $\begin{array}{l}\text { Data } \\
\text { Type }\end{array}$ & Required & Description \\
\hline parcel_id & Integer & $\mathrm{Y}$ & Unique id for parcels \\
\hline parcel_id_local & String $(20)$ & $\mathrm{N}$ & $\begin{array}{l}\text { Users may want to store a local parcel id from the } \\
\text { assessor's office }\end{array}$ \\
\hline land_use_type_id & Integer & Y & Unique id of the land use type of the parcel \\
\hline land_value & Integer & $\mathrm{Y}$ & Assessed value of the land on the parcel \\
\hline parcel_sqft & Integer & Y & Land area of the parcel in square feet \\
\hline plan_type_id & Integer & Y & $\begin{array}{l}\text { Unique id of the land use plan type of the parcel } \\
\text { (regulatory designation) }\end{array}$ \\
\hline centroid_x & Integer & $\mathrm{Y}$ & $\begin{array}{l}\mathrm{X} \text {-coordinate of the parcel centroid, usually in a } \\
\text { projection measured in feet }\end{array}$ \\
\hline centroid_y & Integer & Y & $\begin{array}{l}\text { Y-coordinate of the parcel centroid, usually in a } \\
\text { projection measured in feet }\end{array}$ \\
\hline tax_exempt_flag & Integer & $\mathrm{N}$ & Optional 1 if tax exempt, 0 otherwise \\
\hline city_id & Integer & $\mathrm{N}$ & Unique id of the city in which the parcel is located \\
\hline county_id & Integer & $\mathrm{N}$ & Unique id of the county in which the parcel is located \\
\hline zone_id & Integer & $\mathrm{Y}$ & $\begin{array}{l}\text { Unique id of the zone (as used in the travel demand } \\
\text { models) in which the parcel is located }\end{array}$ \\
\hline census_block_id & string & $\mathrm{N}$ & $\begin{array}{l}\text { Optional unique id of the census block in which the } \\
\text { parcel is located }\end{array}$ \\
\hline
\end{tabular}




\section{persons}

The "persons" table contains the synthesized population for the region, linked to households. It typically reflects an expansion of the Public Use Microdata Sample (PUMS) to approximate a $100 \%$ sample of households and persons.

Table A-21 persons

\begin{tabular}{|c|c|c|c|}
\hline Column Name & Data Type & Required & Description \\
\hline person_id & Integer & $\mathrm{Y}$ & Unique id for each person \\
\hline household_id & Integer & $\mathrm{Y}$ & Unique household id \\
\hline member_id & Integer & $\mathrm{N}$ & Unique id of the person within a household \\
\hline relate & Integer & $\mathrm{N}$ & Relationship of person to census survey respondent \\
\hline age & Integer & $\mathrm{N}$ & Age of person in years \\
\hline sex & Integer & $\mathrm{N}$ & Coded as $1=$ male, $2=$ female \\
\hline race_id & Integer & $\mathrm{N}$ & Unique id of the race category of the person \\
\hline student & Integer & $\mathrm{N}$ & 1 if person is a student, 0 otherwise \\
\hline worker & Integer & $\mathrm{N}$ & 1 if person is a worker, 0 otherwise \\
\hline hours & Integer & $\mathrm{N}$ & Usual hours worked per week by person, if worker \\
\hline work_at_home & Integer & $\mathrm{N}$ & 1 if person works at home, 0 otherwise \\
\hline edu & Integer & $\mathrm{N}$ & Educational attainment of person \\
\hline earning & Integer & $\mathrm{N}$ & annual earnings (wages) of person from employment \\
\hline job_id & Integer & $\mathrm{N}$ & Assigned by workplace choice model, if used \\
\hline
\end{tabular}




\section{plan_types}

The "plan_types" table contains the list of "plan_types", reflecting some classification of land use regulations defining permissible uses and densities of future development.

Table A-22 plan_types

\begin{tabular}{|c|c|c|c|}
\hline Column Name & Data Type & Required & Description \\
\hline plan_type_id & Integer & Y & Unique id for plan type \\
\hline name & String(50) & Y & Description of the plan type \\
\hline
\end{tabular}

\section{target_vacancies}

The "target_vacancies" table is used by the development proposal choice model. It gives the model information about acceptable vacancy rates. The table has one row for each year the simulation runs. Each row gives target values for the residential and nonresidential vacancies for that year, which are defined below. Only data after the base year is used.

Table A-23 target_vacancies

\begin{tabular}{|c|c|c|c|}
\hline Column Name & Data Type & Required & Description \\
\hline building_type_id & Integer & $\mathrm{Y}$ & The building type id \\
\hline target_vacancy_rate & Float & $\mathrm{Y}$ & The ratio of unused space to total building space \\
\hline year & Integer & $\mathrm{Y}$ & The simulation year \\
\hline
\end{tabular}




\section{travel_data}

The "travel_data" table contains zone-to-zone morning peak period travel times for vehicles traveling in mixed flow lanes.

Table A-24 travel_data

\begin{tabular}{|l|c|l|l|}
\hline \multicolumn{1}{|c|}{ Column Name } & $\begin{array}{c}\text { Data } \\
\text { Type }\end{array}$ & Required & \multicolumn{1}{|c|}{ Description } \\
\hline from_zone_id & Integer & Y & origin zone \\
\hline to_zone_id & Integer & Y & destination zone \\
\hline am_single_vehicle_to_work_travel_time & Integer & Y & $\begin{array}{l}\text { zone-to-zone morning peak } \\
\text { period travel time for vehicles } \\
\text { traveling in mixed flow lanes }\end{array}$ \\
\hline
\end{tabular}




\section{velocity_functions}

The "velocity_functions" table is designed to hold the velocity functions that specify the rate at which development occurs. A Development Project Proposal has a calculated variable called "units_proposed" that is the total number of units that will be built. The calculated variable "annual_construction_schedule" on the Development Project Proposal Components dataset uses "units_proposed" to select which of the velocity functions in this table should apply based on the "building_type_id" and "units_proposed" of the Development Project Proposal Component. The user can specify a record from this table, using the "velocity_function_id", to specify the construction schedule for projects specified in the "development_project_proposal" base year table.

Table A-25 velocity_functions

\begin{tabular}{|c|c|c|c|}
\hline Column Name & $\begin{array}{c}\text { Data } \\
\text { Type }\end{array}$ & Required & Description \\
\hline velocity_function_id & Integer & $\mathrm{Y}$ & A unique identifier \\
\hline annual_construction_schedule & String & $\mathrm{Y}$ & $\begin{array}{c}\text { A numbered list in brackets of the form, } \\
\text { [p1, p2,...,pn]', indicating with each entry } \\
\text { the percentage complete of the project each } \\
\text { year from its start. The last entry must be } \\
\text { '100'. }\end{array}$ \\
\hline building_type_id & Integer & $\mathrm{Y}$ & $\begin{array}{c}\text { The building type id for the velocity } \\
\text { function }\end{array}$ \\
\hline minimum_units & Integer & $\mathrm{Y}$ & $\begin{array}{c}\text { The minimum number of units for the } \\
\text { velocity function }\end{array}$ \\
\hline maximum_units & Integer & $\mathrm{Y}$ & $\begin{array}{c}\text { The maximum number of units for the } \\
\text { velocity function }\end{array}$ \\
\hline
\end{tabular}




\section{zones}

The "zones" table contains attributes of traffic analysis zones used in the travel demand models.

Table A-26 zones

\begin{tabular}{|c|c|c|c|}
\hline $\begin{array}{c}\text { Column } \\
\text { Name }\end{array}$ & $\begin{array}{c}\text { Data } \\
\text { Type }\end{array}$ & Required & Description \\
\hline zone_id & Integer & $\mathrm{Y}$ & unique id for each zone \\
\hline city_id & Integer & $\mathrm{N}$ & unique id for each city \\
\hline county_id & Integer & $\mathrm{N}$ & unique id for each county \\
\hline faz_id & Integer & $\mathrm{N}$ & $\begin{array}{c}\text { unique id for each forecast analysis zone or any user- } \\
\text { specified aggregation of zones }\end{array}$ \\
\hline
\end{tabular}


Appendix II Source Codes for Household/Person Assignment

\section{II.1 Assign Parcel to Household}

Dim ds As New DataSet

Dim countMatched As Integer $=0$

Dim countDup As Integer $=0$

Using conn As New

SqlConnection("server=131.247.11.247; uid=wonstran;pwd=288496; database=census") conn.Open()

1Mess.Text $=$ "Retrieving bg data ..."

1Mess.Refresh()

Dim commandString4 As String = "SELECT distinct(tract),bg from households"

Dim command4 As New SqlCommand(commandString4, conn)

Dim adapter4 As New SqlDataAdapter

adapter4. SelectCommand $=$ command 4

adapter4.Fill(ds, "bg")

1Mess.Text = "Retrieving household data ..."

1Mess.Refresh()

Dim commandString1 As String = "SELECT

tract,bg,household_id,parcel_id,parcel_id_local from households"

Dim command1 As New SqlCommand(commandString1, conn)

Dim adapter1 As New SqlDataAdapter

adapter1.SelectCommand $=$ command 1

adapter1.Fill(ds, "household")

1Mess.Text $=$ "Retrieving parcel-bg data ..."

1Mess.Refresh()

Dim commandString2 As String = "SELECT parcel_id_local, parcel_id, tract2, blkgroup from parcel_bg"

Dim command2 As New Sq1Command(commandString2, conn)

Dim adapter2 As New SqlDataAdapter

adapter2. SelectCommand = command2

adapter2.Fill(ds, "parcel")

Dim totalNum As Integer = ds.Tables("bg").Rows. Count

Dim count As Integer $=0$

Dim tabBG As DataTable = ds.Tables("bg")

Dim tabHH As DataTable = ds.Tables("household") 
Dim tabP As DataTable = ds.Tables("parcel")

Using conn2 As New

SqlConnection("server=131.247.11.247;uid=wonstran;pwd=288496; database=census")

conn2.Open()

For Each row As DataRow In tabBG.Rows

Dim tract As String = row.Item("tract").ToString.PadLeft(6, "0")

Dim bg As String = row.Item("bg").ToString.Trim

Dim express As String = "tract2="" + tract + "'" + " and " + "blkgroup="' + bg + "'"

Dim rows() As DataRow $=$ tabP.Select(express)

Dim express2 As String = "tract=" + tract + " and " + "bg=" + bg

Dim rows2() As DataRow $=$ tabHH.Select(express2)

If rows.Length $>0$ Then

countMatched $+=1$

Else

countDup $+=1$

End If

count $+=1$

AssignHousehold2Parcels_2(rows2, rows, conn2, count)

Next

End Using

End Using

MessageBox.Show("Matched:" + countMatched.ToString + "," + countDup.ToString)

Private Sub AssignHousehold2Parcels_2(ByRef hhs As DataRow(), ByRef parcels As

DataRow(), ByVal conn As SqlConnection, ByVal count As Integer)

Dim numHHs As Integer $=$ hhs.Count

Dim numParcels As Integer $=$ parcels. Count

Dim parcel_id As String

Dim parcel_id_local As String

Dim command As New SqlCommand 
command.Connection $=$ conn

$\operatorname{Dim} \mathrm{j}$ As Integer $=0$

For i As Integer $=0$ To numHHs -1

If numParcels $>0$ Then

If $\mathrm{j}>=$ numParcels Then

$\mathrm{j}=0$

End If

parcel_id = parcels(j).Item("parcel_id").ToString.Trim

parcel_id_local $=$ parcels(j).Item("parcel_id_local").ToString.Trim

$\mathrm{j}+=1$

Else

parcel_id $=" 0 "$

parcel_id_local $=" 0 "$

End If

Dim hh_id As String = hhs(i).Item("household_id").ToString.Trim

command.CommandText = "UPDATE households SET parcel_id="' + parcel_id + "', parcel_id_local="' +

parcel_id_local + "' WHERE household_id="' + hh_id + "'"

'command.Execute-̄NonQuery()

If parcel_id_local = "1928091H7000000000007A" Then

Dim s As String = ""

End If

1Mess. Text = "Updating: " + count.ToString + "-" +

hhs(i).Item("household_id").ToString + " -- " + i.ToString + " / " + numHHs.ToString 1Mess.Refresh()

Next

End Sub 


\section{II.2 Assign Building to Household}

Dim ds As New DataSet

Dim countMatched As Integer $=0$

Dim countDup As Integer $=0$

Using conn As New

SqlConnection("server=131.247.11.247;uid=wonstran;pwd=288496;database=urbansim") conn.Open()

\section{Using conn3 As New}

SqlConnection("server=131.247.11.247;uid=wonstran;pwd=288496;database=census")

conn3.Open()

1Mess. Text $=$ "Retrieving parcel data $\ldots$.

1Mess.Refresh()

Dim command1 As New SqlCommand

command1.Connection $=$ conn 3

command1.CommandText = "SELECT distinct(parcel_id) FROM households "

Dim adapter1 As New SqlDataAdapter

adapter1. SelectCommand $=$ command 1

adapter1.Fill(ds, "parcel")

Dim totalNum As Integer = ds.Tables("parcel").Rows.Count

Dim count As Integer $=0$

1Mess. Text = "Retrieving building data ..."

1Mess.Refresh()

Dim command2 As New SqlCommand

command2.Connection $=$ conn

command2.CommandText = "SELECT building_id, parcel_id from buildings"

Dim adapter2 As New SqlDataAdapter

adapter2. SelectCommand $=$ command 2

adapter2.Fill(ds, "building")

Dim tableBud As DataTable = ds.Tables("building")

1Mess. Text $=$ "Retrieving household data ..."

1Mess.Refresh()

Dim command3 As New SqlCommand

command3. Connection $=$ conn 3

households"

command3.CommandText = "SELECT parcel_id, household_id, building_id from 
Dim adapter3 As New SqlDataAdapter

adapter3. SelectCommand $=$ command3

adapter3.Fill(ds, "household")

Dim tableHH As DataTable = ds.Tables("household")

Using conn2 As New

SqlConnection("server=131.247.11.247;uid=wonstran;pwd=288496; database=census") conn2.Open()

Dim command4 As New SqlCommand

command4.Connection $=$ conn 2

For Each row As DataRow In ds.Tables("parcel").Rows

Dim parcel_id As String = row("parcel_id").ToString.Trim

Dim express1 As String = "parcel_id="' + parcel_id + "'"

Dim rows_building As DataRow ()$=$ tableBud.Select(express 1$)$

Dim rows_hh As DataRow ()$=$ tableHH.Select(express1)

countMatched $+=1$

AssignHousehold2Buildings(rows_hh, rows_building, command4)

count $+=1$

1Mess. Text = "Assigning: " + count.ToString + "/" + totalNum. ToString 1Mess.Refresh()

Next

End Using

End Using

End Using

MessageBox.Show("Matched:" + countMatched.ToString + "," + countDup.ToString)

Private Sub AssignHousehold2Buildings(ByRef hh As DataRow(), ByRef buildings As DataRow(), ByRef command As SqlCommand)

Dim numHH As Integer $=$ hh.Count

Dim numBuildings As Integer = buildings.Count 
Dim building_id As String

For i As Integer $=0$ To numHH - 1

If numBuildings $>0$ Then

Dim randomBuilding_index As Integer $=$ Fix $(\operatorname{Rnd}() *$ numBuildings $)$

building_id = buildings(randomBuilding_index).Item("building_id").ToString.Trim

Else

building_id $=" 0 "$

End If

command.CommandText = "UPDATE households SET building id="' + building id + "'

WHERE household_id="' + hh(i).Item("household_id").ToString + "'" command.ExecuteNonQuery()

Next

End Sub 